\title{
Mathematical Simulation of Sediment and Radionuclide Transport in the Columbia River
}

by

Yasuo Onishi

August 1977

Prepared for the Energy Research and Development Administration under Contract EY-76-C-06-1830 
NOTICE

This report was prepared as an account of work sponsored by the United States Covernment. Neiher the United States nor the Energy Research and Development Administration, nor any of their employees, nor any of thei: contractors, subcontractors, or their employees, makes any warranty, express or implied, or assumes any icgal liability or responsibility for the accuracy, completeness or usefulness of any information, apparatus, product or process disclosed, or represents that its use would not intringe privately owned rights.

The views, opinions and conclusions contained in this report are thase of the contractor and do not necessarily represent those of the United States Government or the United States Energy Research and Development Administration.

PACIFIC NORTHWEST LABORATORY

operated by

BATIELLE

for the

ENERGY RESEARCH AND DEVELOPMENT ADMINISTRATION

Under Contract EY-76-C-06-7830

Frinted in the United States of America

Avalabie from

Nationai Technical information Service

U.S. Department sf Commerce

5235 Fort Royal Road

Springtield, Virginia 22151

Price: Printed Copu s_... Microtiche 53.00

\begin{tabular}{|c|c|}
\hline "Pages & Selling Price \\
\hline $201-125$ & 34.50 \\
\hline $0276-050$ & $\$ 5.00$ \\
\hline $051-075$ & 52.50 \\
\hline $076-109$ & $\$ 6,00$ \\
\hline $101-125$ & 56.50 \\
\hline $125-150$ & 57.00 \\
\hline $15 i-7-5$ & $\$ 7.75$ \\
\hline $175-290$ & 58,50 \\
\hline $201-225$ & 38.75 \\
\hline $226-250$ & $\$ 9.00$ \\
\hline 251.275 & 510.00 \\
\hline $275-300$ & $\$ 10.25$ \\
\hline
\end{tabular}


MATHEMATICAL SIMULATION OF SEDIMENT AND RADIONUCLIDE TRANSPORT IN THE COLUMBIA RIVER

by

Yasuo Onishi

August 1977

BATTELLE

PACIFIC NORTHWEST LABORATORIES

RICHLAND, WASHINGTON 99352 


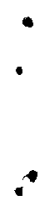




\section{SUMMARY}

Mathematical simulation of radionuclide transport was conducted by applying the finite element sediment and contaminant transport model, SERATRA, to the Columbia River between the Priest Rapids and McNary Dams near the ERDA Hanford Reservation. Model computations were performed to solve time-dependent, longitudinal and vertical distributions of sediments and radionuclides by taking into account sediment-radionuclide interaction. Sediment transport was modeled for three sediment size fractions (i.e., sand, silt and clay), and radionuclide transport was simulated for dissolved and particulate nuclides. Particulate radionuclides were analyzed for those adsorbed by sediment in each sediment size fraction.

Five cases were simulated in this study to identify the effects of river sediments on radionuclide migration:

1. Continuous release of ${ }^{65} \mathrm{Zn}$ without adsorption mechanics

2. Continuous release of ${ }^{65} \mathrm{Zn}$ with adsorption

3. Instantaneous release of ${ }^{65} \mathrm{Zn}$ without adsorption

4. Instantaneous release of ${ }^{65} \mathrm{Zn}$ with adsorption

5. Radionuclide resuspension.

Sediment and radionuclide results of the verification test case, Case 2, indicate very good agreement with measured data. It was revealed that particulate ${ }^{65} \mathrm{Zn}$ concentrations increase from 0 to $70 \%$ of the total radionuclide concentrations within approximately $80 \mathrm{~km}$ downstream from the Hanford reactors. Nuclide concentrations associated with clay sediment are approximately three times higher than those attached to silt because of clay's greater cation exchange capacity. Sand adsorbs the least amount of nuclides among the sediments. Further downstream, particulate nuclide concentrations are reduced because contaminated suspended sediments were deposited in the river bed in the slow moving area. This resulted in the total ${ }^{65} \mathrm{Zn}$ concentrations in this area for case 2 being only 25 to $50 \%$ of those for case 1. Similar results were obtained for the other cases. 
The results of this study indicate that suspended sediment has significant effect: on radionuclide transport through radionuclide adsorption, deposition, and resuspension of contaminated sediments. Hence, in order to obtain realistic predictions of radionulcide migration, interaction between radionuclides and river sediments must be taken into account. The present study demonstrates that the SERATRA code is capable of predicting the transport of both particulate and dissolved radionuclides by taking into account the radionuclide-sediment interaction. However, complete verification of the model is required before reliable predictions can be made concerning the migration of radionuclide and contaminated sediments within river systems. 


\section{CONTENTS}

SUMMARY. . . . . . . . . . . . . . . . . . . . . . . .

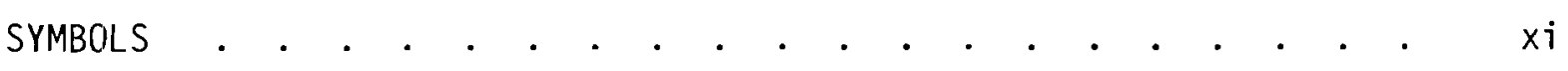

INTRODUCTION .

REVIEW OF PREVIOUS WORK . . . . . . . . . . . . . . . . . . . . 3

MATHEMATICAL MODEL FORMULATION . . . . . . . . . . . . . . . . . 6

SEDIMENT TRANSPORT MODEL . . . . . . . . . . . . . . 6

Governing Equations . . . . . . . . . . . 6

Erosion and Deposition of Cohesive Sediments . . . . 8

Erosion and Deposition of Noncohesive Sediments . . . . 9

DISSOLVED RADIONUCLIDE TRANSPORT MODEL. . . . . . . . . . 10

PARTICULATE RADIONUCLIDE TRANSPORT MODEL.. . . . . . . . . . 12

FINITE ElEMENT TECHNIQUE

Galerkin Weighted Residual Method. . . . . . . . 15

Finite Element Equations. . . . . . . . . . . 16

Time-Dependent Solution . . . . . . . . . . . . 20

CODE DESCRIPTION.

COMPUTATION PROCEDURE . . . . . . . . . . . . . . . 22

EXECUTIVE PROGRAM AND SUBROUTINE DESCRIPTION. . . . . . . 22

SERATRA Executive Routine . . . . . . . . . . . 23

Subroutines . . . . . . . . . . . . . . . . 23

LISTS OF INPUT DATA AND COMPUTER OUTPUT . . . . . . . . 27

Sediment Simulation . . . . . . . . . . . . . 27 
Radionuclide Simulation. . . . . . . . . . . 28

Sediment Simulation . . . . . . . . . . . . . 28

Radionuclide Simulation. . . . . . . . . . . 28

COMPUTER SIMULATION RESULTS . . . . . . . . . . . . . . . . 30

CONTINUOUS RELEASE OF RADIONUCLIDES. . . . . . . . . . 32

Case 1. Dissolved Zinc-65 Without Adsorption. . . . . 33

Case 2. Verification Test of Zinc-65 with Adsorption . . 33

INSTANTANEOUS RELEASE OF RADIONUCLIDES. . . . . . . . . . 38

Case 3. Dissolved Zinc-65 Without Adsorption. . . . . 39

Case 4. Zinc-65 With Adsorption. . . . . . . . . 39

RADIONUCLIDE RESUSPENSION . . . . . . . . . . . . . 42

Case 5. Radionuclide Resuspension . . . . . . . . 43

CONCLUSIONS AND RECOMMENDATIONS. . . . . . . . . . . . . . . . 46 REFERENCES. . . . . . . . . . . . . . . . . . . . Ref-1 


\section{FIGURES}

1 Map of the Columbia River. . . . . . . . . . 50

2 Variations of Water Surface and Bed Elevations of the Columbia River: Discharge of $1860 \mathrm{~m}^{3} / \mathrm{sec}$ at the Priest Rapids Dam . . . . . . . . . . . . 51

3 Longitudinal Distribution of Mean Flow Velocity . . . 52

4 Longitudinai Distributions of Total Amount of Zinc-65 at 240 Hours, Case 1. . . . . . . . . 53

5 Longitudinal Distribution of Dissolved Zinc-65 at 240 Hours, Case 1 . . . . . . . . . . 54

$6 \quad$ Longitudinal Distributions of Sediment Concentrations at 240 Hours, Case 2 . . . . . . . . . . . 55

7 Comparison of Predicted Results of Cases 1 and 2 at 240 Hours with Measured Zinc-65 Concentrations. . . 56

8 Longitudinal Distributions of Zinc-65 Adsorbed by Suspended Sediments at 240 Hours, Case 2. . . . 57

9 Longitudinal Distributions of ${ }^{65}$ Zn Concentrations at 240 Hours, Case 2 . . . . . . . . . 58

10 Longitudinal Distribution of Total Amount of Zinc-65 at 240 Hours, Case 2 . . . . . . . . . . 59

11 Vertical Distributions of Suspended Sediment Concentrations at 240 Hours for River Reach 3 . . . 60

12 Vertical Distributions of Sediment Fraction Ratios in the River Bed at 240 Hours for River Reach 3, Case 2 . . . . . . . . . . . . . . . 61

13 Vertical Distributions of Zinc-65 Adsorbed by Suspended Sediments at 240 Hours for Reach 3, Case 2 .

14 Vertical Distributions of Dissolved and Total Zinc-65 at 240 Hours for Reach 3, Case 2 . . . . . . . . 63 
15 Vertical Distributions of Suspended Sediment Concentrations at 240 Hours for Reach 11 (River Miles 322.6 to 326.6), Case 2 . . . . . . . . . 64

16 Vertical Distributions of Zinc-65 Adsorbed by Suspended Sediments at 240 Hours for Reach 11, Case 2. . . . . . . . . . . . . . 65

17 Vertical Distributions of Dissolved and Total Zinc-65 at 240 Hours for Reach 11, Case 2. . . . 66

18 Vertical Distributions of Zinc-65 in the River Bed at 240 Hours for Reach 11, Case 2 . . . . . . . 67

19 Vertical Distributions of Zinc-65 in the River Bed at 240 Hours for Reach 16 (River Miles 292.0 to 299.6), Case 2 . . . . . . . . . . . . . 68

20 Longitudinal Distribution of Dissolved Zinc- 65 at 24,72, and 240 Hours, Case 3 . . . . . . . 69

21 Longitudinal Distributions of Total Amounts of Zinc-65 at 24, 72, and 240 Hours, Case 3. . . . 70

22 Longitudinal Distributions of Sediment Concentrations at 24,72, and 240 Hours, Case 4. . . . . . . . 71

23 Longitudinal Distributions of Total Zinc-65 Concentrations at 24, 72, and 240 Hours, Cases 3 and 4.72

24 Longitudinal Distributions of Total, Dissolved and Particulate Zinc-65 Concentrations at 24 Hours, Case 4 .

25 Longitudinal Distributions of Total, Dissolved and Particulate Zinc-65 Concentrations at 72 Hours, Case 4.74

26 Longitudinal Distributions of ${ }^{65} \mathrm{Zn}$ Adsorbed by Sand, Silt and Clay at 72 Hours, Case 4 . . . . . . . 75

27 Longitudinal Distributions of Total, Dissolved and Particulate Zinc-65 Concentrations at 240 Hours, Case 4 . . . . . . . . . . . . . . . . . 76

28 Comparison of Longitudinal Distributions of Total Amounts of Zinc-65 at 24, 72, and 240 Hours Between Cases 3 and 4. 
28 Comparison of Longitudinal Distributions of Total

Amounts of Zinc-65 at 24, 72, and 240 Hours

Between Cases 3 and 4 . . . . . . . . . . 77

29 Vertical Distributions of Suspended Sediment

Concentrations at 24 Hours for Reach 3, Case 4. . . . 78

30 Vertical Distributions of Zinc-65 Adsorbed by

Suspended Sediments at 24 Hours for Reach 3, Case 4 . 79

31 Vertical Distributions of Dissolved and Total

Zinc-65 at 24 Hours for Reach 3, Case 4 . . . . . 80

32 Vertical Distributions of Suspended Sediment

Concentrations at 24 Hours for Reach 5 (River

Miles 354.3 to 364.3 ), Case 4 . . . . . . . . . 81

33 Vertical Distributions of Zinc-65 Adsorbed by Suspended

Sediments at 24 Hours for Reach 5 (River Miles 354.3

to 364.3 ), Case 4 . . . . . . . . . . . . 82

34 Vertical Distributions of Dissolved and Total Zinc-65

at 24 Hours for Reach 5, Case 4. . . . . . . . 83

35 Vertical Distributions of Zinc-65 in the River Bed at 72 Hours for Reach 11, Case 4. . . . . . . 84

36 Vertical Distributions of Zinc-65 in the River Bed at 240 Hours for Reach 16, Case 4. . . . . . 85

37 Longitudinal Distributions of Total Radionuclide

Concentrations in the River Bed, Case 5. . . . . 86

38 Longitudinal Distributions of Sediment Concentrations at 240 Hours, Case 5 . . . . . . . . . . . 87

39 Longitudinal Distributions of Particulate ${ }^{65} \mathrm{Zn}$ Concentrations in $\mathrm{pCi} / \ell$ at 240 Hours, Case 5 . . . 88

40 Longitudinal Distributions of Total Amount of ${ }^{65} \mathrm{Zn}$ at 240 Hours, Case 5 . . . . . . . . . . 89

$\underline{T A B L E}$

1 Test Conditions Assumed for Sediment and

Radionuclide Modeling . . . . . . . . . . . 31 
.

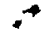

$=$ 


\section{SYMBOLS}

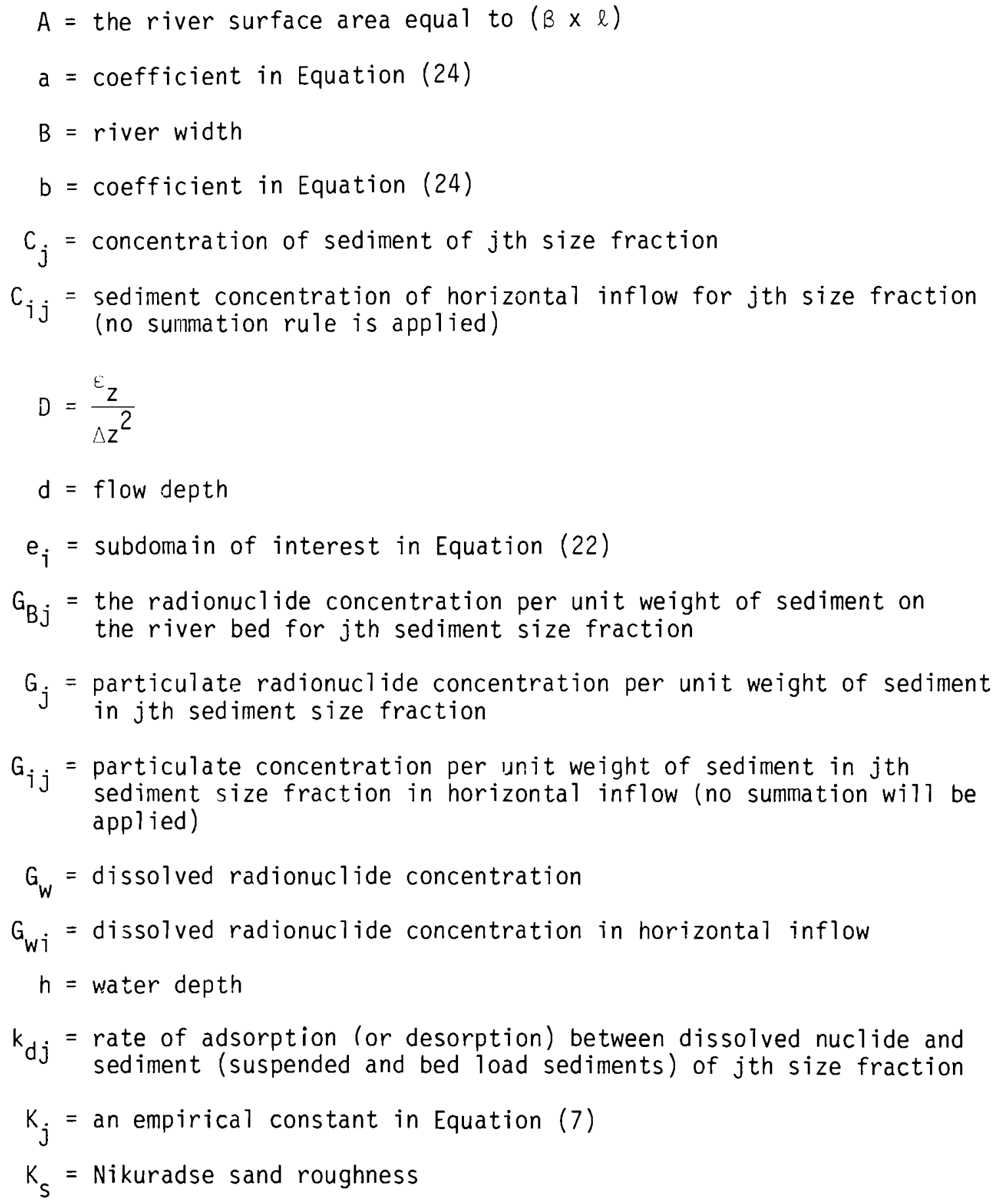




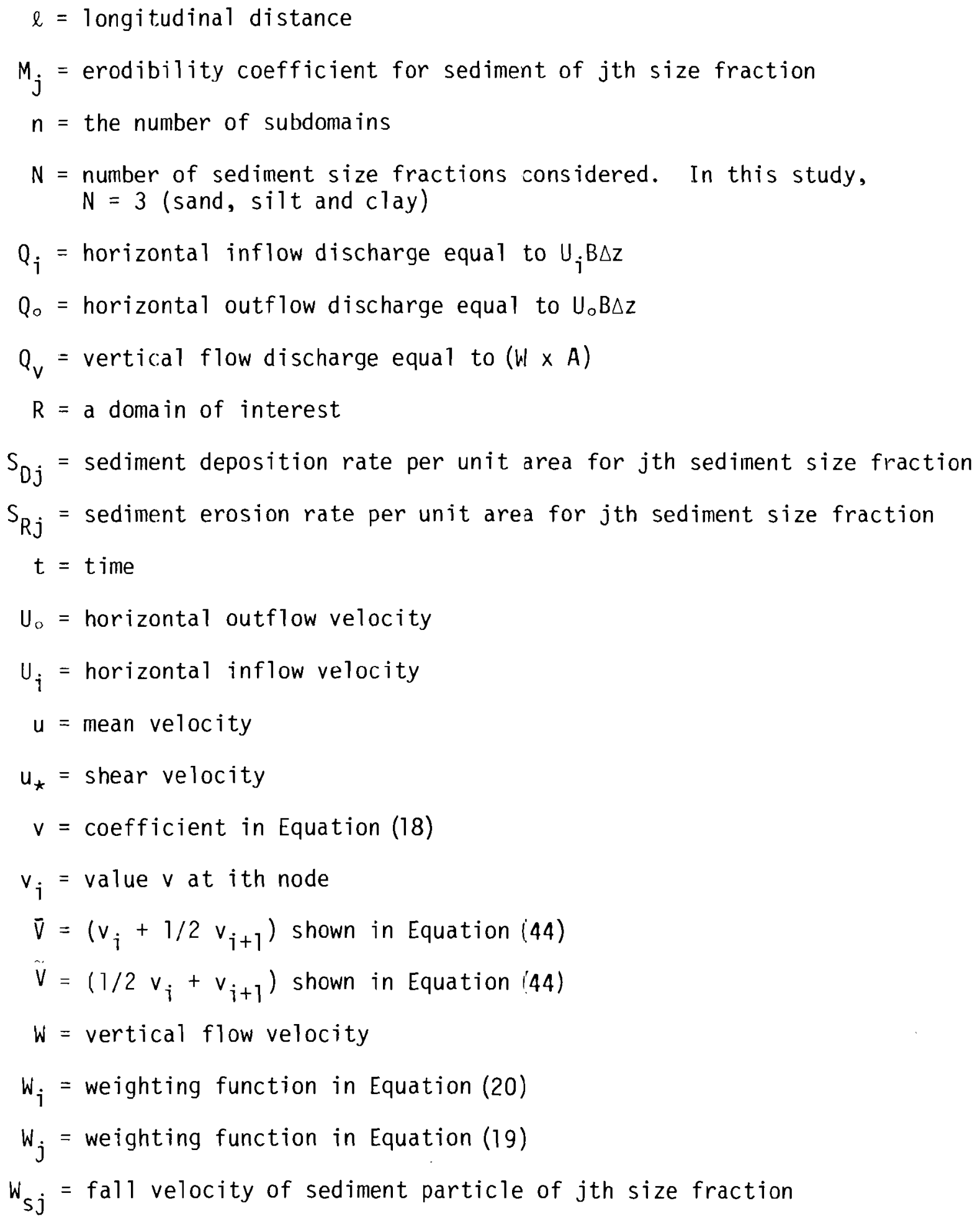


$z=$ vertical direction

$[P]=$ symmetric tridiagonal matrix in Equation (40)

$[\tilde{P}]=$ symmetric tridiagonal matrix in Equation (45)

$[P]=$ symmetric tridiagonal matrix in Equation (48)

$\{R\}=$ load vector in Equation (40)

$\{\tilde{R}\}=$ load vector in Equation (45)

$\{\bar{R}\}=$ load vector in Equation (47)

$[S]=$ unsymmetric tridiagonal matrix in Equation (40)

$[\tilde{S}]=$ unsymmetric tridiagonal matrix in Equation (45)

$[\zeta]=$ unsymmetric tridiagonal matrix in Equation (47)

$\alpha=$ coefficient in Equation (18)

$\beta=$ coefficient in Equation (18)

$\gamma=$ coefficient, i.e., probability that particle settling to the bed is deposited

$\Delta z=$ increment of vertical distance

$\varepsilon_{z}=$ coefficient in Equation (18)

$\varepsilon_{z j}=\begin{aligned} & \text { diffusion coefficient of vertical }(z) \text { component for } j \text { th sediment } \\ & \text { size fraction }\end{aligned}$

$\varepsilon_{Z W}=$ vertical diffusion coefficient for dissolved radionuclides

$\lambda=$ decay rate of radioactive material

$\kappa=$ Kármán constant

$\bar{N}=$ water density

$\tau_{b}=$ bed shear stress

$\tau_{C D j}=\begin{aligned} & \text { critical shear stress for sediment deposition for } j \text { th sediment } \\ & \text { size fraction }\end{aligned}$

$\begin{aligned} \tau_{C R j} & =\text { critical shear stress for sediment erosion for } j \text { th sediment } \\ & \text { size fraction }\end{aligned}$ 


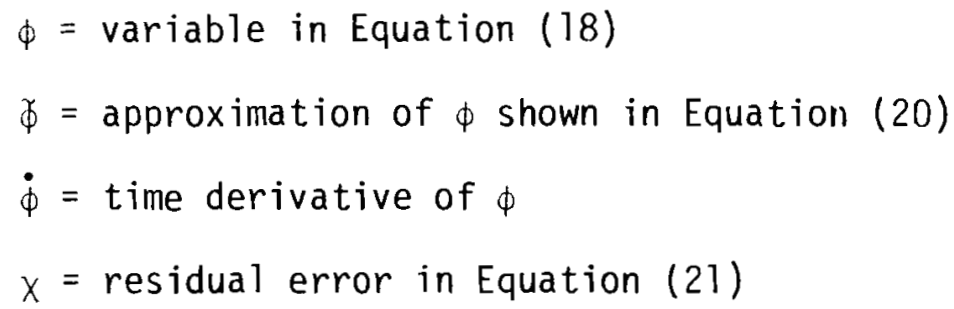




\section{MATHEMATICAL SIMULATION OF SEDIMENT AND RADIONUCLIDE \\ TRANSPORT IN THE COLLIMBIA RIVER}

Yasuo Onishi

\section{INTRODUCTION}

During normai operation of nuclear power reactors and other nuclearrelated facilities small quantities of radioactive materials are released into receiving water bodies via plant cooling and service water discharges. These radionuclides are dispersed by mixing with river water, or can be adsorbed from solution onto sediments. Sorption by sediments is an important mechanism affecting the migration of radionuclides throughout a water body. This is seen by the deposition and resuspension of contaminated sediments on river beds.

In this study, a mathematical simulation was conducted to assess the migration of radionuclides in the Columbia River in Eastern Washington by including the effects of sediment-radionuclide interaction. This study was conducted to provide a useful tool for predicting present and future transport of radionuclides in the river. Although the field data are not sufficiently detailed to verify the computer code completely, the comparison of computer results with the field data shows a good agreement.

The radionuclides found in the Columbia River are attributed to three primary sources: 1) cooling water effluents discharged from early operations of the Hanford production reactors, 2) fallout and 3) natural background. (1-4) Cooling waters from the reactors introduced a wide spectrum of radioactive materials to the river system during plant operation. These isotopes included ${ }^{57} \mathrm{Cr},{ }^{65} \mathrm{Zn},{ }^{46} \mathrm{Sc},{ }^{137} \mathrm{Cs},{ }^{106} \mathrm{Ru}-\mathrm{Rh},{ }^{95} \mathrm{Zr}-\mathrm{Nb},{ }^{124} \mathrm{Sb},{ }^{54} \mathrm{Mn},{ }^{58} \mathrm{Co}$ and 60 co. $(1,5,6)$

By January 1971, the eight reactors having once-through cooling systems had been shutdown. $(4,7) \quad \mathrm{N}$-reactor, with a closed-cycle cooling system, is the only reactor remaining in operation. Closure of the eight reactors reduced the amounts of radionuclides entering the river, its estuary and 
adjacent ocean water. Subsequently, the radionuclides contained in the Columbia River system after January 1971 have been from four sources:

1) those discharged from previous reactor operations which became attached to sediment particles and deposited with the sediments in the river bed (primarily behind McNary Dam), 2) those which may be released from $N$ Reactor, 3) those from fallout and 4) those in the natural background. (4)

Zinc-65 was selected for this study because of its high rate of adsorption by suspended sediments, and because field data were readily available. Field measurements taken in the early 1960's indicated that approximately $75 \%$ of the dissolved radionuclide ${ }^{65} \mathrm{Zn}$ released at the Hanford site was adsorbed by river sediments within 200 miles downstream. (1)

Past studies concerned with sediment-related effects have not advanced because of the extremely complex physical and chemical characteristics of sediments and radionuclides. Because of the lack of existing verified generalized models, ${ }^{(8)}$ engineers have had to rely on field studies or experience to estimate the distribution of radionuclide concentrations.

The SERATRA model was developed as a means for more realistic predictions. $(9,10)$ By use of the finite elenent solution technique with the Galerkin weighted residual method, this model predicts temporal and spatial distributions (vertical and longitudinal) concentrations of both cohesive and noncohesive sediments, as well as dissolved radionuclides and radionuclides attached to each size fraction of river sediments. The model also predicts changes in river bed elevations and radionuclide inventory in the river bed. Sediment transport and adsorption were simulated separately for each sediment size fraction (e.g., sand, silt and clay) because important sediment characteristics, such as fall velocity, exchange capacity, and critical shear stresses for erosion and deposition, vary significantly with sediment particle sizes.

This report details the application of the SERATRA model to the Columbia River. Besides the simulation results, sections are included covering the model formulation and the code description. 


\section{REVIEW OF PREVIOUS WORK}

Comprehensive studies of the impacts of the Hanford operations on the Columbia River and its adjacent coastal zones have been conducted since 1949, first through the sponsorship of the Atomic Energy Commission, and now the Energy Research and Development Administration. These studies have covered a wide range of hydrologic, radiologic and biologic studies and required monitoring and sampling of river water, suspended and bed sediments, fish, wildfowl, plankton and bottom organisms. Various groups from the Hanford Laboratories, Oregon State University, University of Washington, U.S. Geological Survey (USGS) and U.S. Public Health Service have carried out this work. These comprehensive environmental surveillance programs have provided considerable data for the evaluation of environmental impacts resulting from various industrial uses of the Columbia River.

Among these early programs were the following sediment and radionuclide studies.

1. An early study conducted by Nielsen and Perkins (11) concluded that the association of radioactive solutes with suspended sediment is the primary mechanism of radioactive uptake, while biota accounts for a small percentage of the depletion.

2. A field study by Whetten et al. (12) at the University of Washington has provided considerable knowledge of the physical-chemical nature of the sediment system, including patterns of sedimentation. The bulk of the sediment is usually transported downstream in a few days or weeks in the late spring or early summer flood period. Suspended sediment is deposited in the river-run reservoirs during low water discharge periods, while scouring and resuspension of bed sediments behind the reservoirs occur during high flow periods.

3. During the early 1960's, the U.S. Geological Survey (1-3) conducted various field measurement programs which focused on radionuclide 
transport in the Columbia River and its adjacent ocean coastal zone. These programs investigated the radionuclides' temporal variation, association with the sediment, and travel times, as well as the role of the reservoirs in deposition of sediment and radioactive materials. The USGS found that the most abundant radionuclide in the Columbia River was ${ }^{51} \mathrm{Cr}$, which constituted approximately $95 \%$ of the total radioactive materials measured at vancouver, Washington. The studies also showed an interesting transport behavior for ${ }^{65} \mathrm{Zn}$, the next most abundant radionuclide. Zinc-65 was measured as approximately solute at Pasco, Washington, but was only $20 \%$ solute at Vancouver; much ${ }^{65}$ Zn was adsorbed by river sediment during transport. Nelson et al. (13-15) in the 1960's also investigated radionuclide and sediment transport and sedimentation between the Hanfora Reservation and Vancouver. Pruter and Alverson (7) also reported that a substantial fraction of the radionuclides bound to the river sediments was rapidly desorbed in a marine environment.

4. From 1971 through 1973, after the closure of a 11 reactors except $N$ Reactor, PNL collected water and core samples primarily behind McNary Dam. Robertson et a1. (16) and Cushing et al. (17) based their observations on the current state of the radionuclide inventory and its variation with time on this sampling program and indicated substantial reduction of Hanford-origin radioactive materials in the Columbia River. This study, however, did not analyze radionuclide inventory with respect to sediment size fractions, but treated sediment as a bulk.

Presently PNL conducts an ERDA-sponsored monitoring program of Columbia River water quality concerning radiological analysis of the Columbia River water. Previous studies conducted on the Columbia River are summarized in References 7 and 18 .

The field measurements obtained in these programs can be useful in predicting future sediment and radionuclide inventories and their movements 
only if hydrological and other conditions remain similar to those which prevailed during the monitoring periods. However, it is not possible to estimate from these previous observations radionuclide and sediment inventories and their movements in the Columbia River and adjacent coastal areas for hydrologic conditions (including accidental and hypothetical extreme flows) which did not occur during the past monitoring periods. To deal with such eventualities, mathematical simulation must be undertaken. Consequently, the SERATRA code was applied to simulate sediment and radionuclide transport and their interaction under various conditions. 
Lorigitudinal and vertical distributions of sediment and radionuclide concentrations were computed by the SERATRA mode1. The modeling procedure involved simulating the transport of sediments within the water body. The results were then input to models of dissolved and particulate rodionuclides in order to observe the interaction between sediment and radionuclide movements. Finally, changes in river bed conditions were recorded, including river bottom elevation change, ratio of sand, silt ard clay sediments, and distribution of radionuclide concentration in the river bed.

This model is also applicable to other constituents, including nutrients, pesticides and heavy metals, which may undergo physicalcremical reactions with the sediments.

\section{SEDIMENT TRANSPORT MODEL}

Sand, silt and clay transport are modeled separately since sediment movement and adsorption capacity varies significantly with particle size. The model includes the effects of:

1. Convection and dispersion of sediments

2. Fall velocity and cohesiveness

3. Deposition on the river bed

4. Resuspension from the river bed (bed erosion and armoring)

5. Tributaries.

Sediment minerology and water quality effects are implicitly included through the above mentioned effects 2,3 , and 4 .

Governing Equations

Mass conservation of sediment passing through the control volume leads to the following expression for the transport of sand, silt and clay sediments: 


$$
\begin{aligned}
& \frac{j}{j t}\left(C_{j} B i \Delta z\right)+\left(U_{0} C_{j} j z B-U_{i} C_{i j} B i z\right)+\frac{\partial}{j z} i C_{j}\left(w w_{s j}\right) B i j \leq z=\frac{j}{j z}\left(\varepsilon_{z j} \frac{j C_{j}}{j z} B i\right) \Delta z
\end{aligned}
$$

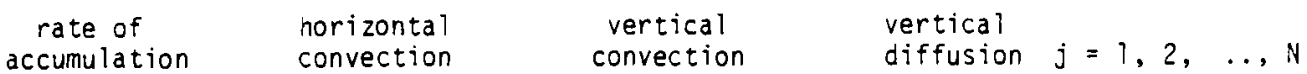

where ${ }^{(a)}$

$$
B=\text { river width }
$$

$C_{j}=$ concentration of sediment of $j$ th size fraction

$c_{i j}=$ sediment concentration of horizontal inflow for $j$ th size fraction (no summation rule is applied)

$$
\begin{aligned}
\varepsilon_{z j}= & \text { diffusion coefficient of vertical }(z) \text { component for } j \text { th sediment } \\
& \text { size fraction } \\
\ell= & \text { longitudinal distance } \\
N= & \text { number of sediment size fractions considered. In this study, } \\
& N=3 \text { (sand, silt and clay) } \\
t= & \text { time } \\
U_{i}= & \text { horizontal inflow velocity } \\
U_{0}= & \text { horizontal outflow velocity } \\
W= & \text { vertical flow velocity } \\
W_{S j}= & \text { fall velocity of sediment particle of } j \text { th size fraction } \\
z= & \text { vertical direction } \\
\Delta z= & \text { increment of vertical distance }
\end{aligned}
$$

This quasi-two-dimensional formulation neglects longitudinal diffusion and assumes lateral sediment concentrations to be uniform. However, the model does simulate longitudinal dispersion due to vertical variation of longitudinal velocity.

In terms of volumetric flow rates, Equation (1) may be written as:

$$
\frac{\partial C_{j}}{\partial t}+\left(\frac{Q_{v}}{A}-W_{s j}\right) \frac{\partial C_{j}}{\partial z}={ }^{\varepsilon} z j \frac{\partial^{2} C_{j}}{\partial z 2}-\frac{Q_{0} C_{j}}{A \Delta z}+\frac{Q_{j} C_{i j}}{A \Delta z}
$$

(a) The symbols defined above remain the same throughout the report 
where

$$
\begin{aligned}
A & =B l \\
Q_{i} & =U_{i} B \Delta z \\
Q_{0} & =U_{0} B \Delta z \\
Q_{v} & =W A
\end{aligned}
$$

Boundary conditions at the water surface $(z=h)$ and river bed $(z=0)$ are:

$$
\begin{aligned}
& \left(\frac{Q_{V}}{A}-W_{S j}\right) C_{j}-\varepsilon_{z j} \frac{\partial C_{j}}{\partial z}=0 \quad \text { at } z=h \\
& -(1-\gamma) W_{S j} C_{j}-\varepsilon_{z j} \frac{\partial C_{j}}{\partial z}=S_{R j}-S_{D j} \quad \text { at } z=0
\end{aligned}
$$

where

$$
\begin{aligned}
h= & \text { water depth } \\
S_{D j}= & \text { sediment deposition rate per unit area for } j \text { th sediment } \\
& \text { size fraction } \\
S_{R j}= & \text { sediment erosion rate per unit area for } j \text { th sediment size fraction } \\
Y= & \text { coefficient, } i . e ., \text { probability that particle settling } \\
& \text { to the bed is deposited. }
\end{aligned}
$$

In this study, $\gamma$ is assumed to be unity, that is, for the same flow condition all suspended sediments settling to the river bed will stay on the river bed without returning to the flow.

Erosion and Deposition of Cohesive Sediments (Silt and Clay)

Sediment erosion and deposition rates, $S_{R j}$ and $S_{D j}$, are also evaluated separately for each sediment size fraction because erosion and deposition characteristics are significantly different for cohesive and noncohesive sediments. Since only Partheniades (19) and Krone ${ }^{(20)}$ formulas for erosion and deposition rates, respectively, are presently available, these formulas were adopted in this study: 


$$
\begin{aligned}
& S_{R j}=M_{j}\left(\frac{\tau_{b}}{\tau_{C R j}}-1\right) \\
& S_{D j}=\frac{2 W_{S j} C_{j}}{h}\left(1-\frac{\tau_{b}}{\tau_{C D j}}\right)
\end{aligned}
$$

where

$$
\begin{aligned}
M_{j}= & \text { erodibility coefficient for sediment of } j \text { th size fraction } \\
{ }^{T_{b}=} & \text { bed shear stress } \\
{ }^{{ }^{T} C D j}= & \text { critical shear stress for sediment deposition for } j \text { th sediment } \\
& \text { size fraction } \\
{ }^{{ }_{C} C R j}= & \text { critical shear stress for sediment erosion for } j \text { th sediment } \\
& \text { size fraction }
\end{aligned}
$$

Values of $M_{j}, \tau_{C D j}$ and $\tau_{C R j}$ must be determined by field and/or laboratory tests for a particular river regime. PNL has been conducting laboratory flume tests by using Columbia River cohesive sediments to examine these values under fresh and saline water environments for a modeling study on sediment and radionuclide transport in the Columbia River. The availability of bed sediments to be resuspended was also examined to determine the actual amount of sediment erosion.

When the fall velocity, $w_{s j}$, depends on sediment concentration and no aggregation occurs, the fall velocity may be assumed: $(20)$

$$
w_{s j}=k_{j} C_{j}^{4 / 3}
$$

where

$K_{j}=$ an empirical constant depending on the sediment type. Erosion and Deposition of Noncohesive Sediments (Sand)

Erosion and deposition of noncohesive sediments are affected by the amount of sediment the flow is capable of carrying. For example, if the amount of sand being transported is less than the flow can carry for given hydrodynamic conditions, the river will scour sediment from the stream bed to increase the sediment transport rate. This occurs until 
the actual sediment transport rate becomes equal to the carrying capacity of the flow or until the bed sediments are all scoured, whichever occurs first. Conversely, the river deposits sand if its actual sediment transport rate is above the flow's capacity to carry sediment. Toffaleti's formula(21) was used to estimate the flow capacity, $Q_{S}$, which was then compared with the actual amount of sand, $Q_{s a}$, being transported in a river water. Hence:

$$
\begin{aligned}
& S_{R j}=\frac{Q_{S}-Q_{S a}}{A} \\
& S_{D j}=\frac{Q_{S a}-Q_{S}}{A}
\end{aligned}
$$

where

$A=$ the river bed surface area.

\section{DISSOLVED RADIONUCLIDE TRANSPORT MODEL}

A study conducted by Nielson and Perkins $(11)$ concluded that the association of dissolved radionuclides with suspended sediments is the primary mechanism of radionuclide uptake, while biota accounts for a small percentage of the depletion. Laboratory flume experiments conducted by Gloyna et a1. (22) also revealed that a small amount of a radionuclide becomes associated with the bottom sediments by direct sorption, and that the larger amount found in the bed sediments is attributed to the settling of suspended sediments. For this study the radionuclide transport model considers only the effects of adsorption (or desorption) of dissolved radionuclide materials (or other dissolved contaminants) by suspended and bed load sediments. In addition to adsorption mechanics, the model includes the effects of:

1. Convection and dispersion of radionuclides (or other contaminants) within the river

2. Adsorption (uptake) of dissolved radionulides (or other contaminants) by sediments (suspended and bed load sediments) or desorption from sediments into water

3. Radionuclide (or other contaminants) decay

4. Tributaries. (Radionuclide contributions from nuclear facilities, fallout and groundwater to a river may be treated as a part of tributary contributions.) 
Effects of water quality (e.g., pH, water temperature, salinity, etc.) and clay minerals are taken into account through changes in adsorption or desorption rate, $K_{d j}$. Mass conservation of dissolved radionuclides (and other contaminants) may be expressed as:

$$
\begin{aligned}
& \frac{\partial}{\partial t}\left(G_{w} B l \Delta z\right)+\left(U_{0} G_{w} B \Delta z-U_{j} G_{w i} B \Delta z\right)+\frac{\partial}{\partial z}\left(W_{w} B l\right) \Delta z \\
& \text { rate of horizontal vertical } \\
& \text { accumulation convection convection }
\end{aligned}
$$

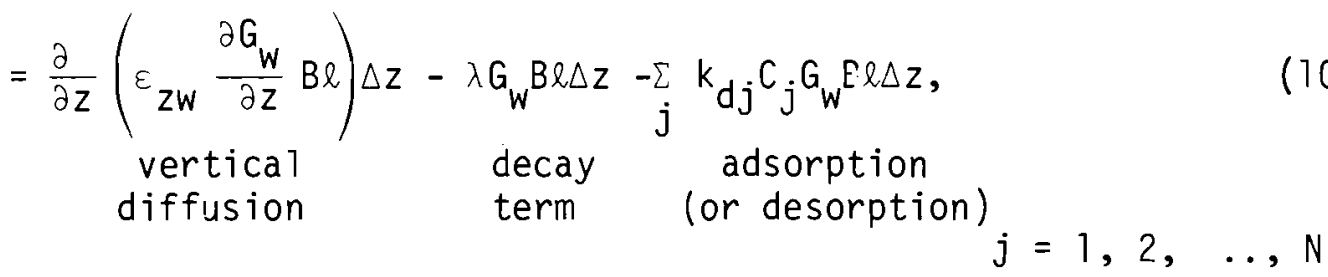

In addition to the previously defined symbols:

$$
\begin{aligned}
E_{Z W}= & \text { vertical diffusion coefficient for dissolved radionuclides } \\
G_{W}= & \text { dissolved radionuclide concentration } \\
G_{W i}= & \text { dissolved radionuclide concentration in horizontal inflow } \\
k_{d j}= & \text { rate of adsorption (or desorption) between dissolved nuclide and } \\
& \text { sediment (suspended and bed load sediments) of jth size fraction } \\
\lambda= & \text { decay rate of radioactive material. }
\end{aligned}
$$

It was assumed that radionuclide uptake is the first order reaction and that the rate of radionuclide uptake is proportional to the product of concentrations of dissolved radionuclides and sediments, as shown in Equation (10). Longitudinal diffusion is considered to be negligible when compared to convection. Longitudinal dispersion due to vertical variation of longitudinal velocity was, however, simulated in this study.

In terms of volumetric flow rates, Equation (10) may be rewritten as:

$$
\begin{gathered}
\frac{\partial G_{W}}{\partial t}+\frac{Q_{v}}{A} \frac{\partial G_{W}}{\partial z}+\left(\frac{Q_{0}}{A \Delta z}+\lambda+\sum_{j} k_{d j} C_{j}\right) G_{W}=\varepsilon_{z W_{\partial z}} \frac{\partial^{2} G_{W}}{{ }^{2}} \\
+\left(\frac{Q_{i} G_{W i}}{A \Delta z}\right), j=1,2, \ldots, N
\end{gathered}
$$


Boundary conditions at the water surface and river bed are:

$$
\begin{aligned}
& \frac{Q_{V} G_{W}}{A}-\varepsilon_{z w} \frac{\partial G_{W}}{\partial z}=0 \quad \text { at } z=h \\
& \frac{\partial G_{W}}{\partial z}=0 \quad \text { at } z=0
\end{aligned}
$$

PARTICULATE RADIONUCLIDE TRANSPORT MODEL

The transport model of radionuclides (or other contaminants) attached to sediment includes the effects of

1. Convection and dispersion of particulate radionuclides

2. Adsorption (uptake) of dissolved radionuclides by sediments or desorption from sediments into water

3. Radionuclide decay

4. Deposition of particulate radionuclides to the river bed or resuspension from the river bed

5. Tributaries. (Radionuclide contributions from nuclear facilities, fallout and groundwater to a river may be treated as a part of the tributary contributions.)

As in the transport of sediments and dissolved radionuclides, the conservation of radionuclides adsorbed by each sand, silt and clay sediment may be expressed as:

$$
\begin{aligned}
& \frac{\partial}{\partial t}\left(G_{j} C_{j} B \ell \Delta z\right)+\left(U_{0} G_{j} C_{j} B \Delta z-U_{i} G_{i j} C_{i j} B \Delta z\right)+\frac{\partial}{\partial z}\left\{\left(W-W_{s j}\right) G_{j} C_{j} B l\right\} \Delta z \\
& \text { rate of } \\
& \text { accumulation } \\
& \text { horizontal } \\
& \text { convection } \\
& \text { vertical } \\
& \text { convection } \\
& =\frac{\partial}{\partial z}\left(\begin{array}{ccc}
E_{z j} \frac{\partial G_{j} C_{j}}{\partial z} B l \\
\text { vertical } \\
\text { diffusion }
\end{array} \quad \begin{array}{l}
\text { decay } \\
\text { term }
\end{array} \quad \begin{array}{c}
\text { adjorption } \\
\text { (or desorption) }
\end{array}\right.
\end{aligned}
$$


where

$$
\begin{aligned}
G_{j}= & \text { particulate radionuclide concentration per unit weight of sediment } \\
& \text { in } j \text { th sediment size fraction } \\
G_{i j}= & \text { particulate concentration per unit weight of sediment in } j \text { th sedi- } \\
& \text { ment size fraction in horizontal inflow (no summation will be } \\
& \text { applied). }
\end{aligned}
$$

Longitudinal dispersion was assumed to be negligible, as compared to longitudinal convection. However, as noted before, the longitudinal dispersion due to nonuniform vertical distribution of longitudinal velocity was simulated in the model.

Subtraction of Equation (1) from Equation (14) yields the following expression in terms of volumetric flow rates:

$$
\begin{aligned}
\frac{\partial G_{j}}{\partial t}+\left(\frac{Q_{v}}{A}-W_{S j}-\frac{2 \varepsilon_{z j}}{C_{j}} \frac{\partial C_{j}}{\partial z}\right) \frac{\partial G_{j}}{\partial z}+\left(\frac{Q_{j} C_{i j}}{C_{j} A \Delta z}+\lambda\right) G_{j} \\
=\varepsilon_{z j} \frac{\partial^{2} G_{j}{ }^{2}}{\partial C^{2}}+\left(\frac{Q_{j} C_{i j} G_{i j}}{C_{j} A \Delta}+k_{d j} G_{w}\right)
\end{aligned}
$$

The boundary condition at the water surface is:

$$
G_{j} C_{j}\left(\frac{Q_{v}}{A}-W_{s j}\right)-\varepsilon_{z j} \frac{\partial G_{j} C_{j}}{\partial z}=0 \quad \text { at } z=h
$$

Noting Equation (3), the above equation becomes:

$$
\frac{\partial G_{j}}{\partial z}=0 \quad \text { at } z=h
$$

The boundary conditions at the river bed is:

$$
-(1-\gamma) W_{S j} G_{j} C_{j}-\varepsilon_{z j} \frac{\partial G_{j} C_{j}}{\partial z}=G_{B j} S_{R j}-G_{j} S_{D j} \quad \text { at } z=0
$$


where $G_{B j}$ equals the radionuclide corcentration per unit weight of sediment on the river bed for $j$ th sediment size fraction, and $\gamma$ was assumed to be unity as previously defined.

Noting Equation (4), this equation may be expressed as

$$
\frac{\partial G_{j}}{\partial z}=-\frac{G_{B j}-G_{j}}{C_{j} \varepsilon_{z j}} S_{R j}
$$

The finite element technique with the Galerkin weighted residual method was used to solve transport equations of sediments, dissolved radionuclides and particulate radionuclides previously described.

\section{FINITE ELEMENT TECHNIQUE}

High speed digital computers have enabled engineers to employ various numerical discretization techniques for approximating solutions to complex mathematical equations. The finite element method is one such technique. (23) This method has recently gained popularity for solving both linear and nonlinear partial differential equations because of its increased solution accuracy, and ready accommodation to various boundary geometrics. $(9,10,24-26)$

To apply the finite element method to a partial differential equation, an alternate but equivalent integral equation is imposed. The finite element method involves five basic steps:

1. Derive a partial differential equation

2. Divide the solution domain into a number of finite elements (polygons) defined by node points to form a computational network

3. Approximate the dependent variables in terms of their unknown node point values within each element by selecting an approximate polynomial

4. Develop finite element equations by minimizing error caused by the approximation

5. Solve the resulting set of equations to get solutions at node points. 
Since the governing equations of sediment and radionuclide transport [Equations (2), (11), and (15)] have similar forms, the finite element technique is described here for a convection-diffusion equation of the general form:

$$
L[\phi]=\frac{\partial \phi}{\partial t}+v \frac{\partial \phi}{\partial z}-\varepsilon_{z} \frac{\partial^{2} \phi}{\partial z^{2}}+\alpha \phi-\beta
$$

The coefficients $v, \varepsilon_{z}, \alpha, \beta$ are defined to accommodate the specific form of the sediment and radionuclide transport equations.

Galerkin Weighted Residual Method

The governing differential equation can be recast as an integral problem employing the Galerkin method. This integral, referred to as the Galerkin functional, is formed by taking the product of $L[\phi]$ with some arbitrary set of weighting functions, $w_{j}$, which yields:

$$
x=\int_{R} L[\phi] W_{j} d z
$$

where

$R=a$ domain of interest.

If $\phi$ is approximated by some polynomial:

$$
\Phi=\sum_{i=1}^{m} \phi^{i} w_{i}
$$

then the quantity $L[\Phi]$ represents the residual error. According to Galerkin's method, the approximating function $w_{i}$ is chosen to be the same as the weighting function $w_{j}$. The Galerkin functional becomes an error distribution principle by which the nodal values $\phi_{j}$ can be determined so that the residual error over the domain $R$ is sma11. This is achieved by imposing an orthogonality constraint so that $x=0$. 
By expanding the equation and integrating by parts, the reduced functional results:

$$
X=\int_{R}\left[\frac{\partial \phi}{\partial t} W_{j}+v \frac{\partial \phi}{\partial z} W_{j}+\varepsilon_{z} \frac{\partial \phi}{\partial z} \frac{\partial W}{\partial z} j+\alpha \phi W_{j}-\beta W_{j}\right] d z
$$

Note that Equation (21) was derived by assuming no net flux across the boundary. In cases where the boundary has positive or negative net flux across it, this flux was incorporated as a source or sink term.

The above integral can be partitioned so that:

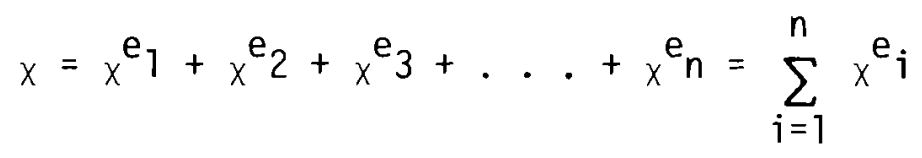

where

$$
\begin{aligned}
& n=\text { the number of subdomains. This may be expanded to give: } \\
& x=\int_{z_{1}}^{z_{2}}[] d z+\int_{z_{2}}^{z_{3}}[] d z+\ldots .+\int_{z_{m-1}}^{z_{m}}[] d z
\end{aligned}
$$

The contents in brackets in Equation (23) are the same as those in Equation (21). The integration of the Galerkin functional given above will yield a set of $\mathrm{m}$ ordinary differential equations in terms of $\phi_{j}$.

\section{Finite Element Equations}

The system of equations for a typical finite element can be developed by using a single functional and particular polynomial approximation for $\phi$. For simplicity, a linear approximation was chosen:

$$
\phi \doteq \gamma=a+b z
$$


The following requirements are imposed:

$$
\begin{aligned}
& \phi_{j}=a+b z_{j} \\
& \phi_{j+1}=a+b z_{j+1}
\end{aligned}
$$

The coefficients $a$ and $b$ are:

$$
\left\{\begin{array}{l}
a \\
b
\end{array}\right\}=\frac{1}{\Delta z}\left[\begin{array}{cc}
z_{i+1} & -z_{i} \\
-1 & 1
\end{array}\right]\left\{\begin{array}{l}
\phi_{i} \\
\phi_{i+1}
\end{array}\right\}
$$

This allows an approximation to $\phi$ over the subdomain:

$$
\tilde{\psi}_{i}(z, t)=\left[w_{1}, w_{2}\right]\left\{\begin{array}{ll}
\phi_{i} & 1 \\
\phi_{i+1}
\end{array}\right\}
$$

The weighting functions are given by:

$$
\begin{aligned}
& w_{1}=\frac{1}{\Delta z}\left(z_{i+1}-z\right) \\
& w_{2}=\frac{1}{\Delta z}\left(z-z_{j}\right)
\end{aligned}
$$

The individual terms in the functional are approximated by:

$$
\begin{aligned}
& \frac{\partial \phi}{\partial t}=\left[W_{1}, W_{2}\right]\left\{\begin{array}{l}
\dot{\phi}_{i} \\
\dot{\phi}_{i+1}
\end{array}\right) \\
& \frac{\partial \phi}{\partial z}=[-1 / \Delta z, 1 / \Delta z]\left\{\begin{array}{l}
\phi_{i} \\
\phi_{i+1}
\end{array}\right\}
\end{aligned}
$$




$$
\frac{\partial W_{i}}{\partial z}=[-1 / \Delta z, 1 / \Delta z]
$$

where

$\dot{\phi}$ represents the time derivative.

Substituting these quantities into the functional for a typical subdomain, a set of integral equations is obtained. The integrals are evaluated using the following formula:

$$
\int_{z_{i}}^{z_{i+1}} w_{1} w_{2} d z=\frac{\gamma ! \beta ! \Delta z}{(\gamma+\beta+1) !}
$$

The results for individual terms are given below.

1. Time Dependent Term:

$$
\left.\int_{z_{i}}^{z_{i+1}}\left[\begin{array}{ll}
w_{1} w_{1} & w_{2} w_{1} \\
w_{1} w_{2} & w_{2} w_{2}
\end{array}\right] d z=\frac{\Delta z}{6}\left[\begin{array}{ll}
2 & 1 \\
1 & 2
\end{array}\right]\right)\left(\begin{array}{l}
\dot{\phi}_{i} \\
\dot{\phi}_{i+1}
\end{array}\right)
$$

2 Advective Term:

$$
\begin{gathered}
\int_{z_{i}}^{z_{i+1}}\left[\begin{array}{cc}
-\left(v_{i} w_{1}{ }^{2}+v_{i+1} w_{1} w_{2}\right) & \left(v_{i} w_{1}^{2}+v_{i+1} w_{1} w_{2}\right) \\
-\left(v_{i} w_{1} w_{2}+v_{i+1} w_{2}^{2}\right) & \left(v_{i} w_{1} w_{2}+v_{i+1} w_{2}^{2}\right)
\end{array}\right] d z\left\{\begin{array}{l}
\phi_{i} \\
\phi_{i+1}
\end{array}\right. \\
=\frac{1}{6}\left[\begin{array}{cc}
-\left(2 v_{i}+v_{i+1}\right) & \left(2 v_{i}+v_{i+1}\right) \\
-\left(v_{i}+i v_{i+1}\right) & \left(v_{i}+2 v_{i+1}\right)
\end{array}\right]\left\{\begin{array}{l}
\phi_{i} \\
\phi_{i+1}
\end{array}\right\}
\end{gathered}
$$


3. Diffusion Term:

$$
\frac{\varepsilon_{z}}{\Delta z^{2}} \int_{z_{i}}^{z_{i+1}}\left[\begin{array}{cc}
1 & -1 \\
-1 & 1
\end{array}\right]\left\{\begin{array}{l}
\phi_{i} \\
\phi_{i+1}
\end{array}\right\} d z=\frac{\varepsilon_{z}}{\Delta z}\left[\begin{array}{cc}
1 & -1 \\
-1 & 1
\end{array}\right]\left\{\begin{array}{l}
\phi_{i} \\
\phi_{i+1}
\end{array}\right\}
$$

4. Decay Term:

$$
\int_{z_{i}}^{z_{i+1}} \alpha\left[\begin{array}{ll}
W_{1} W_{1} & W_{2} W_{1} \\
W_{1} W_{2} & W_{2} W_{2}
\end{array}\right]\left\{\begin{array}{l}
\phi_{i} \\
\phi_{i+1}
\end{array}\right\} d z=\frac{\alpha \Delta z}{6}\left[\begin{array}{ll}
2 & 1 \\
1 & 2
\end{array}\right],\left\{\begin{array}{l}
\phi_{i} \\
\phi_{i+1}
\end{array}\right\}
$$

5. Source Term:

$$
\int_{z_{i}}^{z} \beta\left\{w_{2} w_{1}^{w_{1}}\right\} d z=\beta \Delta z\left\{\begin{array}{l}
1 / 2 \\
1 / 2
\end{array}\right\}
$$

Summing up and gathering terms give the matrix equation for a typical finite element:

$$
\left.[P]^{e} j \mid \begin{array}{l}
\dot{\phi}_{i} \\
\dot{\phi}_{j+1}
\end{array}\right\}+[S]^{e_{j}}\left|\begin{array}{l}
\phi_{j} \\
\phi_{j+1}
\end{array}\right|=\{R\}^{e_{j}}
$$

where

$$
[\mathrm{F}]=\left[\begin{array}{cc}
1 / 3 & 1 / 6 \\
1 / 6 & 1 / 3
\end{array}\right],\{R\}=1 / 2 \quad\left\{\begin{array}{l}
\beta \\
\beta
\end{array} \mid\right.
$$




$$
\begin{aligned}
& {[S]=\left[\begin{array}{cc}
\left(D-\frac{\bar{V}}{3 \Delta z}+\frac{\alpha}{3}\right) & -\left(D-\frac{\bar{V}}{3 \Delta z}-\frac{\alpha}{6}\right) \\
-\left(D+\frac{\tilde{V}}{3 \Delta z}-\frac{\alpha}{6}\right) & \left(D+\frac{\tilde{V}}{3 \Delta z}+\frac{\alpha}{3}\right)
\end{array}\right],} \\
& D=\frac{\varepsilon z}{\Delta z^{2}}, \quad \bar{v}=\left(v_{i}+\frac{1}{2} v_{i+1}\right), \quad \hat{v}=\left(\frac{1}{2} v_{i}+v_{i+1}\right)
\end{aligned}
$$

The summation given in Equation (22) gives the rules for constructing the matrices for all finite elements; the matrices $[\mathrm{P}]$ and $[\mathrm{S}]$ become tridiagonal matrices. The final set of equations is a generalization of Equation (40).

Time-Dependent Solution

The final set of equations derived above can be expressed by:

$$
[\tilde{P}] \frac{d \Phi}{d t}+[\tilde{S}]\{\phi\}=\{\tilde{R}\}
$$

where

$[\tilde{P}]$ matrix $=$ a symmetric tridiagcnal,

$[\tilde{S}]$ inatrix $=$ an unsymmetric tridiagonal

$\{\tilde{R}\}=$ a load vector.

This final system of equations is approximated by a Crank-Nicholson scheme: ${ }^{(27)}$

$$
[\tilde{\mathrm{P}}] \frac{\{\phi\}^{\mathrm{n}+1}\{\phi\}^{n}}{\Delta t}=\frac{1}{2}[\tilde{\mathrm{S}}]\{\phi\}^{n+1}+\{\phi\}^{\mathrm{n}}+\{\tilde{\mathrm{R}}\}
$$

Solving for the $n+1$ value of $\phi$, this expression can be rearranged to obtain:

$$
[\beta]\{\phi\}^{n+1}=[\xi]\{\phi\}^{n}+\{R\}
$$


where

the new coefficient matrices are:

$$
\begin{aligned}
& {[\bar{P}]=[\tilde{P}]+\frac{\Delta t}{2}[\tilde{S}]} \\
& {[\bar{S}]=[\tilde{P}]-\frac{\Delta t}{2}[\tilde{S}]} \\
& \{\bar{R}\}=\Delta t\{\tilde{R}\}
\end{aligned}
$$

This type of approximation is second order correct, unconditionally stable and easily solved by most available tridiagonal solution schemes.

A computer program has been written in FORTRAN IV to implement the model. 


\section{CODE DESCRIPTION}

The computer program described in this section is designed to obtain solutions of the differential Equations (2), (11), and (15) with appropriate boundary and initial conditions. The program consists of subroutines which are managed by the executive routine, SERATRA.

\section{COMPUTATION PROCEDURE}

The procedure for solving the equations is as follows:

1. Read input data

2. Assign new river reach

3. Assign new time

4. Compute vertical velocity distribution and bed shear stress

5. Solve sediment transport equation to compute vertical distributions of sediment concentrations for
a. sand
b. silt
c. clay

6. Solve dissolved radionuclide transport equations to compute vertical distributions of dissolved contaminant

7. Solve particulate radionuclide transport equation to compute vertical distributions of concentrations of contaminant attached to
a. sand
b. silt
c. clay

8. Update river bed history

9. Repeat Steps 3 through 8 until all computation time is covered.

10. Repeat Steps 2 through 9 until a 11 river reaches (1ongitudinal distance) are covered.

11. Print computer results.

\section{EXECUTIVE PROGRAM AND SUBROUTINE DESCRIPTION}

The computer code consists of an executive routine called SERATRA and 20 subroutines. A list of the primary duties served by each of these routines follows: 


\section{SERATRA Executive Routine}

1. Reads data for program control

2. Calls subroutines for data input, problem set up and initialization, and program execution.

3. Performs minor computations such as presetting variables, converting input data to appropriate units, etc.

Subroutines

The subroutines cailed from the main program are:

INPUT

SHEAR

TRIB

AVERAGE

SEGMTX

NUCCON

TRANSP

PRINTS

Subroutine INPUT

General data input routine

- Reads input data from cards or teletype

- Reads restart file if required

- Converts portions of input data to appropriate quantities

- Calls subroutines

PROFIL

SHEAR

Subroutine PROFIL

Computes vertical distribution of flow discharge assuming the velocity distribution is logarithmic. 
Subroutine SHEAR

Computes bed shear stress and shear velocity for a sediment laden flow. Subroutine TRIB

Sets up input quantities of tributaries

- Computes vertical discharge distribution from vertically averaged value, assuming the velocity is logarithmically distributed.

- Computes vertical distributions of contaminants from vertically averaged values.

\section{Subroutine AVERAGE}

Calculates inflow concentrations of sediments and contaminants into a river reach by adding tributary input to the main river contributions to the reach.

\section{Subroutine SEGMTX}

Converts output of upstream reach to input of immediate downstream reach by taking into account possible different numbers of vertical computation elements for these two reaches.

Subroutine NUCCON

Obtains total concentration of a contaminant.

- Sums up concentrations of contaminant attached to sand, silt and clay in water.

- Sums up concentration of contaminant attached to bed sediment for all sediment size fractions.

Subroutine TRANSP

Solves concentrations of sediment, dissolved contaminant and particulate contaminant. Calls subroutines for a 11 transport equations.

- Calls subroutine FALL

- Calls subroutine SAND

- Calls subroutine SILCLA 
- Calls subroutine SEDIME

- Calls subroutine RDSOL

- Calls subroutine RDSSC

- Calls subroutine BEDHST

- Calls subroutine SETUP

- Calis subroutine COMB

- Calls subroutine TRISOL

The code spends the majority of the execution time for this routine.

Subroutine FALL

Calculates the contribution of sediment fall velocity to the sediment transport equations.

\section{Subroutine SAND}

Calculates the amount of sand deposition to the river bed or resuspension from the bed. Availability of sand in the river bed is also checked if resuspension occurs. The Toffaleti's sediment discharge formula is used for computation of flow capacity to carry the noncohesive sediment for an assigned river reach.

\section{Subroutine SILCLA}

- Calculates the amount of silt deposition or erosion.

- Calculates the amount of clay deposition or erosion.

Availability of silt and clay on the river bed is checked if erosion occurs. The Partheniades and krone formulas are used to calculate the rates of cohesive sediment deposition or erosion.

\section{Subroutine SEDIME}

Calculates coefficients of convection, diffusion, decay and source terms in the sediment transport convection-diffusion equations. This will be performed for each sediment size fraction. 
Subroutine RDSOL

Calculates coefficients of convection, diffusion, decay and source terms in the dissolved contaminant transport convection-diffusion equation.

Subroutine RDSSC

Calculates coefficients of convection, diffusion, decay and source terms in the particulate contaminant transport convection-diffusion equation. This will be performed for a particulate contaminant attached to sediment of each sediment size fraction.

\section{Subroutine BEDHST}

- Maintains and updates a record of bed history for river bed elevation, bottom sediment size ratio and concentration of particulate contaminants.

- Calls subroutine LEFT

\section{Subroutine LEFT}

- Computes the amount of sediment in the top river bed layer for each sediment size fraction.

- Computes the amount of particulate contaminant attached to sediment of each size fraction in the top river bed layer.

\section{Subroutine SETUP}

Sets up finite element matrices, $[P],[S]$, and $\{R\}$ in Equation (40) for equations of

- Sediment transport

- Dissolved contaminant transport

- Particulate contaminant transport

Subroutine COMB

Adds two terms in Equation (47)

- Multiplies the unsymmetric band matrix [S] to $\{\phi\}^{n}$

- Adds the result to the load vector $\{\bar{R}\}$ 
Subroutine TRISOL

Solves a system of equations $[A]\{X\}=\{B\}$ for $\{X\}$. The algorithm employs the Gaussian elimination technique.

\section{Subroutine PRINTS}

This is the primary output call routine. The computer results are printed out by line printer and simultaneously stored to an output file for concentration contour plotting.

\section{LISTS OF INPUT DATA AND COMPUTER OUTPUT}

The following summarizes the input data used for the SERATRA code:

Sediment Simulation

1. Flow and Channel Characteristics for Each River Reach

- Discharge

- Flow depth and water surface elevation

- Channel geometry (i.e., river width, cross-sectional shape)

- Diffusion coefficients

2. Sediment Characteristics for Each Sediment Size Fraction for Each River Reach

- Diameter, density and fall velocity of sediment

- Critical shear stress and erodibility coefficient for erosion of cohesive sediment in the river bed

- Critical shear stress for deposition of cohesive sediment

3. Initial and Boundary Conditions

- Concentration of total (suspended and bed load) sediment for each size fraction at each vertical element for a river reach

- Sediment weight fraction in the river bed at each vertical depth for a river reach 
Radionuclide Simulation

1. Radionuclide Characteristics

- Radionuclide type

- Adsorption and/or desorption rate for each river reach

2. Initial and Boundary Conditions

- Dissolved radionuclide concentration at each vertical

element for a river reach

- Concentration of radionuclide attached to sediment for each sediment size fraction at each vertical element for a river reach

- Concentration of radionuclide attached to sediment in the river bed at each vertical depth for a river reach

With the data input described above the model will simulate the sediment and radionuclide movement in a river. A summary of the computer output (simulation) is as follows:

Sediment Simulation

1. For Each River Reach at Assigned Time

- Vertical distribution of sediment (suspended and bed load) concentration for each sediment size fraction

- Vertical distribution of sediment size weight fraction ratio in the river bed

- River bed elevation (changes due to sediment deposition and/or scour)

2. Longitudinal Distribution of Sediment Load for Each Sediment Size Fraction at Assigned Time

Radionuclide Simulation

1. For Each River Reach at Assigned Time

- Vertical distribution of dissolved radionuclide concentration 
- Vertical distribution of radionuclide concentration adsorbed by sediment for each sediment size fraction

- Vertical distribution of total radionuclide concentration in motion

- Vertical distribution of radionuclide concentration in the river bed sediment for each sediment size fraction

- Vertical distribution of total radionuclide in the river bed

2. Longitudinal Distributions of Dissolved, Particulate (for each sediment size fraction) and Total Radionuclide Concentrations at Assigned Time 


\section{COMPUTER SIMULATION RESULTS}

To calculate sediment and radionuclide transport in the Columbia River, the SERATRA code was applied to a 169-km reach between the Priest Rapids Dam (River Mile 397.1) and the McNary Dam (River Mile 292.0), Figure 1. Of the radioactive materials found in the river, ${ }^{65} \mathrm{Zn},{ }^{54} \mathrm{Mn},{ }^{46} \mathrm{SC}$ and ${ }^{137} \mathrm{Cs}$ are very easily adsorbed by suspended sediments, whereas ${ }^{51} \mathrm{Cr}$ and ${ }^{124} \mathrm{Sb}$ were mostly transported downstream as dissolved radionuclides. $(7,28-30)$

Zinc-65 was selected for purposes of examining radionuclide transport and interaction with river sediments because it is easily adsorbed by suspended sediments and because field datà are available. The transport of dissolved ${ }^{65} \mathrm{Zn}$ without adsorption by suspended sediments was also simulated to establish a reference case for comparision with other cases, in order to identify the effects of radionuclide adsorption by suspended sediment.

Five cases were simulated: two for continuous release of radionuclides from the reactors; two for instantaneous release from the reactors; and the last case with no radionuclide release from the reactor, but with a radioisotope entering the river system through erosion of contaminated river bed sediments. Test conditions are listed in Table 1. The entire river stretch was divided into 16 river reaches (Figure 1). Reaches 1 and 16 correspond to the upstream and downstream ends of the study area, respectively. Water surface elevation and mean flow velocity in the study area were computed by a onedimensional hydrodynamic model, EXPLORE, (31) (Figures 2 and 3 ). Figure 2 shows variations of water surface and bed elevations of the Columbia River for a discharge of $1860 \mathrm{~m}^{3} / \mathrm{sec}$. This figure indicates the significant variations of water surface slope and bed elevations. The Columbia River flows freely up to approximately $35 \mathrm{~km}$ downstream from Priest Rapids Dam (River Reach 1, 2 and 3). Downstream, McNary Dam retards the flow (Figure 3 ). 


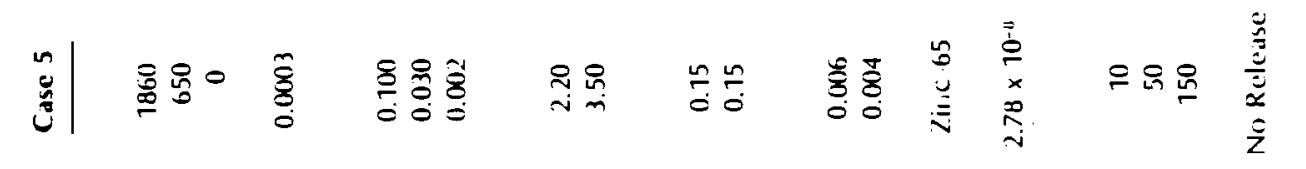

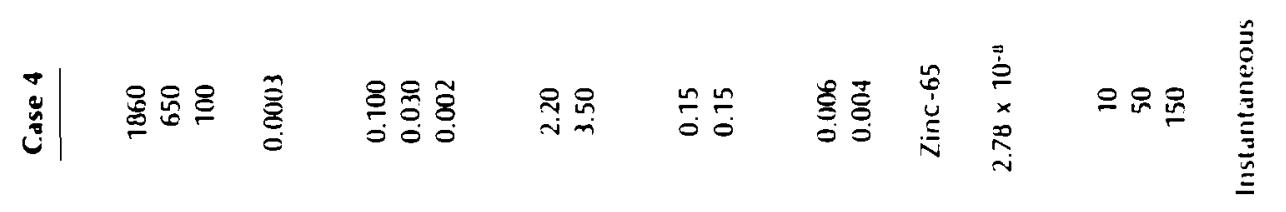

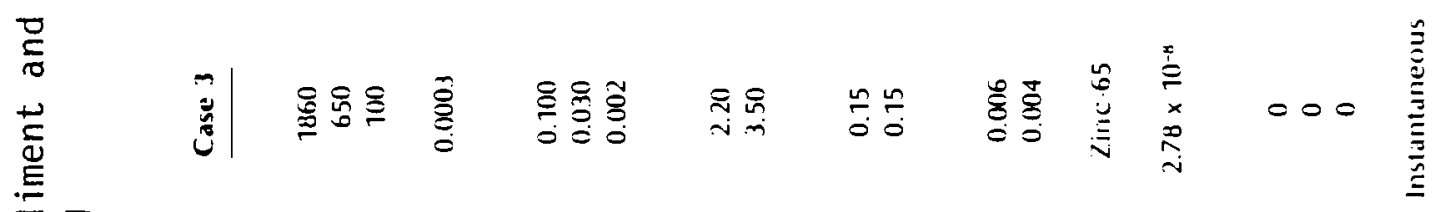

घัฐ

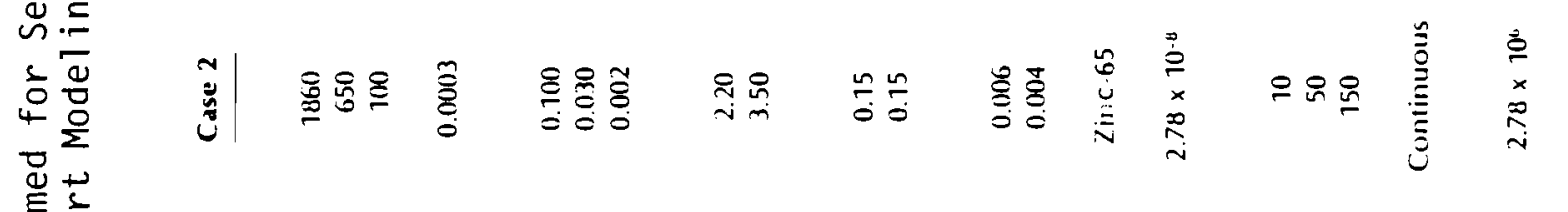

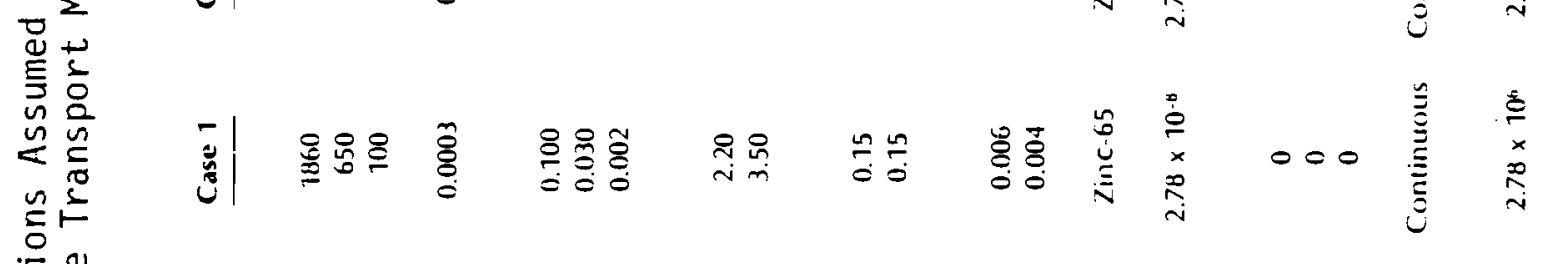

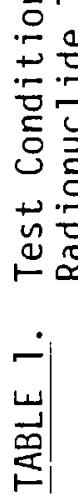

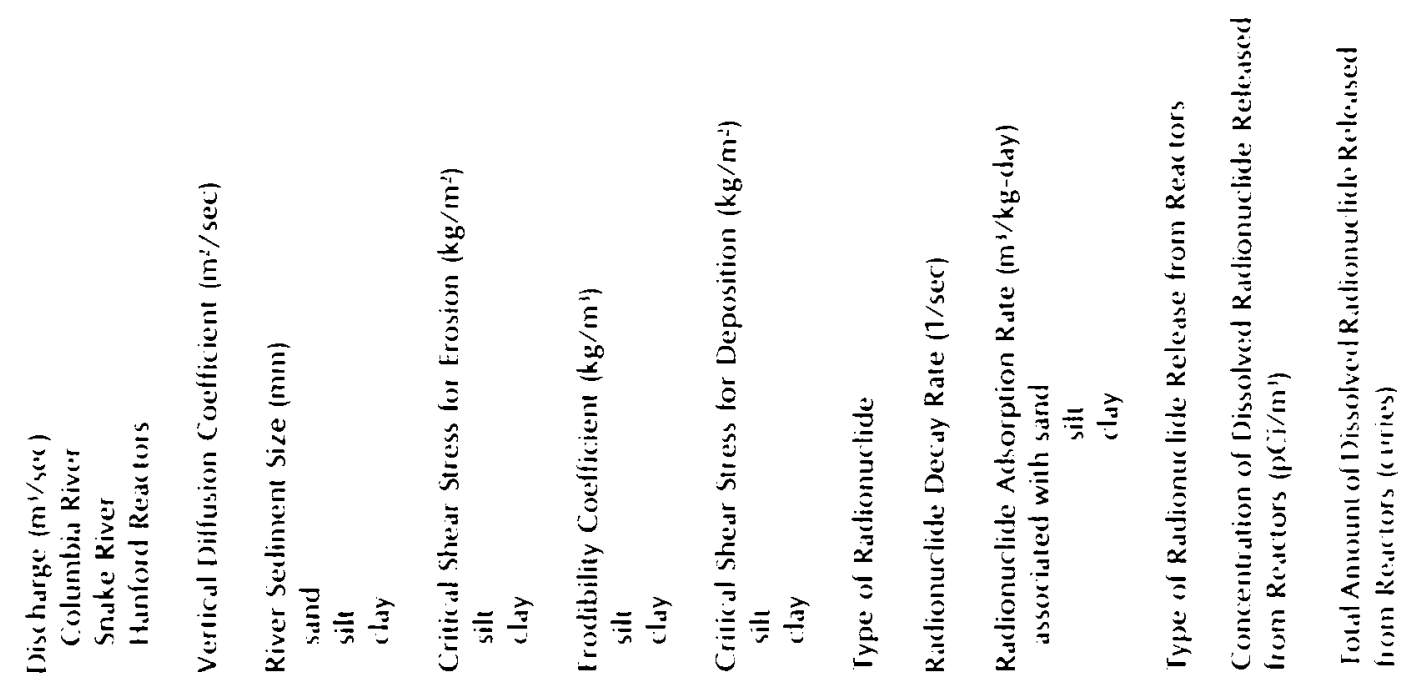




\section{CONTINUOUS RELEASE OF RADIONUCLIDES}

Two continuous releases of dissolved ${ }^{65} \mathrm{Zn}$ (Cases 1 and 2) were tested to identify the effects of river sediments on the migration of radionuclides, and to examine the applicability of the SERATRA code to radionuclide transport. For these cases, radionuclide transport was modeled for the continuous releases of dissolved ${ }^{65} \mathrm{Zn}$ assumed to be introduced to the Columbia River through the eight reactors ( $100 \mathrm{~B}, \mathrm{C}, \mathrm{D}, \mathrm{DR}, \mathrm{F}, \mathrm{H}, \mathrm{KE}$ and $\mathrm{KW}$ ) shown in Figure 1. The ${ }^{65} \mathrm{Zn}$ introduced from these reactors was diluted by the river and its tributaries, and some was adscrbed by suspended sediments before reaching McNary Dam.

Case 1 dealt with the transport of dissolved ${ }^{65} \mathrm{Zn}$ without the adsorption mechanism and established a baseline for comparison with Case 2 (transport of dissolved and particulate ${ }^{65} \mathrm{Zn}$ with the adsorption mechanisin). The analysis of Case 2 included interaction between ${ }^{65} \mathrm{Zn}$ and river sediments through adsorption of ${ }^{65} \mathrm{Zn}$ by suspended sediments of each sediment size fraction, and erosion and deposition of clean and contaminated sediments. The river sediments consist of sand, silt and clay. Particle sizes were assumed to be $0.100,0.030$ and $0.002 \mathrm{~m}$, respectively. $(1,3,29)$ Based on other Columbia River studies $(1,7)$ and sensitivity anaiyses on the adsorption rate being conducted in this study, ${ }^{65} \mathrm{Zn}$ adsorption rates for sand, silt and clay were selected to be 10,50 and $150 \mathrm{~m}^{3} / \mathrm{kg}$-day, respectively. Values of parameters related to deposition and resuspension of cohesive sediments are indicated in Table 1. Furthermore, the decay rate of ${ }^{65} \mathrm{Zn}$ is $2.78 \times 10^{-8}$ per sec (a half life of 245 days).

Because field data were available for calibration and verification of the simulation mode1, a 10-day period in October $1962(28,29,32)$ was used for Cases 1 and 2. Average river flow discharges of the Columbia, Snake, Yakima and Walla Walla Rivers were $1860,650,62$ and $2.3 \mathrm{~m}^{3} / \mathrm{sec}$, respectiveiy, during that period. Since the Yakima and Walla Walla Rivers contributed oniy about 2 and $0.1 \%$ to the Columbia River, their contributions were omitted 
from the analysis. It was assumed that originally there were no suspended sediments and no radionuclides in the entire study reach, and that only clean water was entering the river from the upstream boundary (Priest Rapids Dam) and from the Snake River. All the computer results shown for Cases 1 and 2 occurred on the 10th day.

Case 1. Dissolved Zinc-65 Without Adsorption

Simulation results at 240 hours are shown in Figures 4 and 5 which present both longitudinal distributions of the amount of total radionuclides in the water body for each river reach, and dissolved radionuclide concentration. Since adsorption mechanics were not included in this case, dissolved concentrations are equal to total radionuclide concentrations. Dissolved concentrations initially increase from 0 to 140 picocuries per liter $(p C i / l)$ as a result of the release of the radioisotope from the reactors and become constant until the Snake River joins the Columbia River at $117 \mathrm{~km}$ downstream of Priest Rapids Dam. Continuous decrease of dissolved ${ }^{65} \mathrm{Zn}$ concentration in the downstream direction after this point occurs because ${ }^{65} \mathrm{Zn}$ introduced from the reactors did not completely reach the lowest one-third of the study reach within 10 days. Nonetheless, as shown in Figure 4, the amount of radionuclides in the water body is highest in this region because of the greater depth and width of the river.

${ }^{51} \mathrm{Cr}$ (half 1 ife 27.8 days) and ${ }^{124} \mathrm{Sb}$ (half 1 ife 60.2 days) have very smal1 adsorption rates and more than 95\% of these radionuclides are transported as a dissolved phase. (29) Hence, their transport movements are expected to be almost the same as the dissolved ${ }^{65} \mathrm{Zn}$ without adsorption except for the effect of radionuclide decay, as shown from the comparison of transport phenomena between ${ }^{90} \mathrm{Sr}$ (a half 1 ife of 28.8 years and having a very small adsorption rate) and dissolved radionuclides without adsorption in the $\mathrm{Clinch}$ River near the Oak Ridge National Laboratory in Tennessee. (10)

\section{Case 2. Verification Test of Zinc-65 with Adsorption}

The results of Case 1 were compared with Case 2 to identify the effects of radionuclide adsorption by suspended sediments on the migration of radioactive materials. Figure 6 shows simulation results of longitudinal 
distributions of sediment concentrations (sum of suspended and bed load sediments) for sand, silt and clay, and the total sediment concentration. Measured total sediment concentration is also included for comparison with the predicted results. The field data were obtained from E. R. Leeson of the U.S. Geological Survey, Men1o Park, California in May 1973. Figure 6 indicates that for the uppermost river reach (up to approximately $40 \mathrm{~km}$ downstream of Priest Rapids Dam), the concentration of total sediments consisting mainly of silt increases to about $8.0 \mathrm{ppm}$. Since it was assumed that there were originally no suspended sediments in the study area and no sediments were entering this area from upstream of Priest Rapids Dam and from the Snake River, the increase of sediment concentration in the uppermost river reach is due to the river bed scouring caused by the free moving Columbia River flow. No measurable sand appears to be scoured.

When the river depth greatly increases and the flow velocity decreases (about $0.080 \mathrm{~m} / \mathrm{sec}$ ), as occurs approximately $120 \mathrm{~km}$ downstream of the Priest Rapids Dam, almost all suspended silt is deposited to the river bed. The SERATRA model also predicted that suspended clay reduces its concentration through deposition in the reach downstream of this area. The variation of total sediment concentration (sum of sand, silt and clay) reflects these changes. Comparison of predicted results with the field data shows that they are in reasonable agreement.

Figures 7 through 10 show computed longitudinal distributions of ${ }^{65} \mathrm{Zn}$ between the Priest Rapids and McNary Dams. Figure 7 presents predicted concentrations of total (sum of dissolved and particulate forms), dissolved and particulate (attached to sediment) ${ }^{65} \mathrm{Zn}$, together with field data $(5,32)$ and the predicted value of ${ }^{65} \mathrm{Zn}$ for Case 1 for comparison. The field data collected by the U.S. Geological Survey ${ }^{(32)}$ were also cited in a report, Comments on Proposed Research to Determine the Fate of Radionuclides in the Columbia River, by B. B. Ewing in August 1963. Figure 7 illustrates that in the river reaches up to approximately $110 \mathrm{~km}$ downstream of Priest Rapids Dam, concentrations of dissolved ${ }^{65} \mathrm{Zn}$ steadily decrease because of 
the uptake of ${ }^{65} \mathrm{Zn}$ by suspended sediments. This is reflected by the fact that the concentrations of particulate ${ }^{65} \mathrm{Zn}$ increase monotonically.

Total ${ }^{65} \mathrm{Zn}$ concentrations initially increase to $140 \mathrm{pCi} / \mathrm{l}$ as a result of ${ }^{65} \mathrm{Zn}$ release from the reactors and then become constant until approximately $115 \mathrm{~km}$ downstream of the Priest Rapids Dam because contaminated sediments are not deposited on the river bed. At $110 \mathrm{~km}$ downstream of the dam, dissolved concentration is reduced to $40 \mathrm{pCi} / \ell$, while particulate concentration becomes $100 \mathrm{pCi} / \ell$; the particulate concentration increases from 0 to $70 \%$ of the total radionuclide concentration within $80 \mathrm{~km}$ downstream of the reactor locations. In the vicinity of $115 \mathrm{~km}$ downstream of the dam, particulate concentration is abruptly reduced, owing to the contaminated silt deposition. Around $135 \mathrm{~km}$ downstream of the dam, particulate concentration further drops, this time a result of contaminanted clay deposition. Some of the reduction of the dissolved concentration at $115 \mathrm{~km}$ is due to dilution of ${ }^{65} \mathrm{Zn}$ by clean Snake River water.

Because of the low sediment concentration in the area downstream of $120 \mathrm{~km}$, reduction of dissolved radionuclides which is due to adsorption by sediments becomes insignificant in that area. The behavior of particulate and dissolved ${ }^{65} \mathrm{Zn}$ is reflected by the variation of total ${ }^{65} \mathrm{Zn}$ concentration in this area. Comparison of predicted concentrations of total, dissolved and particulate ${ }^{65} \mathrm{Zn}$ with field data indicates excellent agreement. Comparison between the total ${ }^{65} \mathrm{Zn}$ concentrations of Case 1 and 2 reveals that in the river region up to $115 \mathrm{~km}$ downstream of the Priest Rapids Dam, where no measurable sediment deposition occurs, these two cases indicate no difference in ${ }^{65} \mathrm{Zn}$ concentration. However, downstream from $115 \mathrm{~km}$, total ${ }^{65} \mathrm{Zn}$ concentration in Case 2 is 25 to $50 \%$ of that for Case 1, mainly because of the reduction of particulate ${ }^{65} \mathrm{Zn}$ concentration through deposition of contaminated sediments to the river bed for Case 2 .

Particulate concentrations are categorized into those attached to sand, silt and clay (Figures 8 and 9). Figure 8 shows that the concentration of ${ }^{65} \mathrm{Zn}$ associated with suspended clay (in $\mathrm{pCi} / \mathrm{g}$ of dry sediment) is approximately three times more than those attached to suspended silt. This is 
because clay has a much greater cation exchange capacity of attracting radioactive materials than silt. (7) Silt, in turn, has a higher radionuclide concentration than sand, resulting from its greater exchange capacity. Particulate concentrations of ${ }^{65} \mathrm{Zn}$ in $\mathrm{pCi} / \mathrm{l}$ of water containing suspended sediments (Figure 9) indicate that the suspended silt contains the highest concentration because of its highest silt concentration in the water. For example, at $110 \mathrm{~km}$ downstream of Priest Rapids Dam, $70 \%$ of the total ${ }^{65} \mathrm{Zn}$ is transported in a particulate form and only $30 \%$ is in a dissolved form. Among the particulate ${ }^{65} \mathrm{Zn}$ materials, those attached to silt constitute $68.0 \%$ $(68.0 \mathrm{pCi} / \ell)$ of the total particulate concentration $(100 \mathrm{pCi} / \ell)$. The radionuclide attached to clay constitutes $32 \%(32.0 \mathrm{pCi} / \ell)$. Sand contains only a trace of the radionuclide. The ratios of the amount of each particulate radionuclide associated with sand, silt and clay to the total amount of particulate radionuclides are almost unchanged until sedimentation occurs.

Figure 10 presents the longitudinal distribution of total amount of radionuclides in each river reach (sum of the dissolved and particulate forms), together with that of Case 1. A greater amount of ${ }^{65} \mathrm{Zn}$ appears in the lowest one-third of the study reaches even though these areas contain the lowest total ${ }^{65} \mathrm{Zn}$ concentrations (see Figure 7 ). The water volumes in these regions are much greater because the river is wider and deeper. Comparison of Case 2 with Case 1 also reveals the significant reduction (more than 50\% reduction) of the total amount of ${ }^{65} \mathrm{Zn}$ for Case 2 in these downstream areas. This reduction is a result of contaminated sediment deposition.

Vertical distributions of sediment and radionuclide concentrations in the water and river bed are presented in Figures 11 through 19. Vertical distribution of suspended sediments (i.e., sand, silt and clay) in Reach 3 (River Miles 374.3 to 384.3 ) are shown in Figure 11 , with the vertical change in the percentage of each bed sediment size fraction to the total river bed sediment (by weight) shown in Figure 12. The sediment that appeared in Reach 3 was from the river bed in Reaches 1,2 and 3. Distributions of suspended silt and clay have higher concentrations near the river bed implying most of suspended silt and clay were eroded from the river bed 
in Reach 3, and vertical dispersion is not large enough to uniformly distribute these eroded sediments in a vertical direction within Reach 3 . Figure 12 supports this since near the river bed surface the percentages of silt and clay slightly decrease from the original ratios of sand, silt, and clay of 86,12 and $2 \%$, respectively. Vertical distributions of ${ }^{65} \mathrm{Zn}$ are shown in Figures 13 and 14 . The concentration of ${ }^{65} \mathrm{Zn}$ attached to clay is much higher than that of silt, while sand has the smallest ${ }^{65} \mathrm{Zn}$ concentration.

Figure 13 illustrates an interesting behavior of adsorption mechanics. The vertical distributions of ${ }^{65} \mathrm{Zn}$ adsorbed by silt and clay indicate that the ${ }^{65} \mathrm{Zn}$ concentrations in $\mathrm{pCi} / \mathrm{g}$ of sediment is lower near the river bed and higher near the water surface. However, particulate ${ }^{65} \mathrm{Zn}$ concentrations expressed in $\mathrm{pCi} / \mathrm{l}$ of water (obtained by multiplying the particulate ${ }^{65} \mathrm{Zn}$ concentration in $\mathrm{pCi} / \mathrm{g}$ of sediment times sediment concentration in $\mathrm{g} / \mathrm{l}$ ) are higher near the river bed. This implies that the greater amount of suspended sediments can adsorb the greater amount of radionuclides from the water. However, there is a limitation on how much can be adsorbed. Excessive amounts of suspended sediments may dilute the concentrations of ${ }^{65} \mathrm{Zn}$ attached. This may occur at Reach 3. Dissolved radionuclide concentration is uniformly distributed in a vertical direction indicating that vertical variation of the amounts of ${ }^{65} \mathrm{Zn}$ adsorbed by sediment is negligibly simal1 as compared to the total dissolved concentration. Figure 14 also indicates the distribution of the total amount of ${ }^{65} \mathrm{Zn}$ (sum of dissolved and particulate ${ }^{65} \mathrm{Zn}$ ) in each layer of the water body. Near the water surface, the total amount in curies is smaller than in the other layers because the computation cells were set up in such a way that the top layer contained the smaller water body volume.

Figures 15 through 18 present simulation results of sediments and radionuclides in the water body and the river bed for Reach 11 (River Miles 322.6 to 326.6) where the Snake River joins the Columbia River. Suspended silt and clay in this reach (Figure 15) indicate major and minor reduction in their concentrations as compared to those of Reach 3 (Figure 11), thus denoting the deposition of contaminated suspended sediments to the river bed. This is because of the large reduction of flow velocity in Reach 11 . 
Unlike those in Reach 3, silt and clay show almost uniform vertical distributions for the following reasons: 1) there is no resuspension from the river bed; 2) sediments in the water body are already well mixed with vertical dispersion; and 3) fall velocities of silt and clay are too small to induce significant vertical non-uniformities of sediment distributions.

Particulate ${ }^{65} \mathrm{Zn}$ concentrations in Figure 16 show their vertical uniformities which are due to uniform sediment distributions. Dissolved ${ }^{65} \mathrm{Zn}$ concentration and total amount of ${ }^{65} \mathrm{Zn}$ in Reach 11 are shown in Figure 17. River bed conditions reflect the behavior of sediments and radionuclides moving above it. Zinc-65 associated with silt appears in the top bed layer (see Figure 18) as a result of deposition of contaminated suspended silt. No measurable nuclides associated with sand and clay appear in the river bed in Reach 11.

In Reach 16 (River Miles 292.0 to 299.6), almost no suspended sediments are passing through without deposition. This aspect of sediment transport also reflects the variations of ${ }^{65} \mathrm{Zn}$ in the river bed. Figure 19 indicates that a small amount of ${ }^{65} \mathrm{Zn}$ associated with silt and clay is deposited in the top layer of the river bed.

The above two cases demonstrated that SERATRA is capable of predicting the sedirent and radionuclide transport with sediment-radionuclide interaction. However, since there are only a few field data available to examine the validity of the computer prediction, additional detailed field data are needed to conduct more complete model verification.

\section{INSTANTANEOUS RELEASE OF RADIONUCL IDES}

In addition to the continuous release tests of radionuclides, two hypothetical instantaneous radionuclide cases (Cases 3 and 4 ) were tested to further identify effects of river sediments on the migration of radioactive materials and to examine the applicability of the SERATRA code to instantaneous release cases, such as accidental radionuclide spills to rivers. For these cases, radionuclide transport modeling was performed for dissolved radionuclide 
releases to the Columbia River assumed to be from the nine Hanford reactors that appear in Figure 1. Case 3 involved dissolved ${ }^{65}$ Zn without adsorption mechanics. Based on the $\mathrm{Clinch}$ River study ${ }^{(10)}$ the results of Case 3 may be extended to ${ }^{51} \mathrm{Cr}$, ${ }^{124} \mathrm{Sb}$ and ${ }^{90} \mathrm{Sr}$ transport, except the effects of radionuclide decay. Case 4 dealt with ${ }^{65} \mathrm{Zn}$ with adsorption. For both cases, 300 curies of dissolved radionuclides were assumed to be released to the river. Instead of simulating true instantaneous releases of ${ }^{65} \mathrm{Zn}$ from the reactors, it was assumed that they were discharged for 20 minutes. Simulations were conducted for 10 days.

Case 3. Dissolved Zinc-65 Without Adsorption

In order to establish a baseline case for comparison, the transport of dissolved ${ }^{65} \mathrm{Zn}$ without adsorption by suspended sediments was simulated. Simulation results at 24, 72 and 240 hours are shown in Figures 20 and 21 which present longitudinal distributions of dissolved ${ }^{65} \mathrm{Zn}$ concentration and total amount of ${ }^{65} \mathrm{Zn}$ in the water body of each river reach. Since ${ }^{65} \mathrm{Zn}$ was assumed not to be adsorbed by suspended sediments, dissolved concentrations are equal to total ${ }^{65} \mathrm{Zn}$ concentrations. These figures clearly indicate dispersion and dilution of ${ }^{65} \mathrm{Zn}$ in the river. These results were compared with those of Case 4 to identify the effects of radionuclide adsorption by suspended sediments on the migration of radioisotopes.

Case 4. Zinc-65 With Adsorption

Longitudinal distributions of sediment concentrations at 24,72 and 240 hours for Case 4 are shown in Figure 22. Comparison of these distributions for three different times (24, 72 and 240 hours) clearly indicates that the cohesive sediments (silt and clay) eroded from the uppermost river reaches (up to approximateiy $40 \mathrm{~km}$ downstream of the Priest Rapids Dam) are transported downstream by flow convection and dispersion. The model shows that the majority of sediments at 240 hours are deposited in the vicinity of the $120 \mathrm{~km}$ area. Figures 23 through 28 present longitudinal distributions of ${ }^{65} \mathrm{Zn}$. Comparisons of total ${ }^{65} \mathrm{Zn}$ concentrations at 24,72 and 240 hours between Case $3\left({ }^{65} \mathrm{Zn}\right.$ without adsorption) and Case $4\left({ }^{65} \mathrm{Zn}\right.$ with adsorption) are shown in Figure 23 . In Figure $23,{ }^{65} \mathrm{Zn}$ concentrations which appear 
downstream of $110 \mathrm{~km}$ at 72 and 240 hours are higher for Case 3 . This occurs because some of the dissolved radionuclides for Case 4 are adsorbed by suspended sediments and these contaminated sediments are deposited to the river bed downstream of $110 \mathrm{~km}$. Case 3 has only dissolved radionuclides and is not subject to the sedimentation effect.

Longitudinal distributions which appear at 24 hours for Cases 3 and 4 are almost identical because no measurable sediment deposition occurs in the region where ${ }^{65} \mathrm{Zn}$ is transported within this time period. Figure 24 shows longitudinal distributions of total, dissolved and particulate ${ }^{65} \mathrm{Zn}$ concentrations at 24 hours. At 24 hours after the dissolved radionuclide is discharged to the river, the major portion of the ${ }^{65} \mathrm{Zn}$ is still in the dissolved form. Among the particulate ${ }^{65} \mathrm{Zn}$ forms, those attached to silt show the highest concentrations, while sand adsorbs the least amount of ${ }^{65} \mathrm{Zn}$.

The maximum total ${ }^{65} \mathrm{Zn}$ occurs at $88 \mathrm{~km}$ downstream of Priest Rapids Dam as a result of river flow convection. The total ${ }^{65} \mathrm{Zn}$ concentration there is $1660 \mathrm{pCi} / \mathrm{l}$. The breakdown of this concentration is as follows: 1) $1360 \mathrm{pCi} / \ell$ of dissolved ${ }^{65} \mathrm{Zn}$, 2) $190 \mathrm{pCi} / \ell$ of particulate ${ }^{65} \mathrm{Zn}$ attached to silt, 3) $110 \mathrm{pCi} / \ell$ of particulate ${ }^{65} \mathrm{Zn}$ with clay and 4) almost no particulate ${ }^{65} \mathrm{Zn}$ with sand. Hence, dissolved ${ }^{65} \mathrm{Zn}$ constitutes approximately $82 \%$ and total particulate ${ }^{65} \mathrm{Zn}, 18 \%$. Particulate ${ }^{65} \mathrm{Zn}$ with silt and clay is 11.4 and $6.6 \%$, respectively.

Flow convection and longitudinal dispersion enables the radionuclide to reach $115 \mathrm{~km}$ downstream from Priest Rapids Dam within 24 hours. Figures 25 and 26 show longitudinal distributions of ${ }^{65} \mathrm{Zn}$ at 72 hours. The maximum total ${ }^{65} \mathrm{Zn}$ appears at $110 \mathrm{~km}$. The total concentration there is approximately $560 \mathrm{pCi} / \mathrm{l}$. The dissolved and total particulate concentrations are both $280 \mathrm{pCi} / \mathrm{l}$. The ${ }^{65} \mathrm{Zn}$ concentrations assuciated with silt and clay are 185 and $95 \mathrm{pCi} / \mathrm{l}$. Sand carries almost no radionuclides. These concentration values indicate that $50 \%$ of the total ${ }^{65} \mathrm{Zn}$ there is transported downstream in a dissolved phase. 
Particulate ${ }^{65} \mathrm{Zn}$ associated with silt and clay constitutes 33.0 and $17.0 \%$, respectively. As compared to those which occurred at 24 hours, the contribution of particulate ${ }^{65} \mathrm{Zn}$ to the total ${ }^{65} \mathrm{Zn}$ at its peak increases from 18 to $50 \%$. This seems to indicate that the adsorption mechanics may not be instantaneous reactions but require some finite time. Most suspended silt deposits in the vicinity of $115 \mathrm{~km}$, resulting in a rapid reduction in the particulate ${ }^{65} \mathrm{Zn}$ concentration associated with silt. Particulate ${ }^{65} \mathrm{Zn}$ with silt has the highest concentrations (Figure 24 and 25). However, as shown in Figure 26 , clay sediment contains the highest ${ }^{65}$ Zn concentration per unit weight of dry sediment because of its greater cation exchange capacity. The sediment concentration of clay is much smaller than that of silt; consequently, the ${ }^{65} \mathrm{Zn}$ attached to clay per unit volume of water body is less than that attached to silt. Zinc-65 distributions that occurred at 240 hours are shown in Figure 27. Since in this case most of contaminated suspended silt was already deposited in the vicinity of $115 \mathrm{~km}$, particulate ${ }^{65} \mathrm{Zn}$ is only associated with clay.

More than $50 \%$ of ${ }^{65} \mathrm{Zn}$ is carried by suspended clay in the area up to approximately $132 \mathrm{~km}$. Because the sedimentation of clay occurred downstream of $135 \mathrm{~km}$, dissolved ${ }^{65} \mathrm{Zn}$ constitutes more than $90 \%$ in that area.

Figure 28 shows the longitudinal distributions of total amount of ${ }^{65} \mathrm{Zn}$ for Cases 3 and 4 . Comparison of Cases 3 and 4 clearly indicates that the total ${ }^{65} \mathrm{Zn}$ amounts in the river water body which appeared at 72 and 240 hours for Case 4, are approximately 90 and $50 \%$ of those of Case 3 because contaminated sediments were deposited in the lower river reaches.

Vertical distributions of sediment-radionuclide concentrations in the water body and in the river bed are shown in Figures 29 through 36 . Sediment and ${ }^{65} \mathrm{Zn}$ concentrations in River Reach 3 at 24 hours are presented in Figures 29, 30 and 31 . Sediment concentratioris of silt and clay show the higher concentrations near the river bed implying the erosion of silt and clay from the river bed, as discussed in Case 2. 
Vertical distributions of particulate ${ }^{65} \mathrm{Zn}$ absorbed by sand, silt and clay indicate similar patterns to those of River Reach 3 for Case 2 because: 1) ${ }^{65} \mathrm{Zn}$ associated with clay is the highest whereas ${ }^{65} \mathrm{Zn}$ attached to sand is the lowest; and 2) concentrations of ${ }^{65} \mathrm{Zn}$ near the bed are higher than those near the water surface for silt and clay and ${ }^{65} \mathrm{Zn}$ attached to sand shows the opposite trend. As discussed in Case 2, this implies that the larger amounts of suspended sediments can absorb more radionuclides from the water until their limits are reached. Beyond these limits, the excessive amount of sediments will dilute particulate ${ }^{65} \mathrm{Zn}$ concentrations. This may be the case at this reach. Silt and clay may exceed their concentration limits whereas sand is below the limitation. Slight nonuniformity of dissolved ${ }^{65} \mathrm{Zn}$ concentration is due to the nonuniformity of vertical river flow velocity distribution (logarithmic velocity distribution) causing nonuniform vertical dilution. The total amount of ${ }^{65} \mathrm{Zn}$ in the river reach reflects the above discussed patterns of particulate and dissolved ${ }^{65} \mathrm{Zn}$.

Figures 32 through 34 present simulation results of sediments and ${ }^{65} \mathrm{Zn}$ in River Reach 5 (River Miles 354.3 to 364.3) at 24 hours. Since no measurable erosion and deposition of sediment occur, vertical distributions of sediment concentration and ${ }^{65} \mathrm{Zn}$ become more uniform by vertical dispersion than those that appeared in River Rea $=h 3$.

Radionuclide concentrations in the river beds in River Reach 11 at 72 hours and River Reach 16 at 240 hours are shown in Figures 35 and 36 , respectively. In River Reach 11, a large amount of silt is deposited, while minor deposition of silt and clay occurs in River Reach 16 . Since it was again assumed that originally no radionuclides appeared in the river bed, 65 Zn associated with silt in the top river bed layer in River Reach 11 and ${ }^{65}$ Zn with silt and clay in River Reach 16 result from the deposition of these contaminated sediments.

\section{RADIONUCLIDE RESUSPENSION}

For the previous four cases, the effects of radionuclide adsorption by suspended sediments and deposition of contaminated sediments on 
radionuclide transport were mainly investigated. In the fifth case, another important aspect of sediment and radionuclide transport is involved, that is, resuspension of sediments and contaminants from the river bed.

The radionuclides contained in the Columbia River system after January 1971 are: 1) those discharged from previous reactor operations which became attached to sediment particles and deposited with the sediments in the river bed (primarily behind the McNary Dam), 2) those which may be released from $N$ Reactor, the dual purpose power-plutonium production reactor, 3) those from fallout, and 4) those in the natural background. (4)

\section{Case 5: Radionuclide Resuspension}

In this case it was assumed that there were no radionuclide releases from any reactors but radioactive material, ${ }^{65} \mathrm{Zn}$, entered the river system through erosion of contaminated river bed sediments. By omitting the possible radionuclide contribution from $N$ Reactor and other sources, a similar condition of radionuclide distribution in the river bed that appeared in March 1973 was simulated. Assumed test conditions for Case 5 are shown in Table 1.

Monthly average flow discharges of the Columbia and Snake Rivers in March 1973 were $2870 \mathrm{~m}^{3} / \mathrm{sec}$ at Priest Rapids Dam and $1000 \mathrm{~m}^{3} / \mathrm{sec}$ at the Snake River mouth. However, the simulation was conducted for the same flow condition as the other four cases; the Columbia and Snake River discharges of $1860 \mathrm{~m}^{3} / \mathrm{sec}$ and $650 \mathrm{~m}^{3} / \mathrm{sec}$, respectively. By assuming ${ }^{65} \mathrm{Zn}$ associated with the river bed sediments to be 870,2700 and $3300 \mathrm{pCi} / \mathrm{kg}$ for sand, silt and clay, respectively, the river bed condition on the total radionuclide distribution becomes as illustrated in Figure 37 . Measured total ${ }^{65}$ Zn concentration in the river bed within Lake Wallula ${ }^{(4)}$ (the reservoir behind the McNary Dam) in March 1973 was approximately $3300 \mathrm{pCi} / \mathrm{kg}$ of river sediment. Because the desorption of ${ }^{65} \mathrm{Zn}$ from the sediments to water is relatively minor, $(7,16)$ these mechanics were not taken into account for the analysis. 
Simulation results at 240 hours are given in Figures 38 through 40. Sediment concentrations shown in Figure 38 are approximately $15 \%$ smaller than those in Figure 6 . This surprising difference was caused by the small flow discharge contribution $\left(100 \mathrm{~m}^{3} / \mathrm{sec}\right)$ from the reactors to the Columbia River for Case 2. Since all suspended sediments for both cases were eroded from the river bed, this is an indication of the sensitive nature of selecting critical shear stress for cohesive sediment erosion. When these sediments were resuspended from the river bed, radionuclides were also resuspended from the river bottom. Resulting longitudinal distributions of particulate ${ }^{65} \mathrm{Zn}$ concentrations are shown in Figure 39 . Similar to the previous cases, ${ }^{65} \mathrm{Zn}$ attached to silt indicates the highest concentration in $\mathrm{pCi} / \mathrm{l}$ because of the highest suspended sediment concentration of silt. Total particulate concentration of ${ }^{65} \mathrm{Zn}$ measured in March 1973 was $1.17 \mathrm{pCi} / \ell$ behind McNary Dam.

Since effects of the $\mathrm{N}$ Reactor radionuclide contribution to the river and the actual higher flow discharge were not taken into account in the simulation, the predicted total particulate concentrations of ${ }^{65} \mathrm{Zn}$ are lower than the measured data. In order to evaluate the actual river flow case that occurred in March 1973, the following computation was made to briefly examine the validity of the model. In River Reach 15 (River Miles 299.6 to 307.6), which has the slowest river velocity of the entire study area, the bed shear stress, $\tau_{b}$ was estimated to be $0.0058 \mathrm{~kg} / \mathrm{m}^{2}$ by using ${ }^{(33)}$ :

$$
\begin{aligned}
& \frac{u_{*}}{u_{*}}=17.66+\frac{2.3}{k} \log \left(\frac{d}{96.5 k_{s}^{-}}\right) \\
& \tau_{b}=\rho u_{\star}^{2}
\end{aligned}
$$


where

$$
\begin{aligned}
d & =\text { flow depth } \\
k_{s} & =\text { Nikuradse sand roughness } \\
u & =\text { mean velocity } \\
u_{\star} & =\text { shear velocity } \\
\rho & =\text { water density } \\
k & =\text { Kármán constant }
\end{aligned}
$$

The critical shear stresses for silt and clay deposition in the simulation model are 0.006 and 0.004 . Hence, most of the suspended silt will be deposited in Reach 15, but unlike the results shown in Figure 38, suspended clay will not be deposited in Reaches 15 and 16 . Consequently, the particulate ${ }^{65} \mathrm{Zn}$ attached to clay will appear in the water bodies of Reaches 15 and 16. The computed value is expected to be fairly close to the measured value of $1.17 \mathrm{pCi} / \mathrm{l}$. This demonstrates the general acceptance of the model results for this case. However, more rigorous verification tests must be conducted prior to judging the accuracy of the simulation. The longitudinal distributions of the total amount of particulate ${ }^{65} \mathrm{Zn}$ at 240 hours is shown in Figure 40, reflecting patterns of the contaminated sediment resuspension and redeposition. 


\section{CONCLUSIONS AND RECOMMENDATIONS}

Radionuclide migration in the Columbia River was simulated by including the effects of sediment-radionuclide interaction to obtain a more accurate prediction. The finite element sediment and contaminant transport model, SERATRA, was applied to the Columbia River reach between Priest Rapids and McNary Dams to solve time-dependent, longitudinal and vertical distributions of sediments and radionuclides and their chemical and physical interactions. The model procedure involved simulating the movements of sediments for each sediment size fraction. These results were input to models of dissolved and particulate radioactive materials attached to river sediments for each sediment fraction in order to observe the interaction between sediment and radionuclide movements. Finally, changes in river bed conditions were recorded, including river bottom elevation changes, ratio of sand, silt and clay sediments and distribution of radionuclide concentration in the river bed.

The following conclusions were made from the model simulations subject to the present selection of model input data:

1. The model, SERATRA, calculated sediment concentrations for each sediment size fraction and the predicted total sediment concentration indicates a reasonable agreement with the measured data (Figure 6). The model predicted that for the uppermost 40-km river reaches, the fast moving flow scours the river bed to increase concentration of suspended silt and clay. However, almost all of these suspended sediments, first suspended silt and then suspended clay, are deposited in the downstream slow moving areas. It also reveals that suspended concentrations of cohesive sedimerits are very sensitive to the critical shear stresses for cohesive sediment erosion and careful attention is required for the selection of these values. The model indicated that there was no measurable sand being transported in the study area under the flow condition selected in this study. 
2. The model computed not only dissolved ${ }^{65} \mathrm{Zn}$ concentrations but particulate ${ }^{65} \mathrm{Zn}$ adsorbed by sand, silt and clay sediments. Results of the verification test on the continuous release of ${ }^{65} \mathrm{Zn}$ with adsorption mechanics (Case 2) indicate that longitudinal distributions of total, dissolved, and particulate radionuclide concentrations show excellent agreement between the predicted and measured data (Figure 7). In this case, total ${ }^{65} \mathrm{Zn}$ concentration initially increases to $140 \mathrm{pCi} / \mathrm{l}$ through ${ }^{65} \mathrm{Zn}$ release from the reactors, and stays constant until approximately 115 $\mathrm{km}$ downstream of Priest Rapids Dam. However, in this region, dissolved ${ }^{65} \mathrm{Zn}$ concentrations steadily decrease and particulate ${ }^{65} \mathrm{Zn}$ increases its concentrations monotonically because of the uptake of dissolved ${ }^{65} \mathrm{Zn}$ by suspended sediments. Particulate ${ }^{65} \mathrm{Zn}$ concentrations increase from 0 to $70 \%$ of the tota 1 radionuclide concentration within approximately $80 \mathrm{~km}$ downstream of the reactors. Further downstream, particulate nuclide concentrations, and hence the total concentration, are reduced because of the deposition of contaminated suspended sediments in this slow moving area. The concentration of particulate ${ }^{65} \mathrm{Zn}$ attached to clay sediment $(\mathrm{pCi} / \mathrm{g})$ is approximately three times as much concentration of ${ }^{65} \mathrm{Zn}$ attacined to suspended silt because clay has a greater cation exchange capacity of attracting radioactive materials. Sand adsorbs the least amount of radionuclides among the sediments. However, suspended silt, having the highest suspended sediment concentrations, transports the largest amount of particulate ${ }^{65} \mathrm{Zn}$.

3. Comparison of Case 1 (continuous release of ${ }^{65} \mathrm{Zn}$ without adsorption mechanics) with Case 2 reveals that the total ${ }^{65}$ Zn concentration is almost identical for these two cases in the river region up to $115 \mathrm{~km}$ downstream of the Priest Rapids Dam. However, downstream of $115 \mathrm{~km}$, total ${ }^{65} \mathrm{Zn}$ concentration of Case 2 becomes only 25 to $50 \%$ that of Case 1 , because of the reduction of particulate ${ }^{65} \mathrm{Zn}$ concentrations through deposition of contaminated suspended sediments. 
4. For two cases of instantaneous releases of ${ }^{65} \mathrm{Zn}, 300$ curies of dissolved nuclides were hypothetically discharged from the Hanford reactors to the river; ${ }^{65} \mathrm{Zn}$ without adsorption (Case 3 ), and ${ }^{65} \mathrm{Zn}$ with adsorption (Case 4 ). Comparison of predicted results for these cases shows that in the lowermost reaches the total radionuclide concentration for Case 4 was reduced to approximately $50 \%$ of Case 3 since contaminated sediments were deposited in this slow moving area. Similar to Case $2,{ }^{65} \mathrm{Zn}$ concentrations associated with clay sediment show the highest concentration per unit weight of sediment, but suspended silt carries the greater amount of ${ }^{65} \mathrm{Zn}$ than clay before it is deposited on the river bed. Suspended sand adsorbs only a trace of ${ }^{65} \mathrm{Zn}$.

5. Cases 1 through 4 indicate the importance of sediment transport on radionuclide migration through the nuclide adsorption and sediment deposition phenomena. Computed results of Case 5 (radionuclide resuspension) illustrate the importance of sediment resuspension by demonstrating that even without any radionuclide releases from the reactors, radioisotopes can enter the river water system through resuspension of contaminated sediments from the river bed and their translocations. In Case 5, a condition of radionuclide distribution in the river bed similar to that on March 1973 was simulated. Computed patterns of this radionuclide transport are similar to those of the particulate radionuclides for Cases 2 and 4 . Since the radionuclide input from the $N$ Reactor to the river was not taken into account and the actual river flow rate was higher than the one used for the modeling, the predicted total particulate ${ }^{65} \mathrm{Zn}$ concentration is lower than the measured value. A brief evaluation of the effect of the higher river flow discharge on the sediment transport reveals that the model would predict the particulate ${ }^{65} \mathrm{Zn}$ concentration having reasonable agreement with the measured value if the actual flow rate in March 1973 was used for the model simulation.

6. Vertical distribution of sediment and radionuclide concentrations in the water body and in the river bed were also calculated for all five cases. They indicate that when the sediments were resuspended from the river, their vertical distributions were not uniform. This nonuniformity in 
turn causes the nonuniform distributions of radioactive materials being adsorbed by the suspended sediments. These vertical maldistributions of sediments and radionuclides were gradually reduced by the vertical dispersion as the river flow moved downstream. However, the validity of model prediction for the vertical distributions could not be examined in this study because field data were not available for comparison.

Examination of the above five Columbia River cases clearly indicates that suspended sediments have significant effects on radionuclide transport through radionuclide adsorption, and deposition and resuspension of contaminated sediments. Hence, in order to obtain realistic predictions of radionuclide migration, interaction between radionuclides and river sediments must be taken into account. The present study demonstrates that the SERATRA code is capable of predicting the transport of both particulate and dissolved radionuclides by taking into account the radionuclide-sediment interaction and that the code is also judged to be partially verified using available field data. However, it became evident that detailed field data are not available for complete verification of the model. In particular, data of sediment concentration and radionuclide distributions on the various sediment size fraction are scarce. Accordingly, complete field verification of the mathematical model is recommended before using it to accurately predict the migration of radionuclides in riverine environments. 


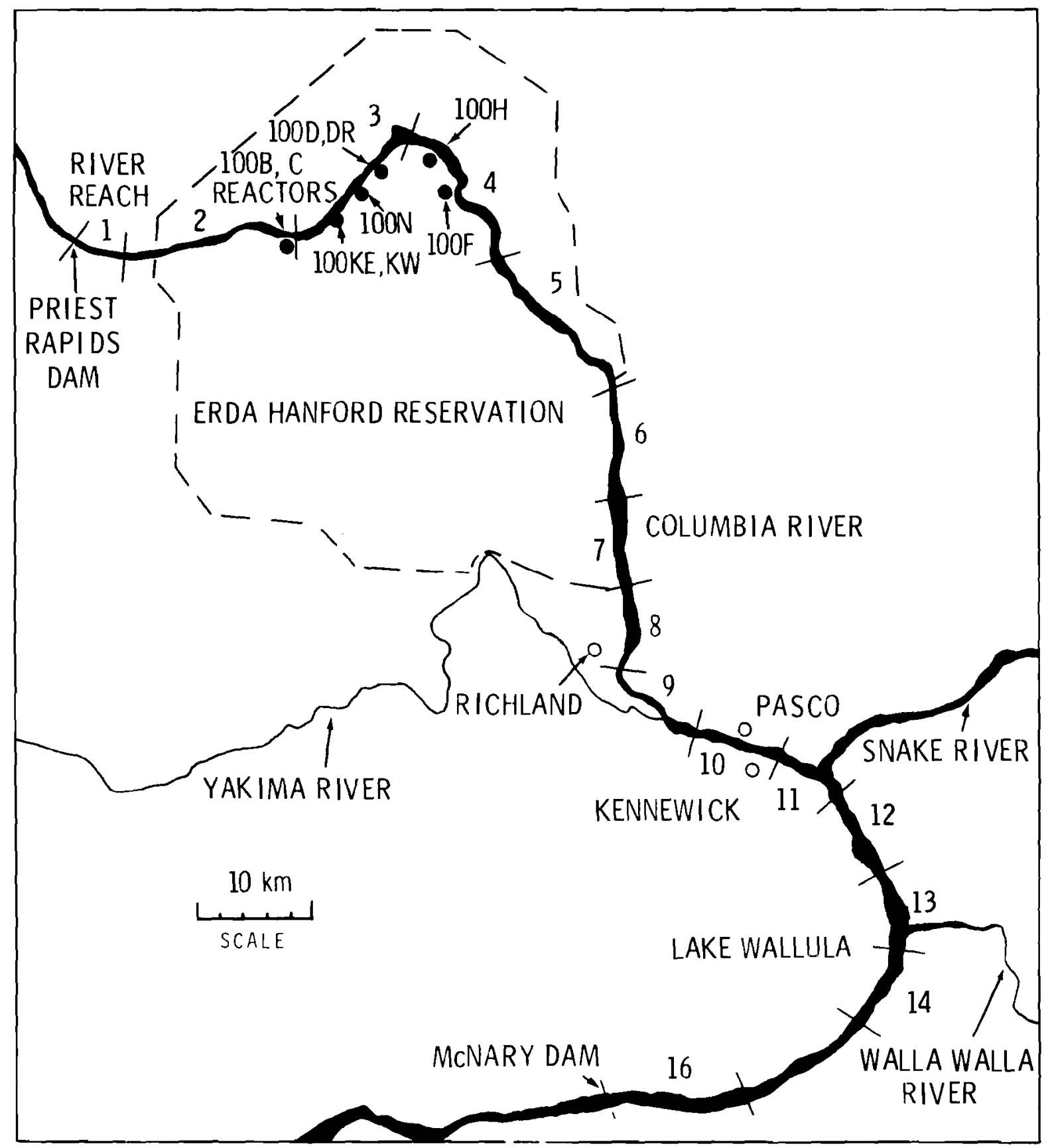

FIGURE 1. Map of the Columbia River 


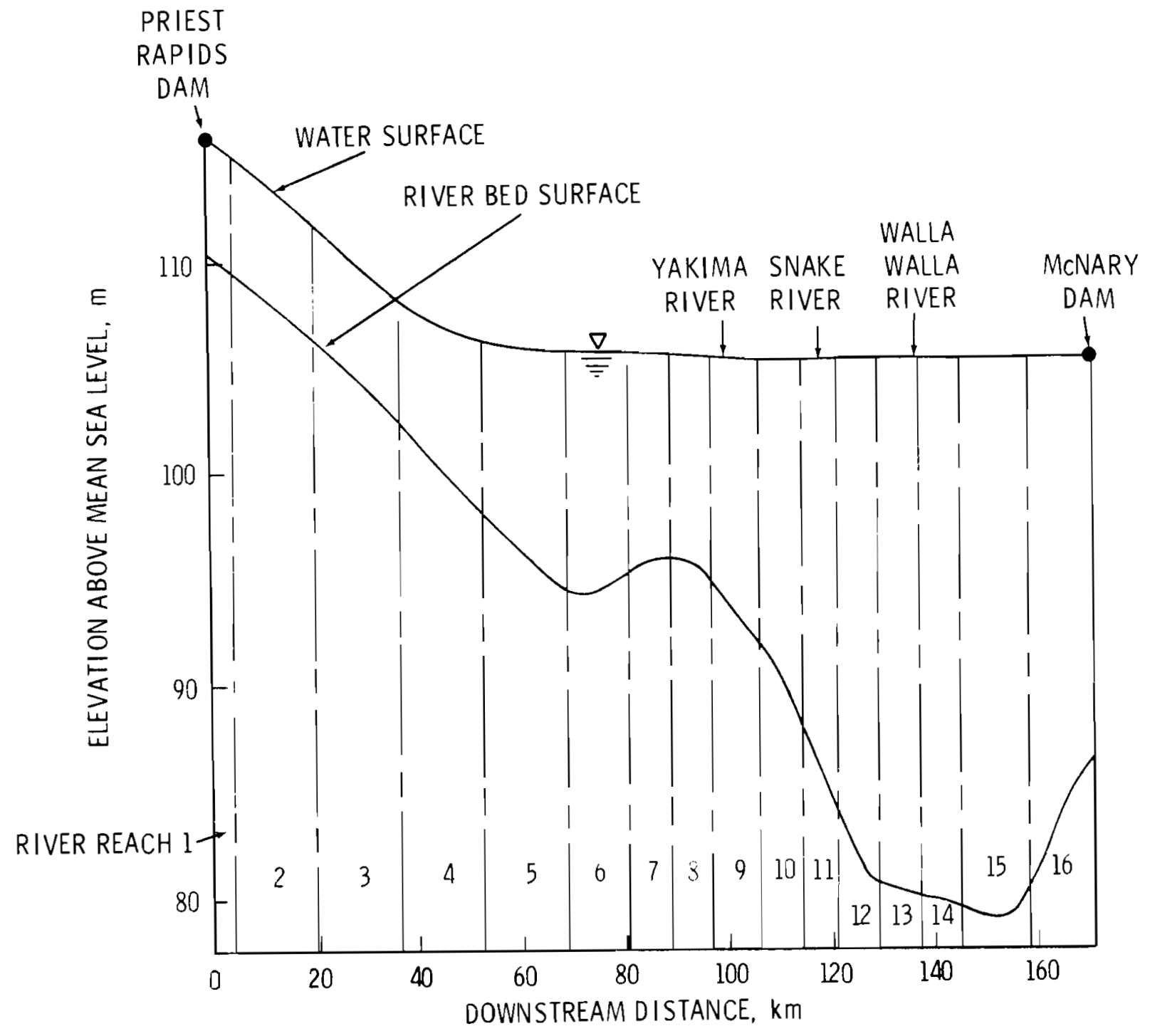

FIGURE 2. Variations of Water Surface and Bed Elevations of the Columbia River: Discharge of $1860 \mathrm{~m}^{3} / \mathrm{sec}$ at the Priest Rapids Dam 


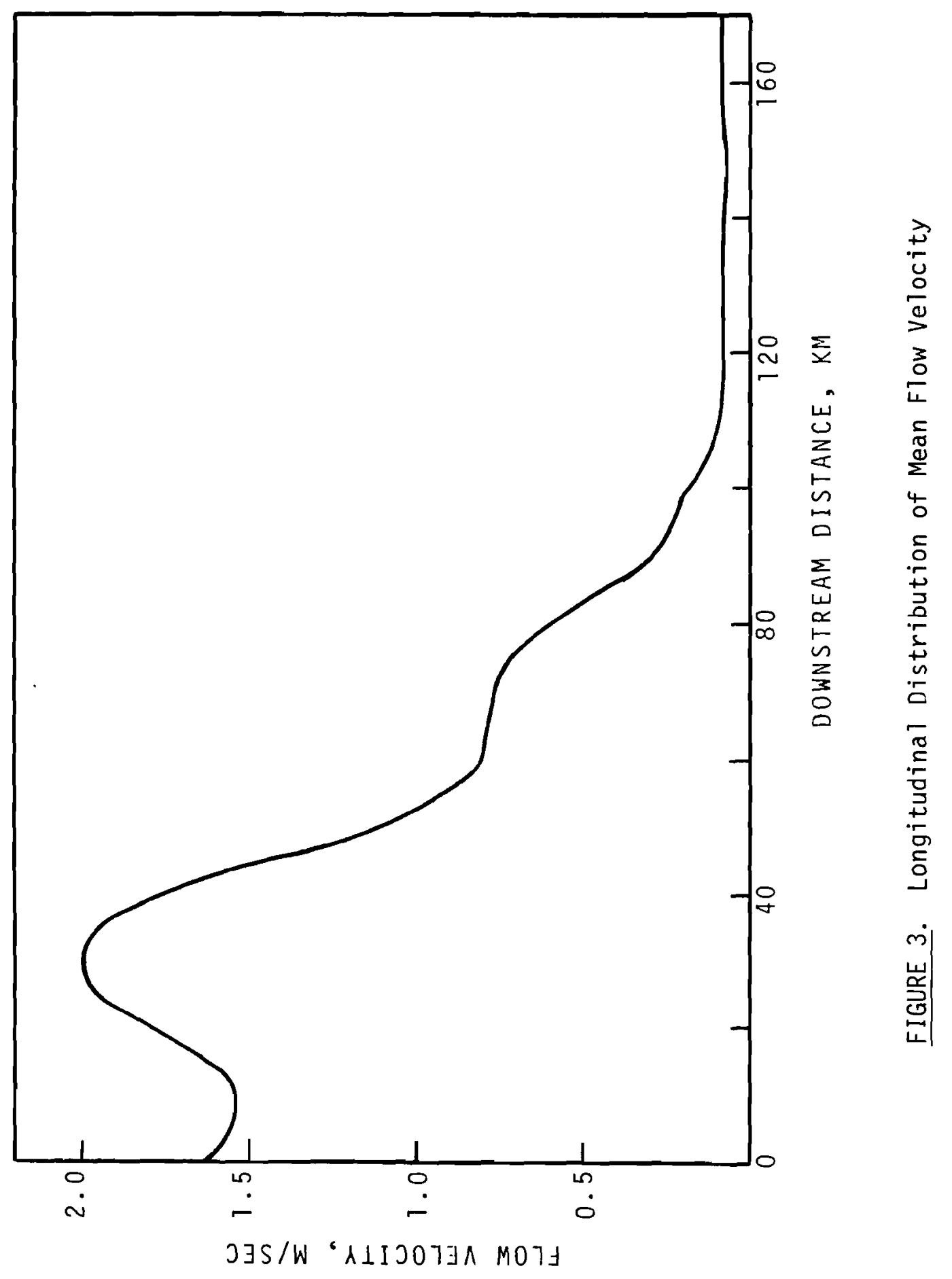




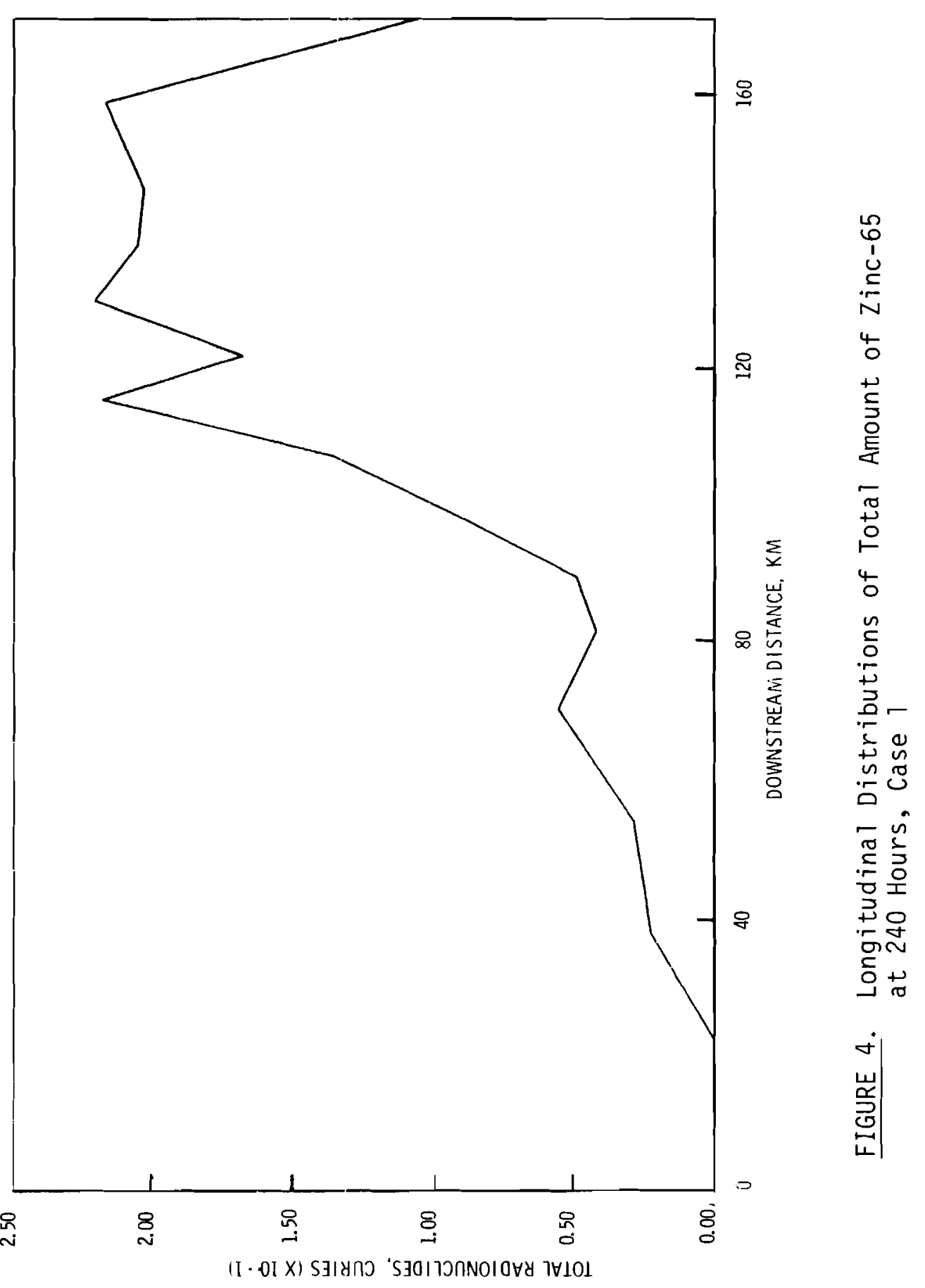




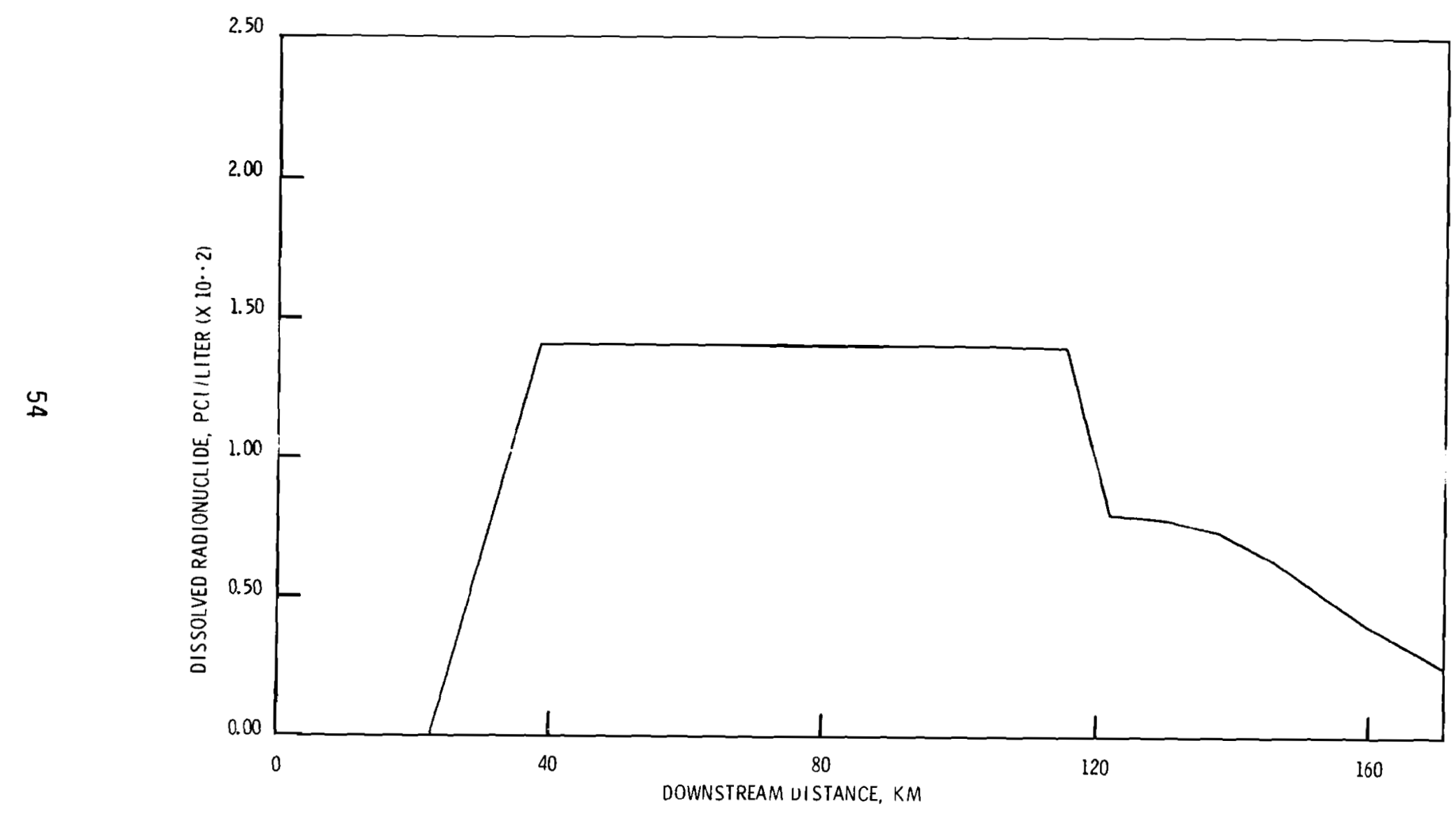

FIGURE 5. Longitudinal Distribution of Dissolved Zinc-65 at 240 Hours, Case 1 


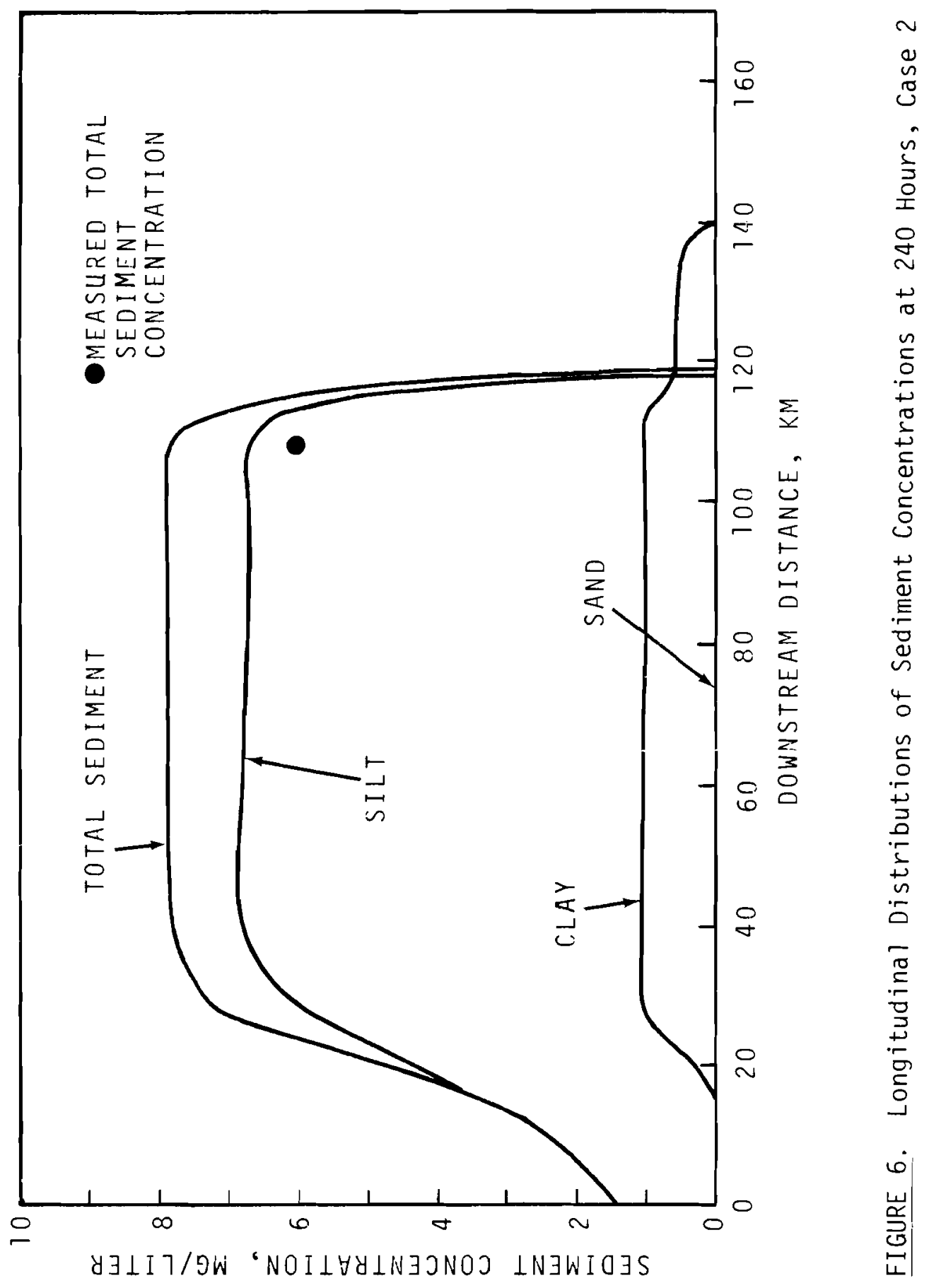




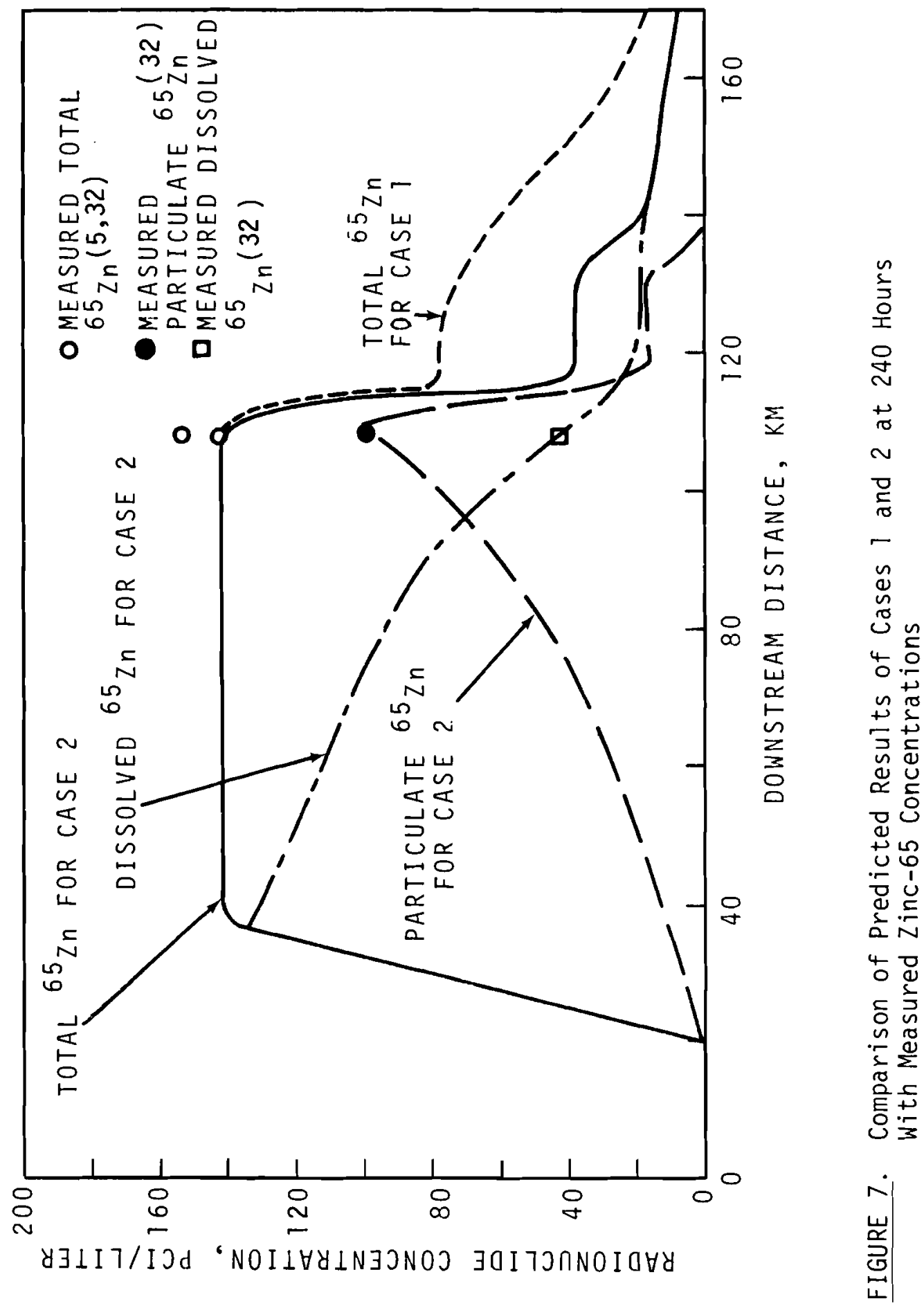




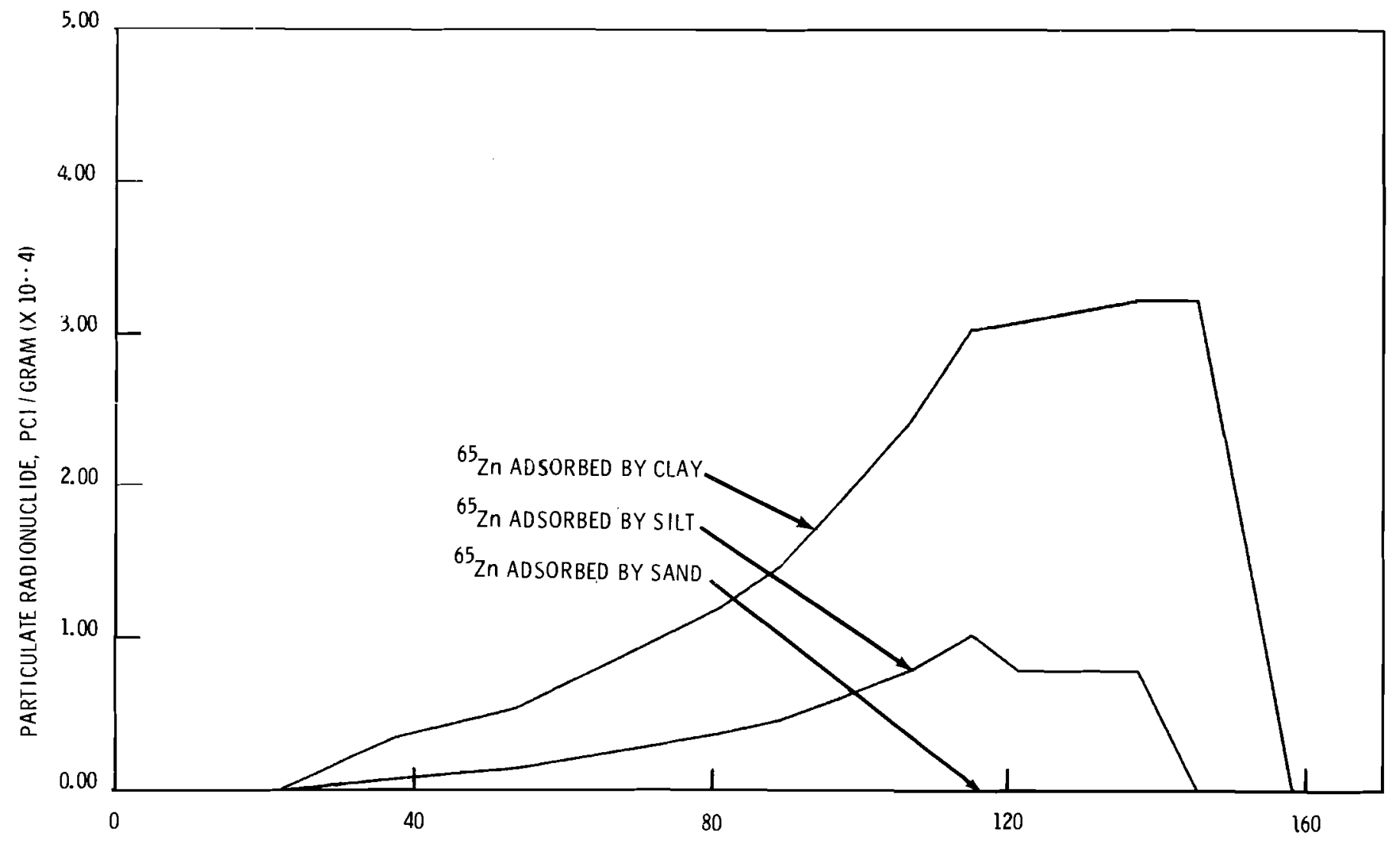

FIGURE 8. Longitudinal Distributions of Zinc-65 Adsorbed by Suspended Sediments at 240 Hours, Case 2 


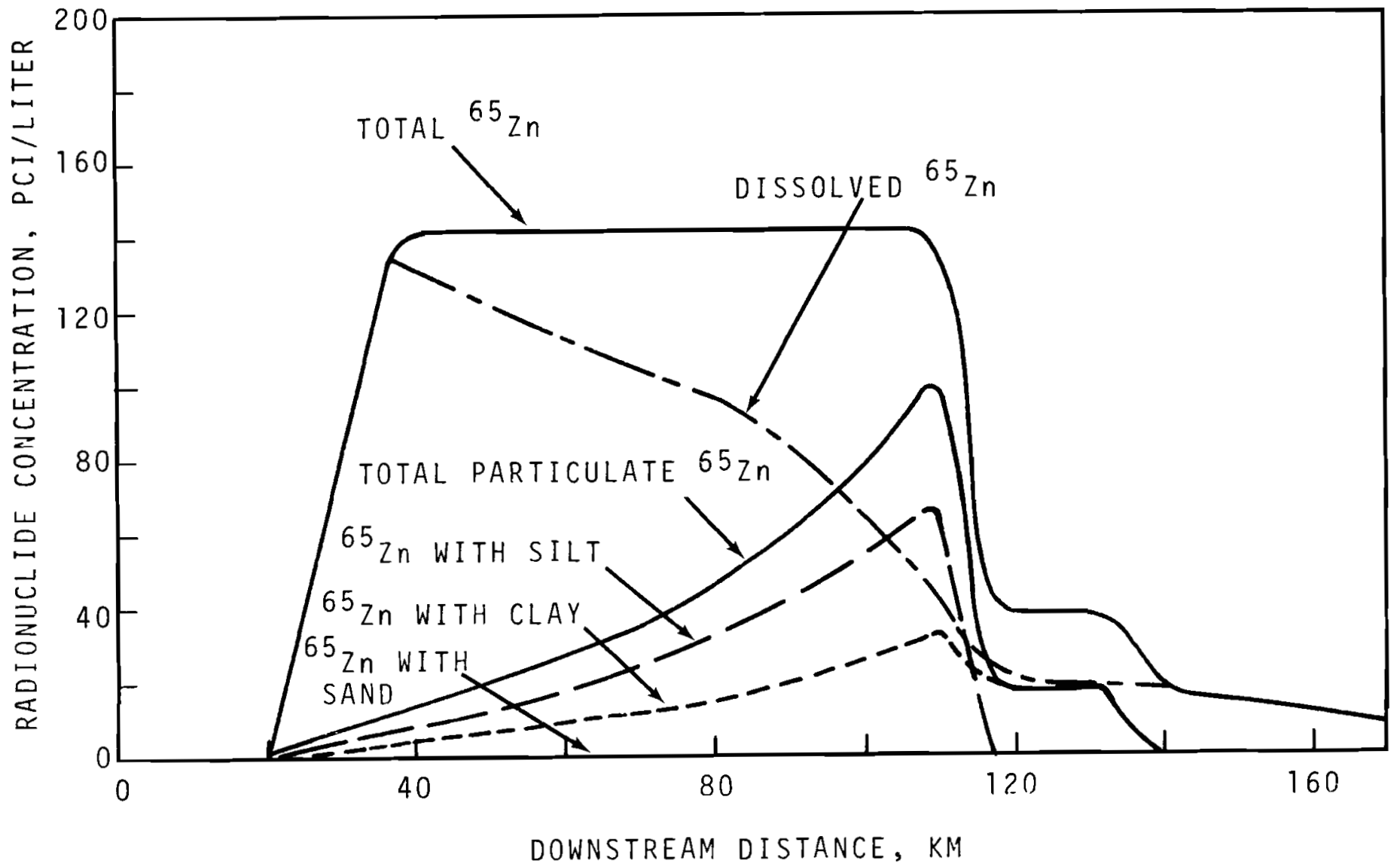

FIGURE 9. Longitudinal Distributions of ${ }^{65} \mathrm{Zn}$ Concentrations at 240 Hours, Case 2 


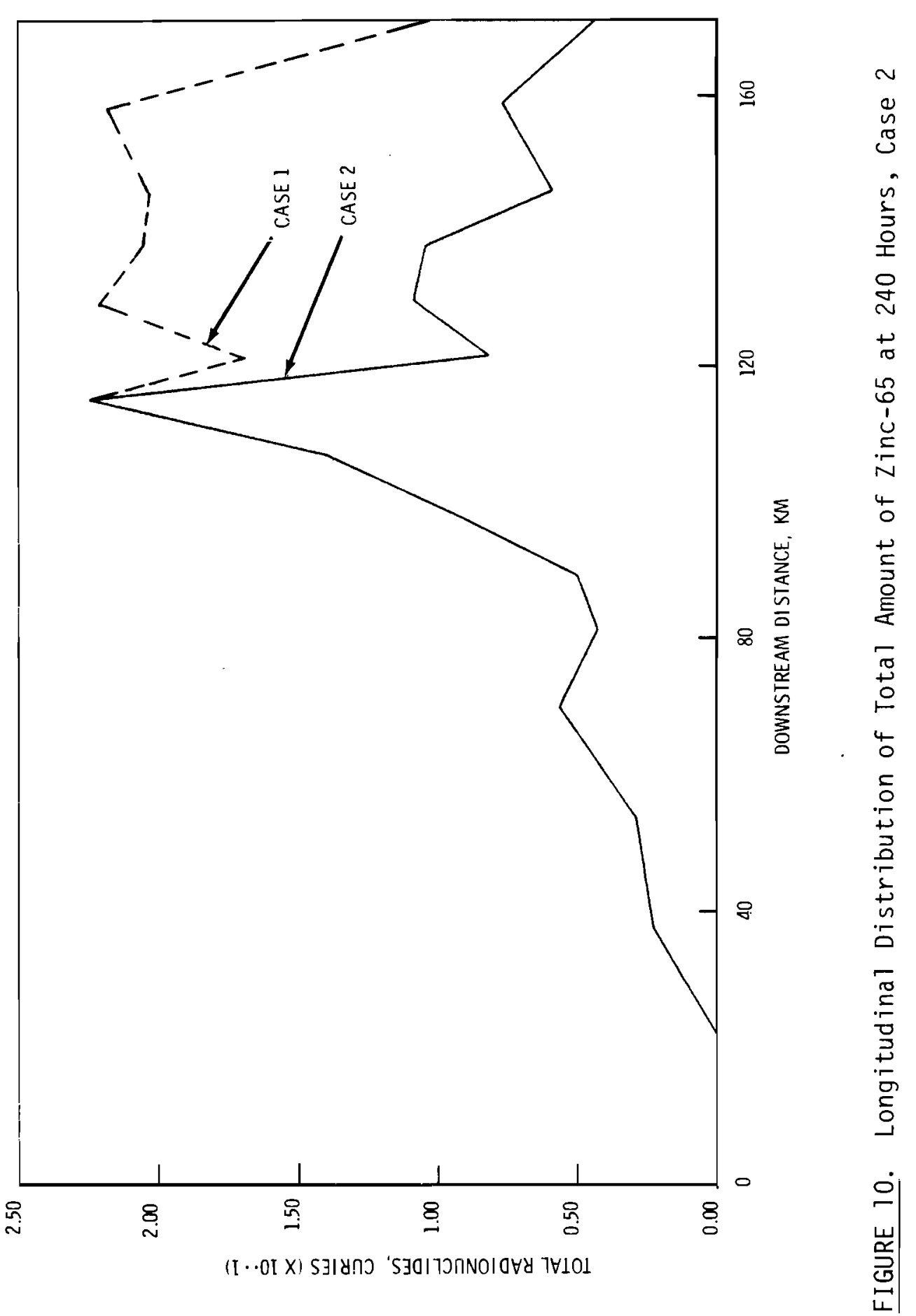



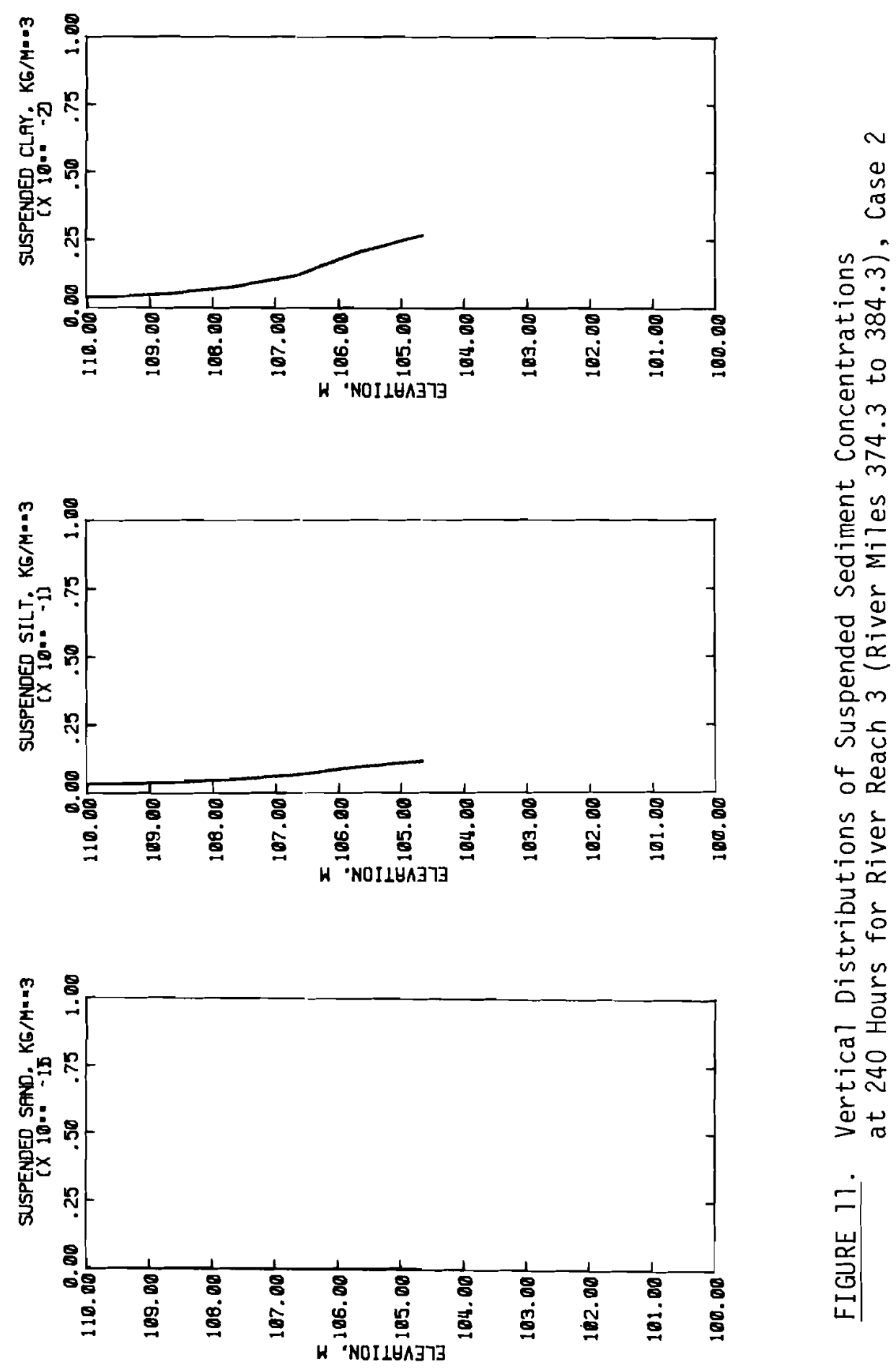

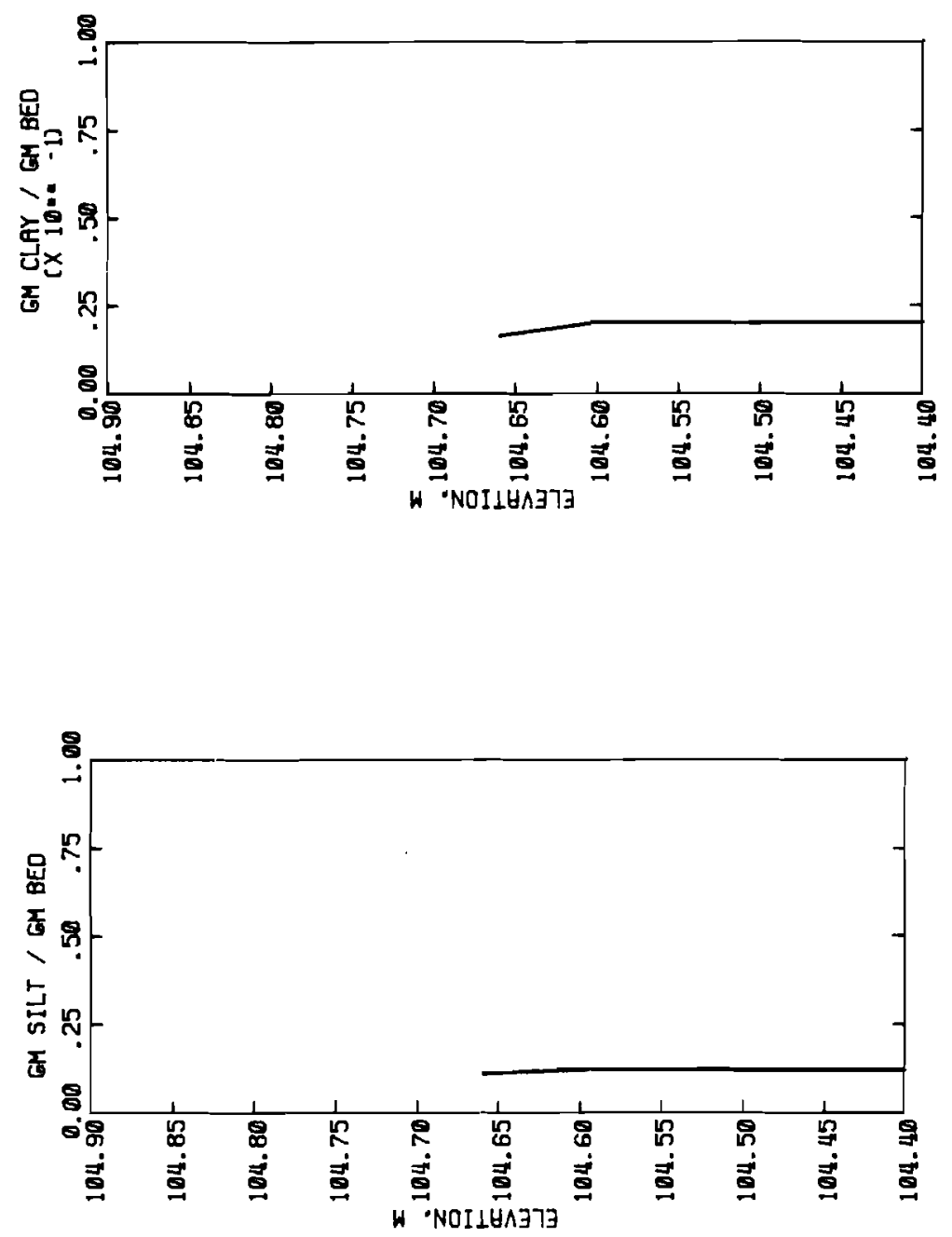

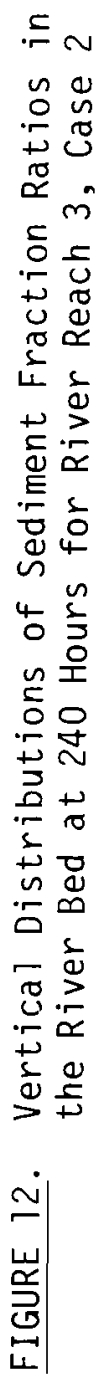



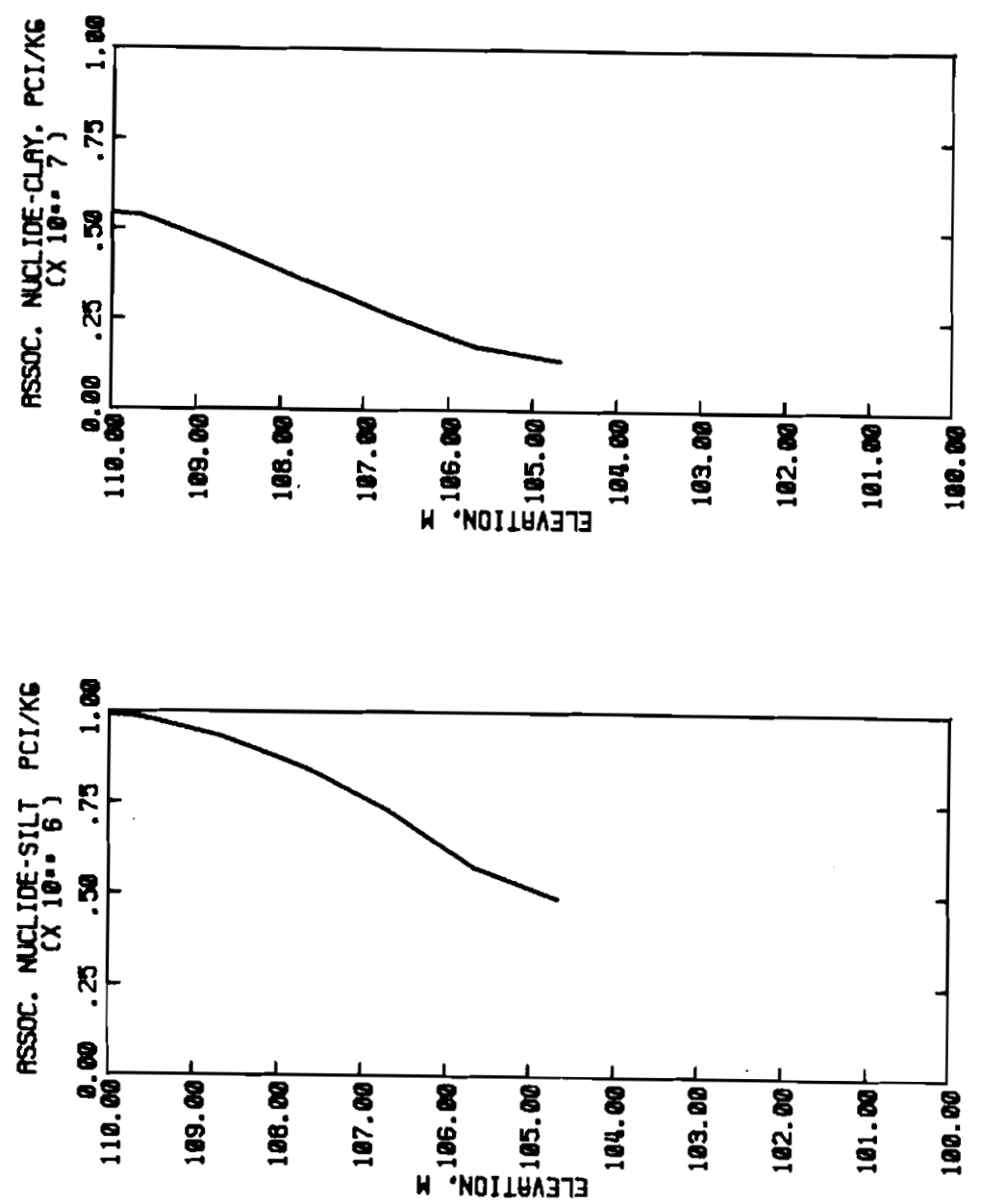

0
+
0
0
0
0
0
0
0
0
0
0
0

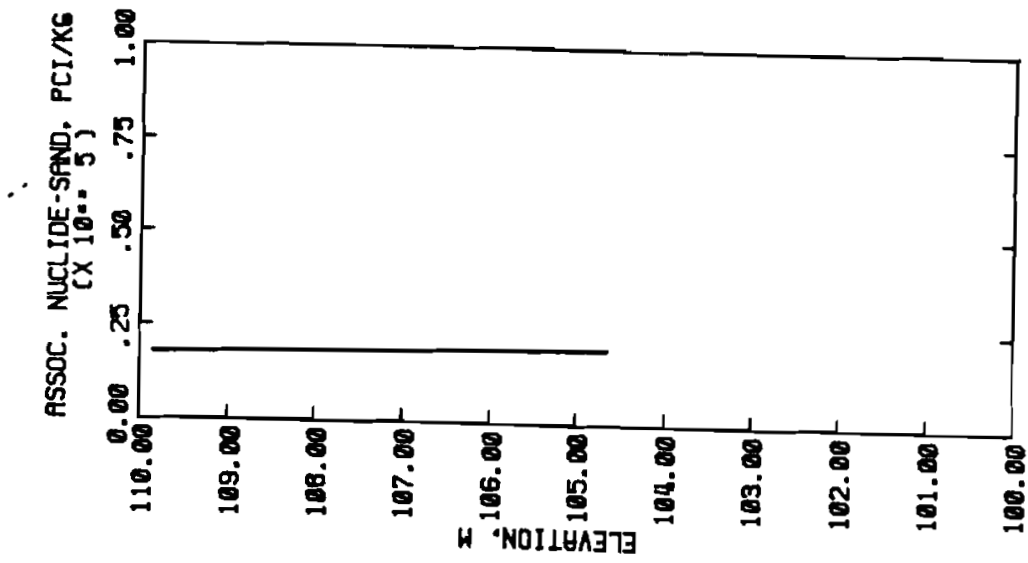

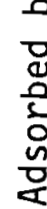

\&)

Ů

N

$40 \mathrm{~m}$

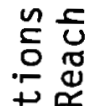

兘

的

드ㄴㅗㅗ

잉

엉

妾

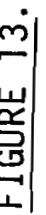



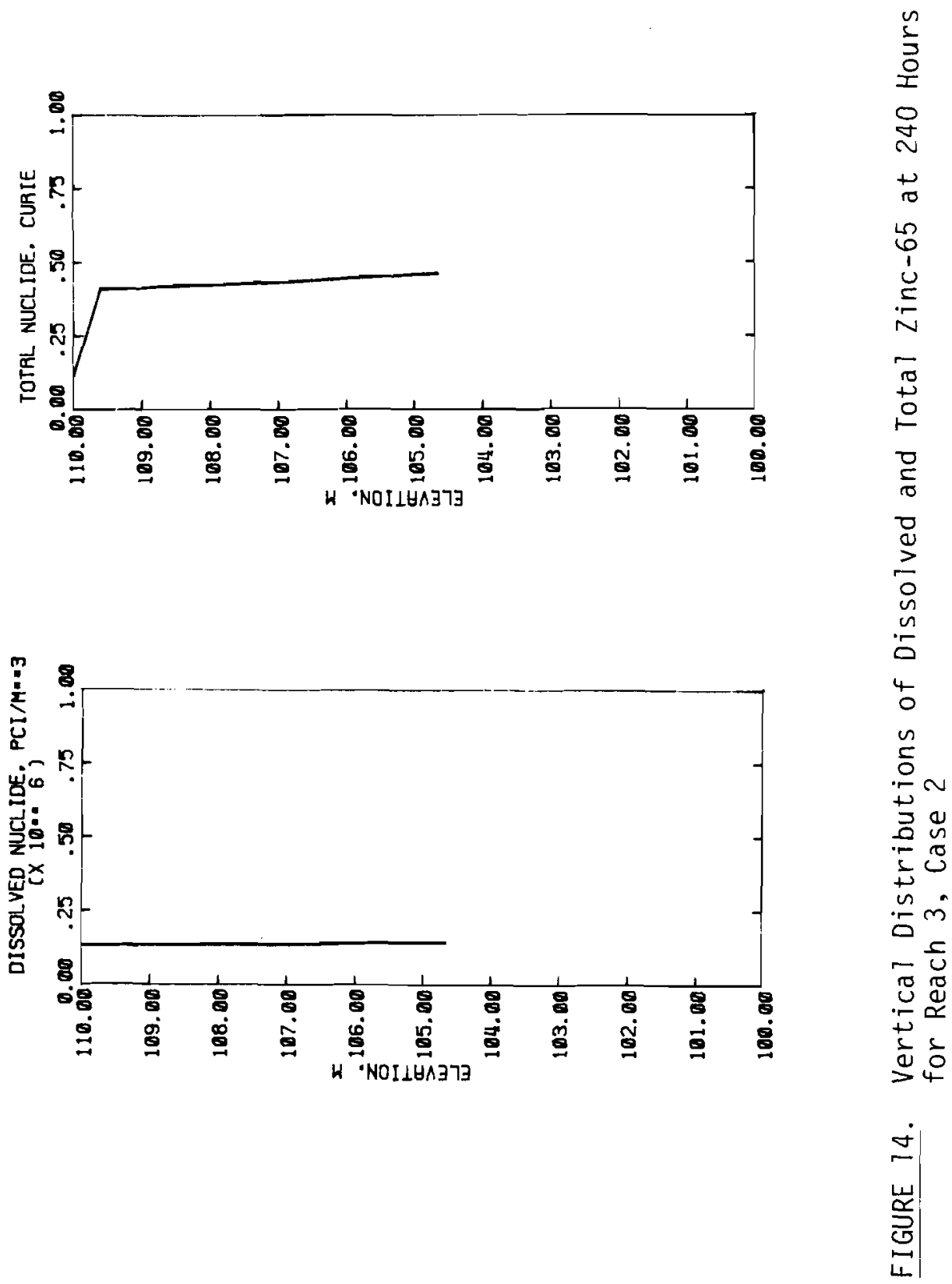


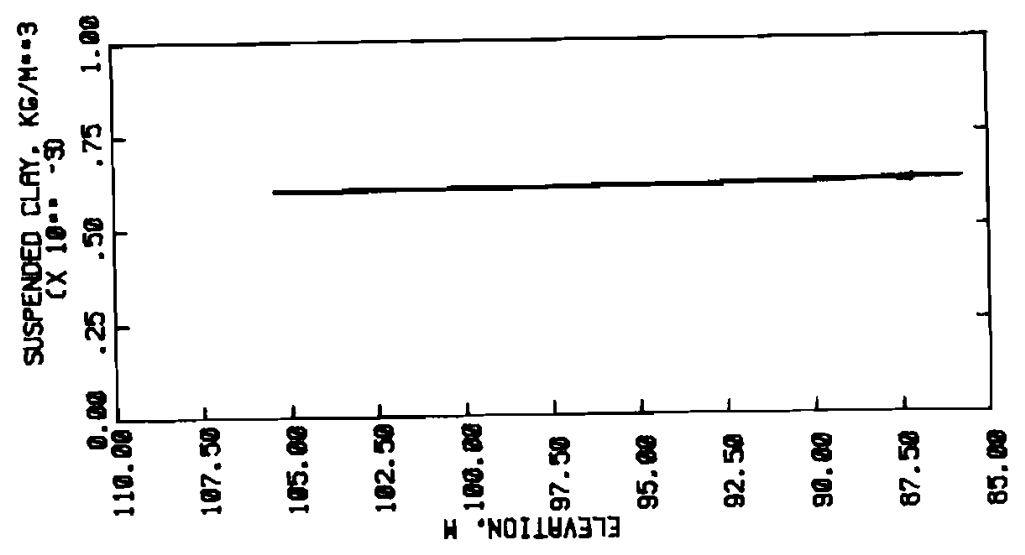

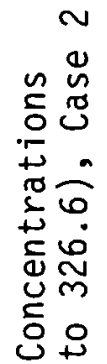

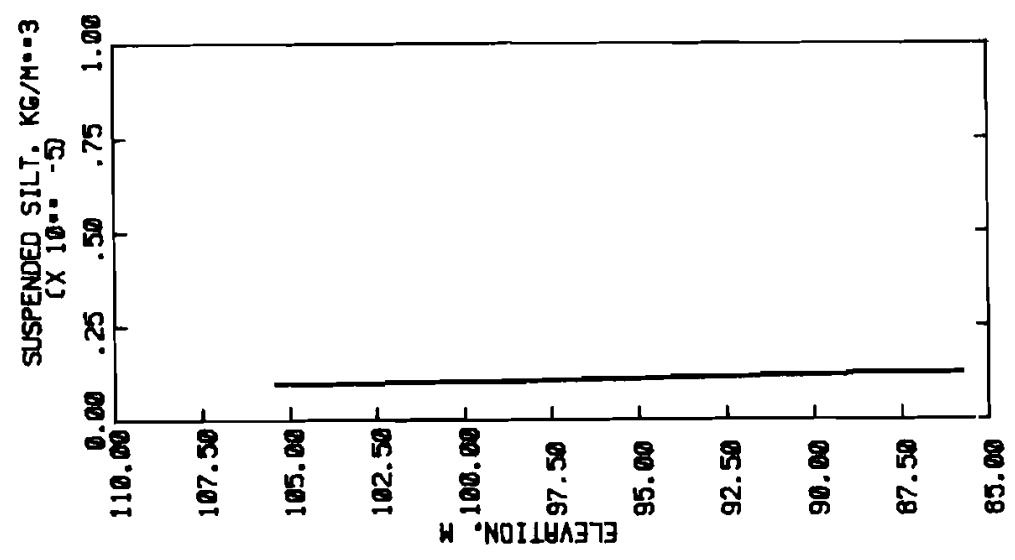

芒

远

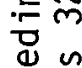

๗ั \&

멍

동

은ㅈ

$\stackrel{\sim}{a}$

4드

동

응

$+\infty$ 㝴

n

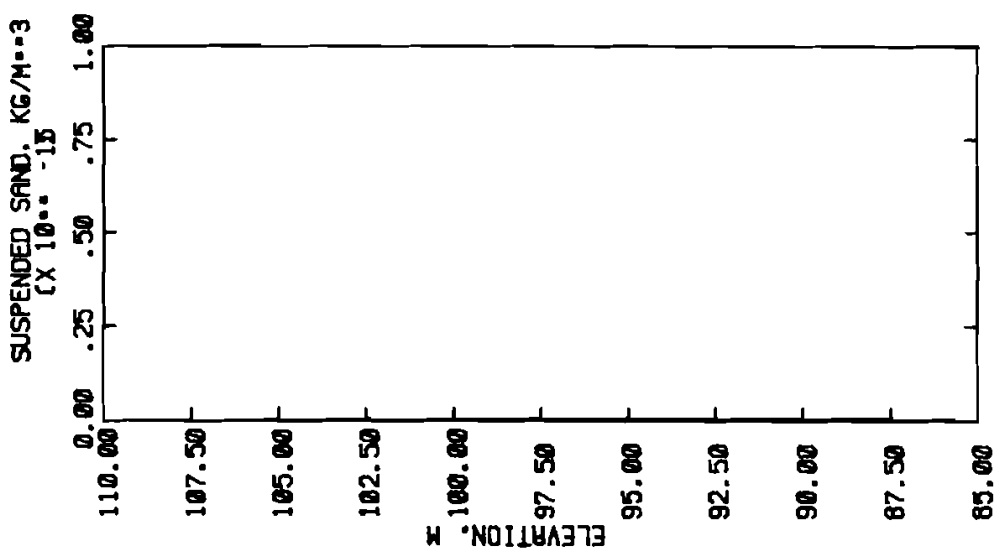

도오

엉ㅇ

滎出

$\stackrel{0}{>}$

임 

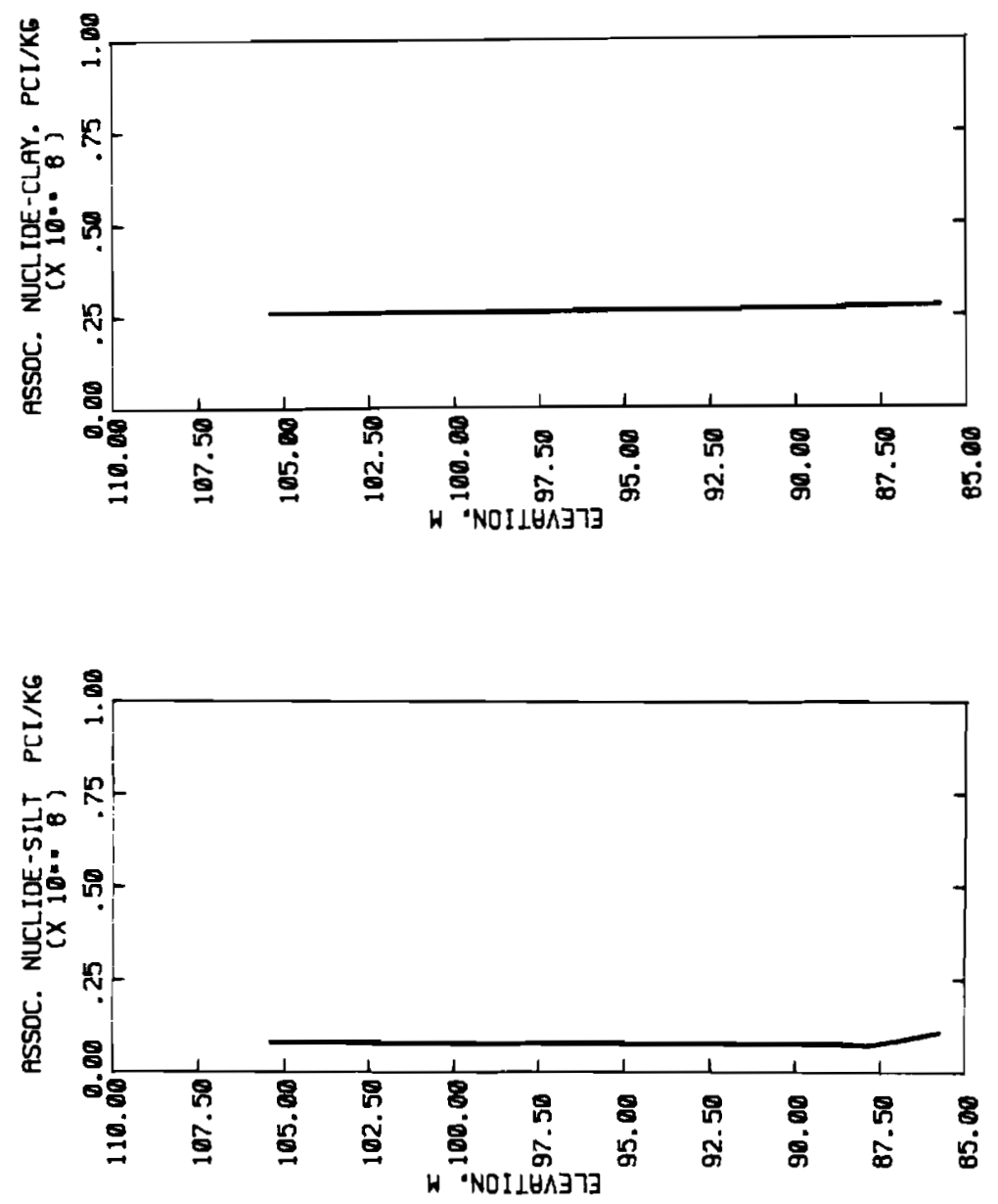

$\frac{8}{8}$
$\frac{0}{0}$
$\frac{0}{n}$
के

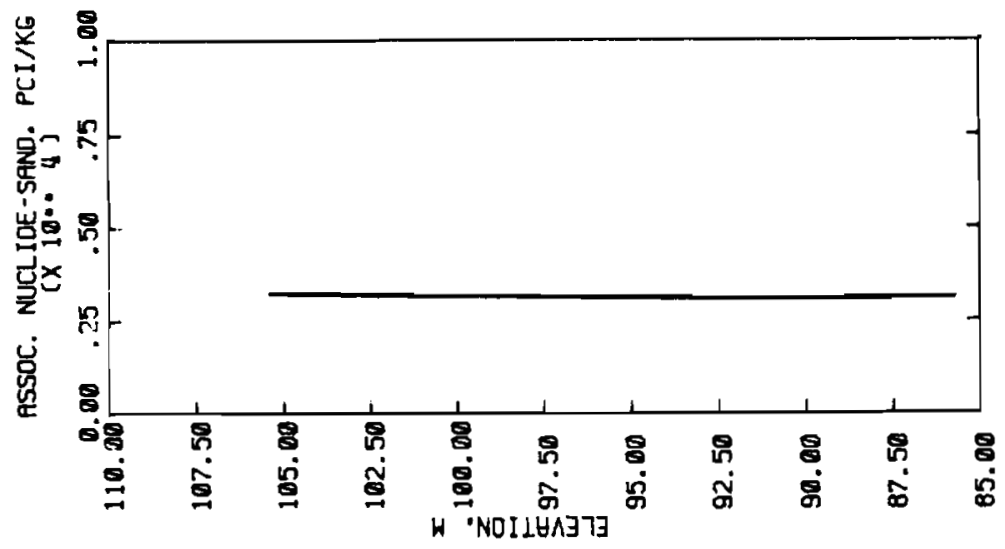

ذे

잉

ปั

ठ。

둔

둥

워

․ㅛㅇ

N

$4 \frac{1}{0}$

동 ํํㄱ

롱

언

in

万。

范

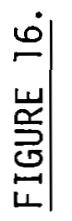




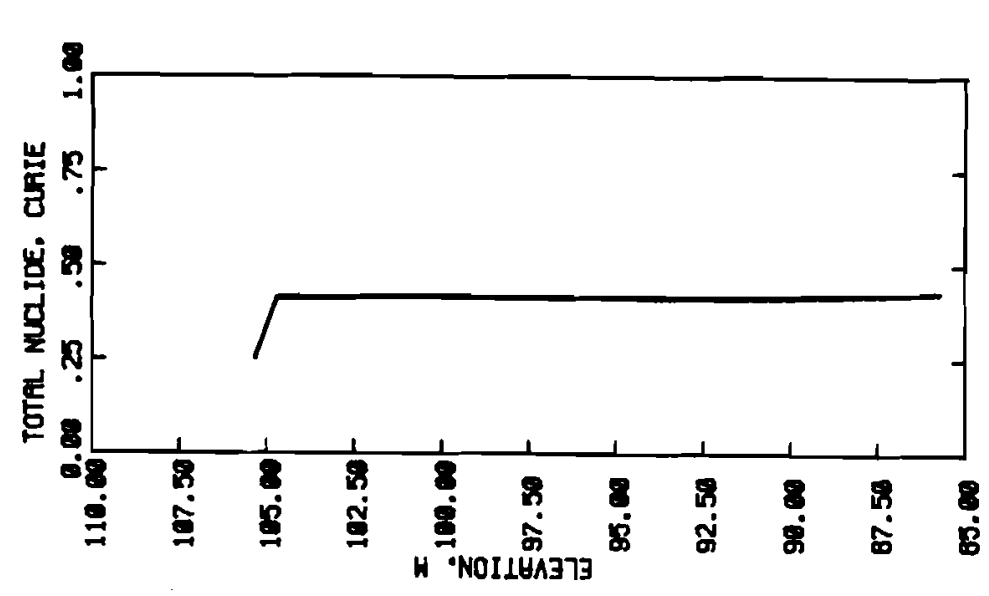

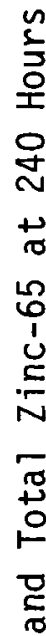

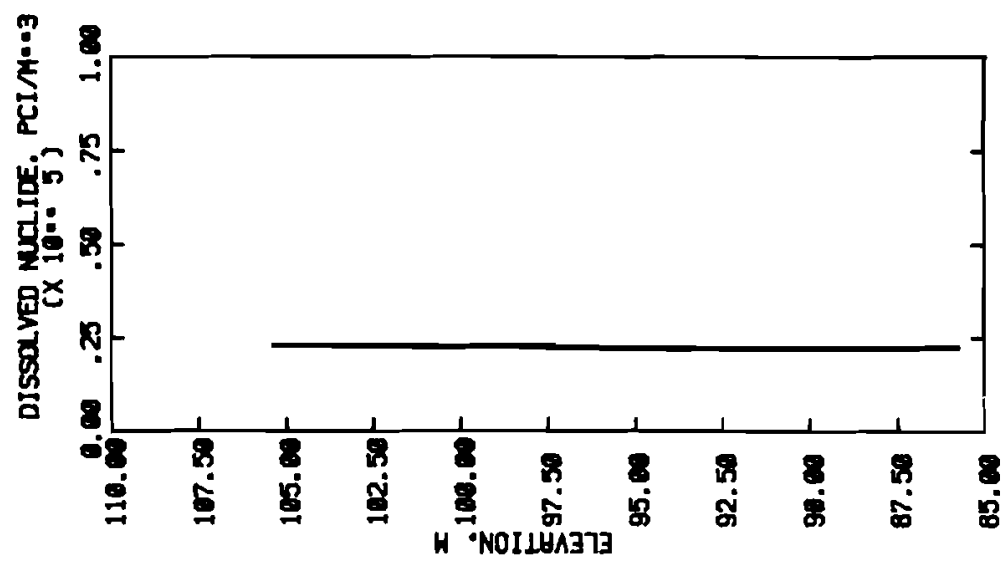

$\stackrel{9}{2}$

4

ธุ๊

$+$

근

-

芯-

-

헝

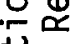

造放

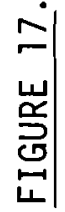



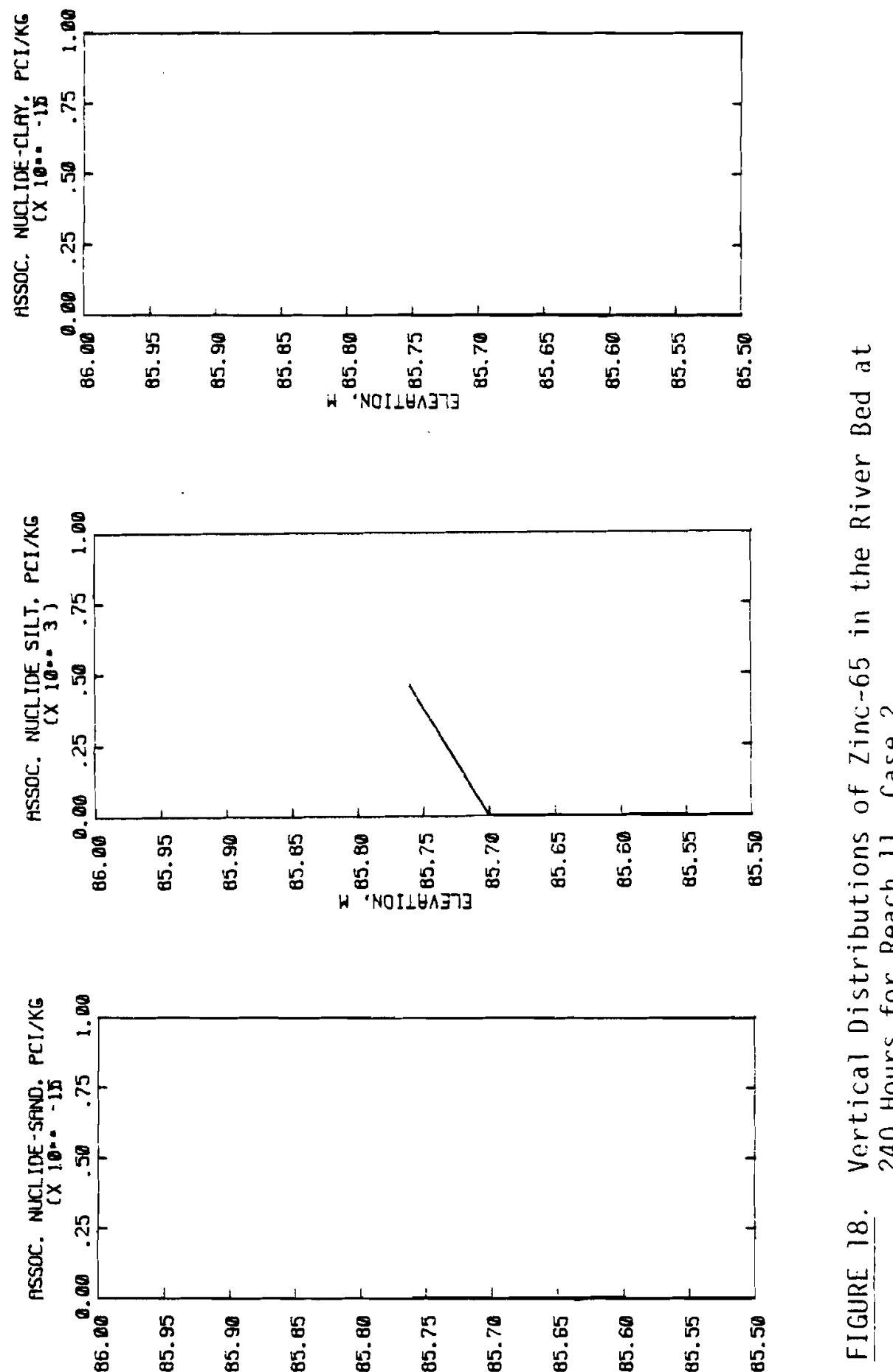


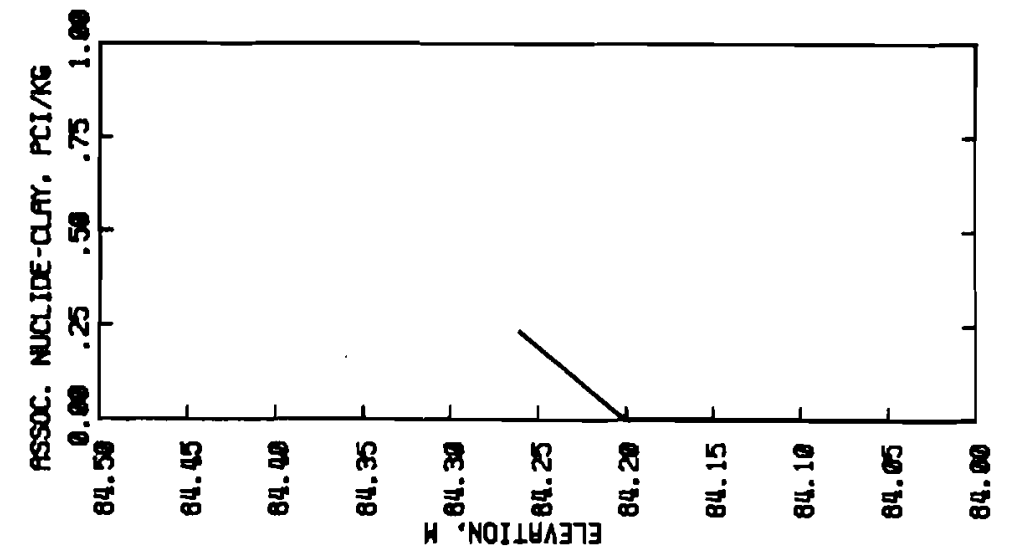

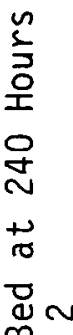

$\infty$

齐帒

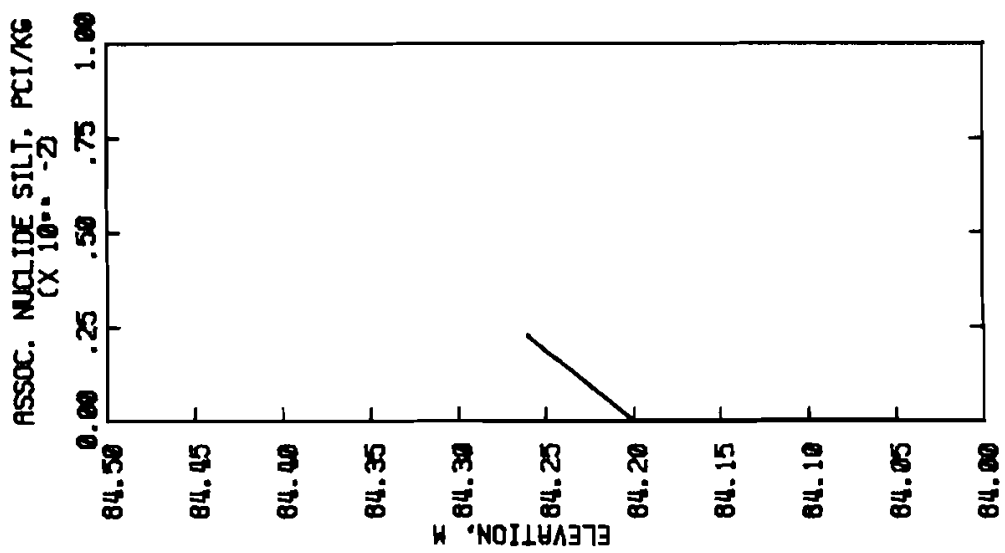

두

ஸे

+

든

노오

i。

บ뭉

꽁

4 号

동

产

궁중

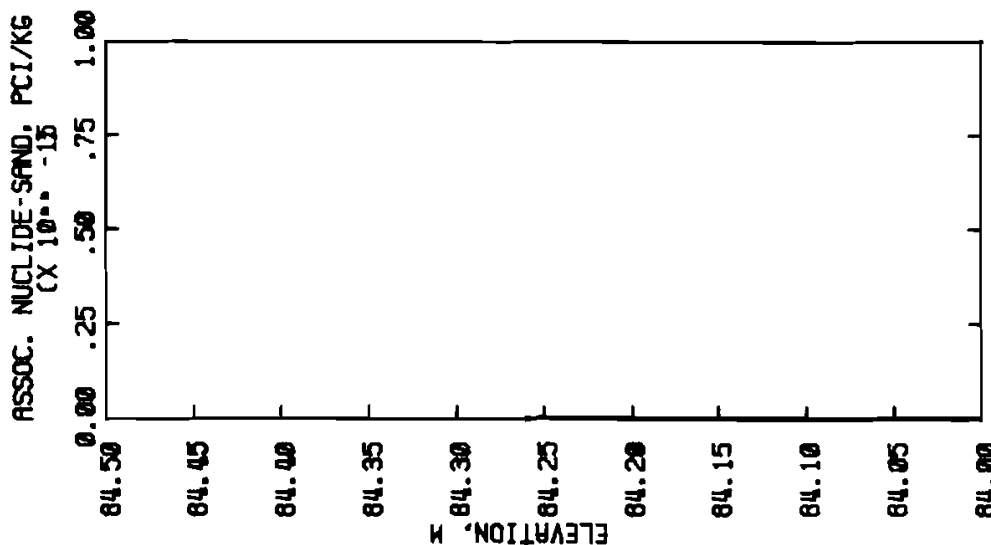

$+$

뚱

둥

웜

产兘

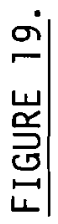




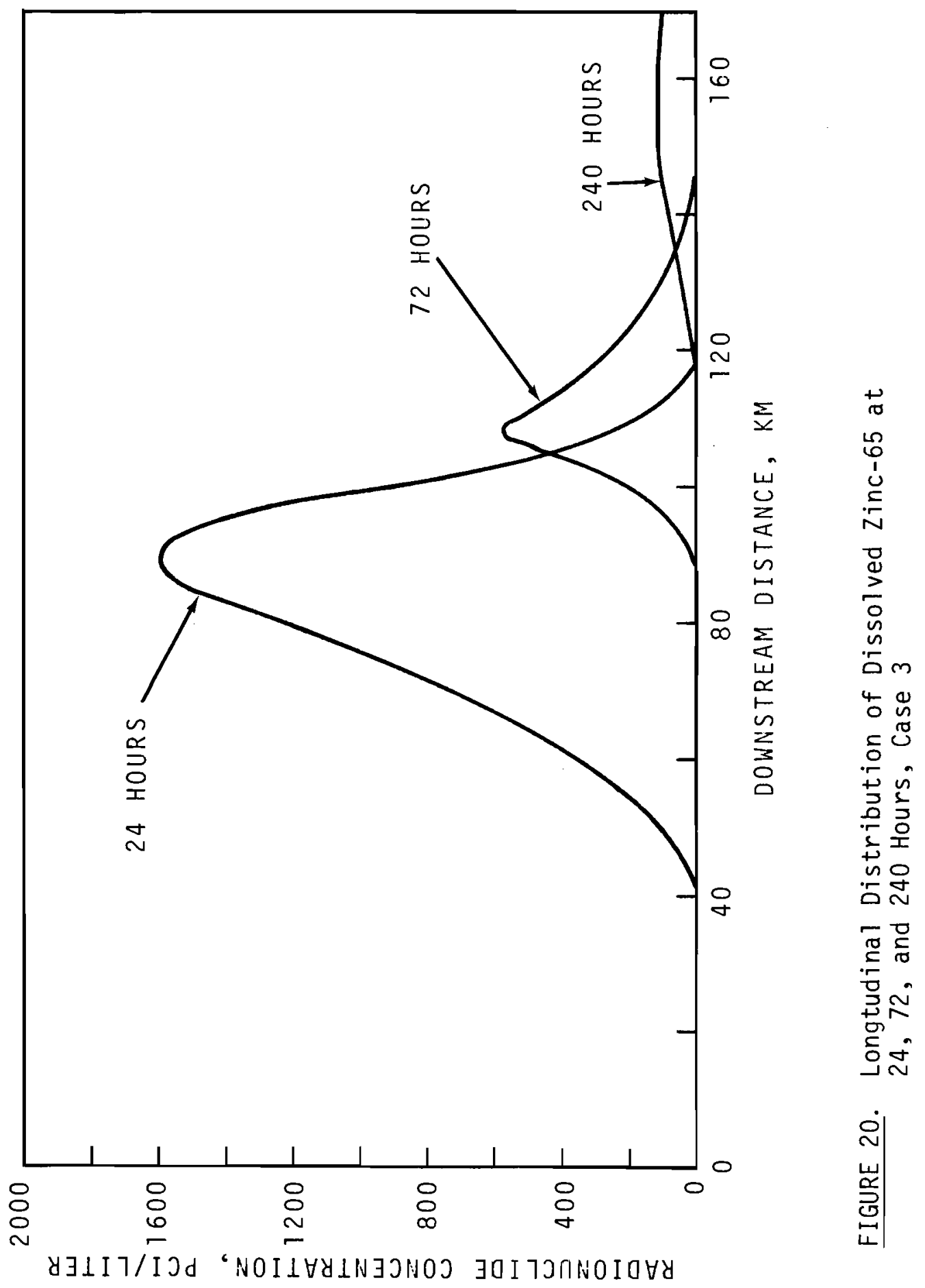




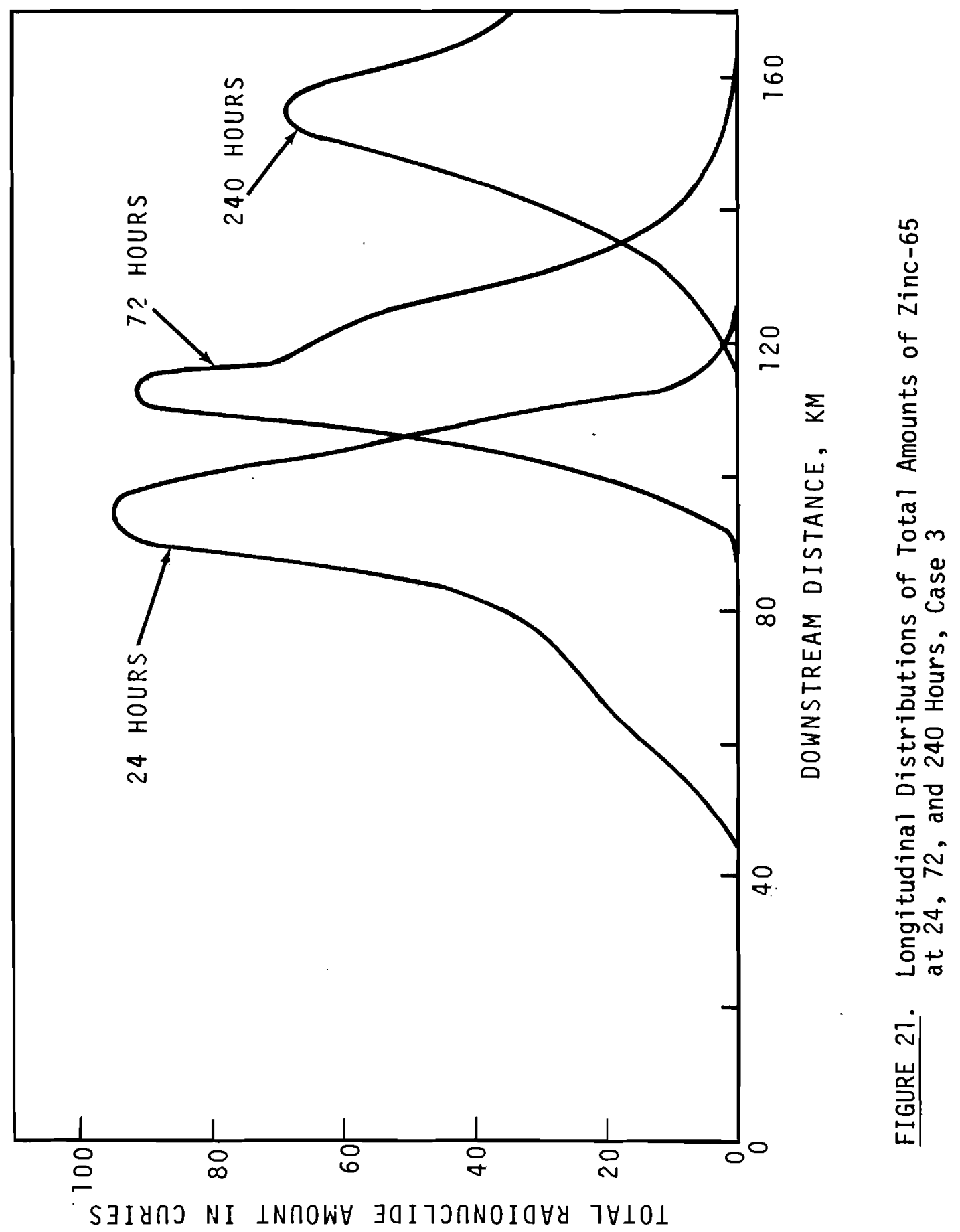




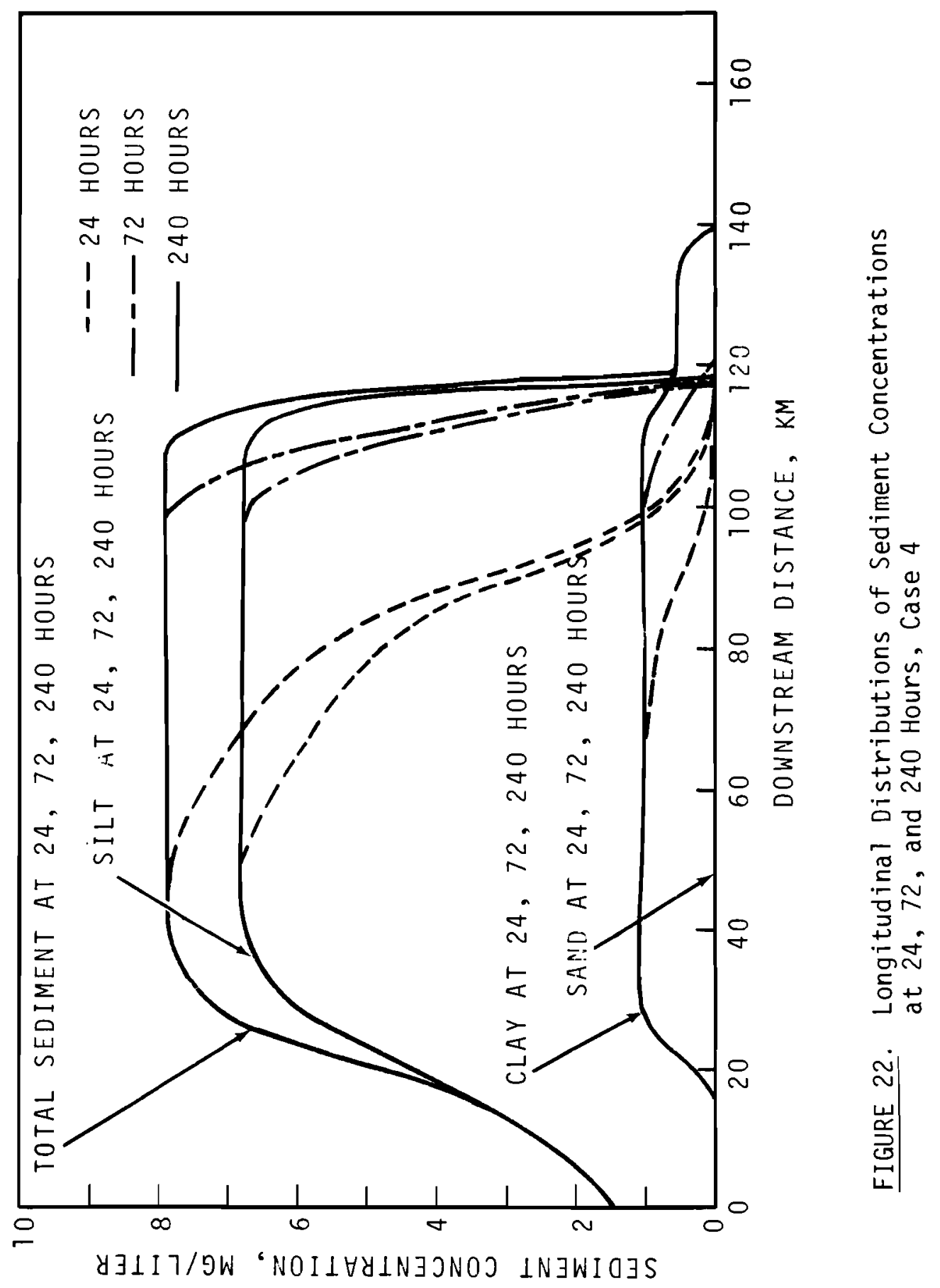




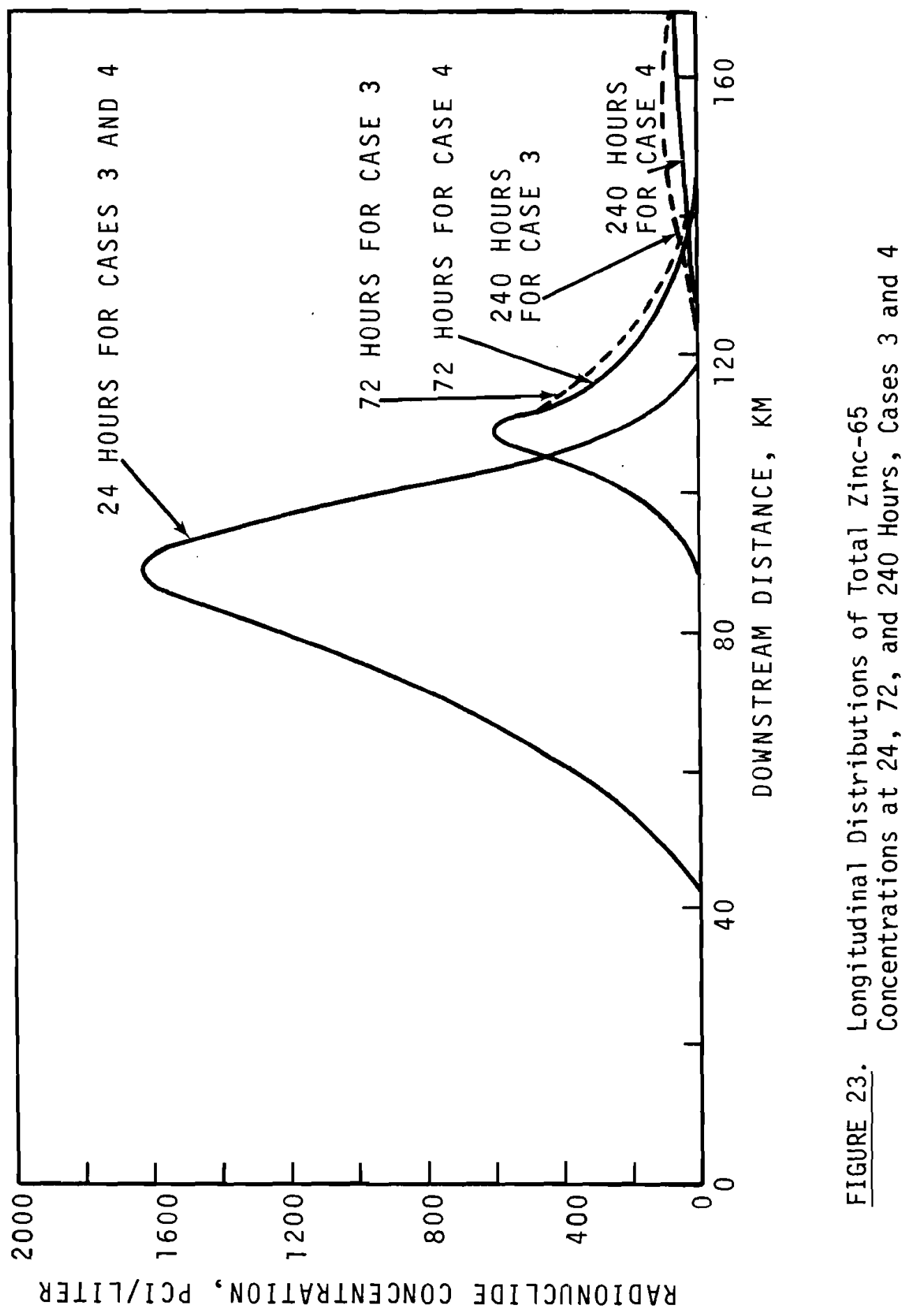




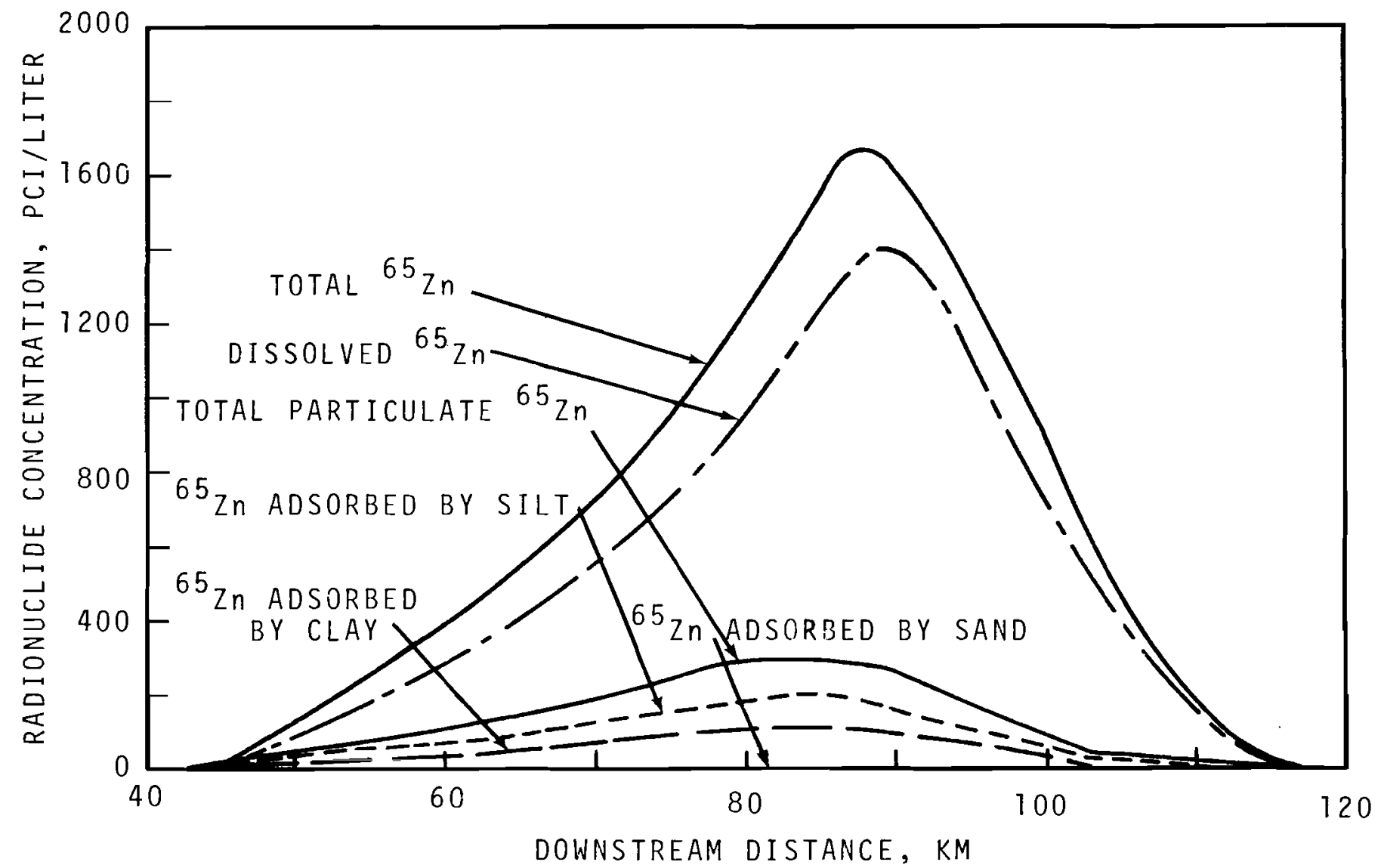

FIGURE 24. Longitudinal Distributions of Total, Dissolved and Particulate Zinc-65 Concentrations at 24 Hours, Case 4 


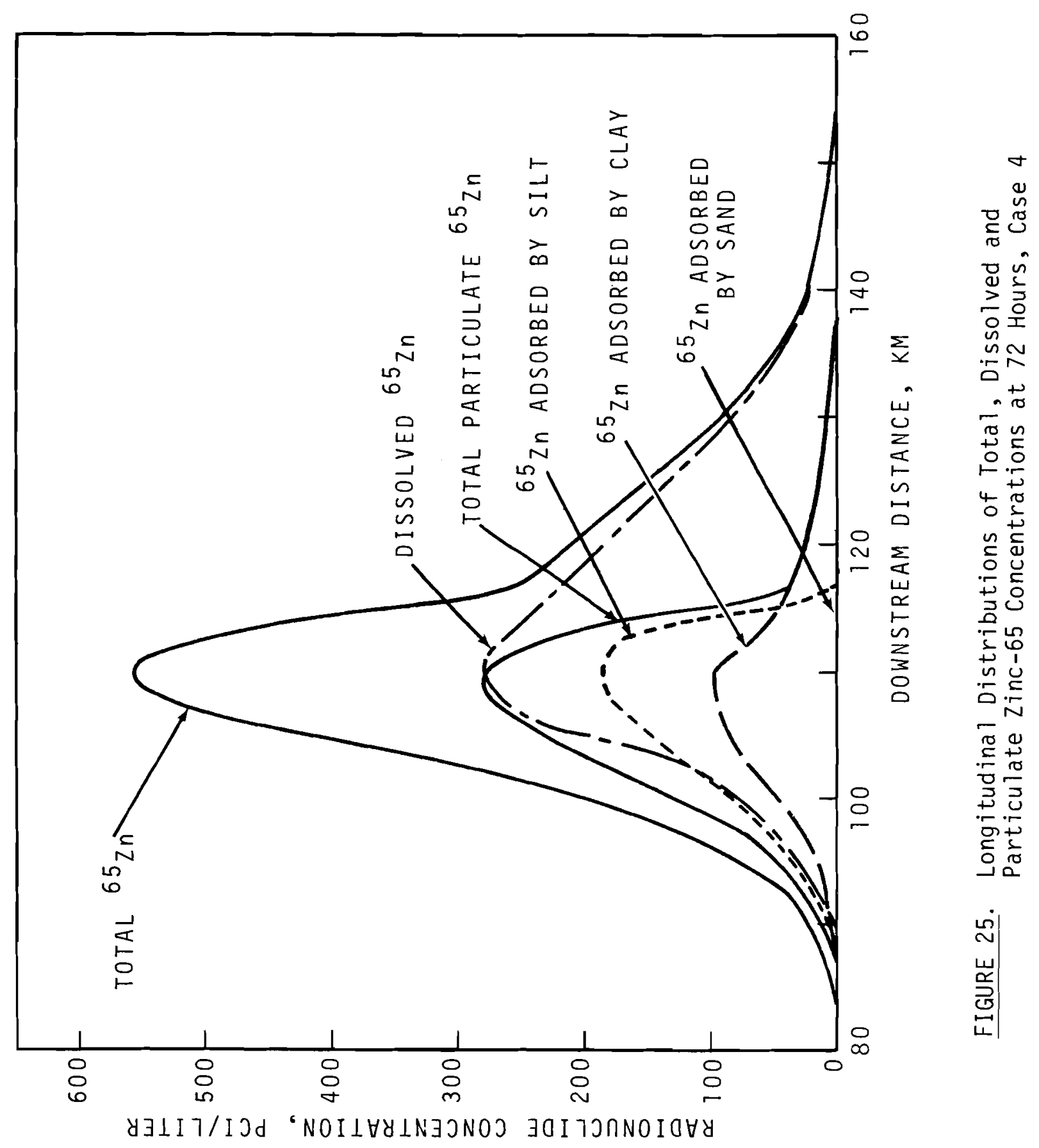




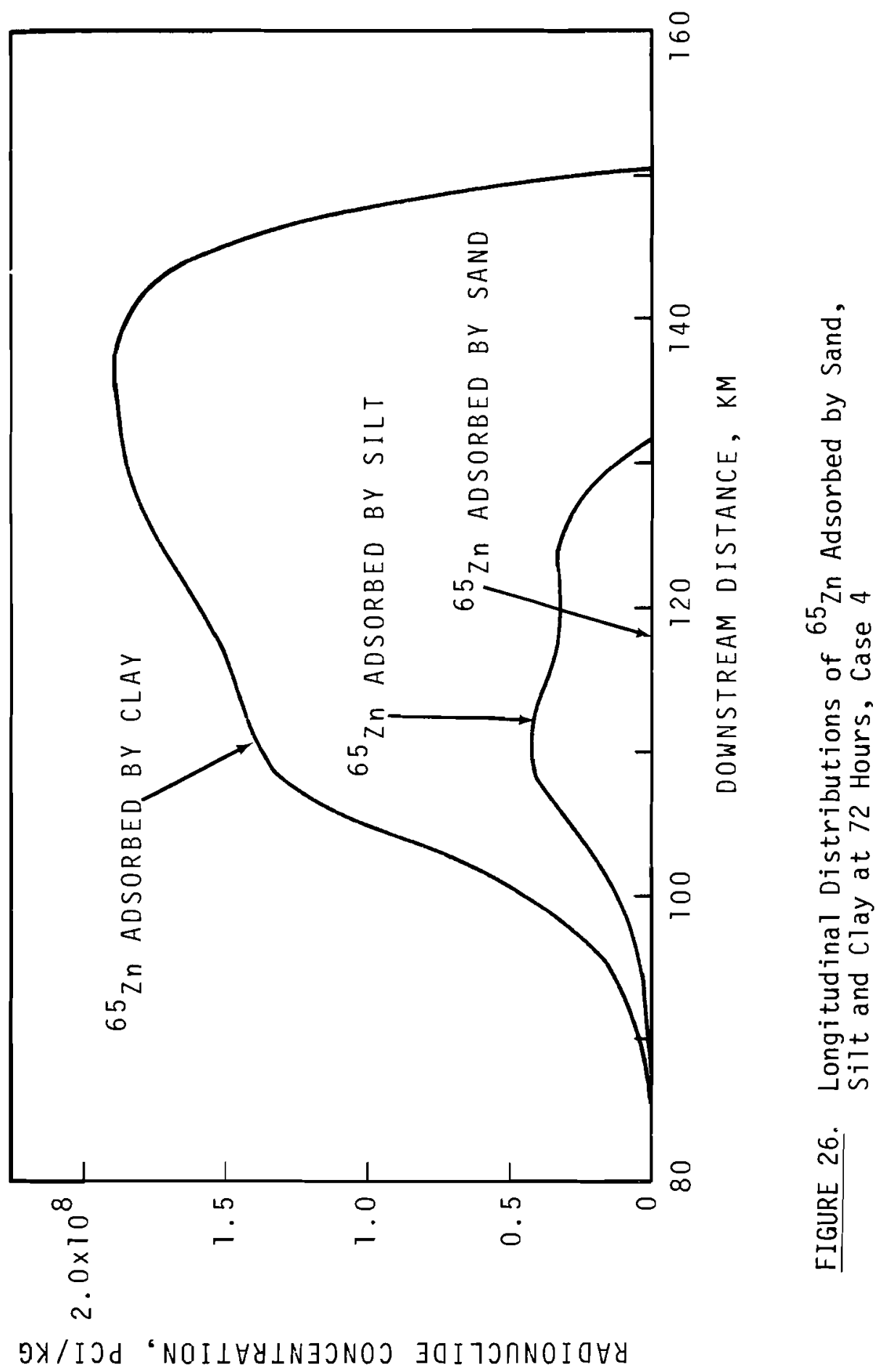




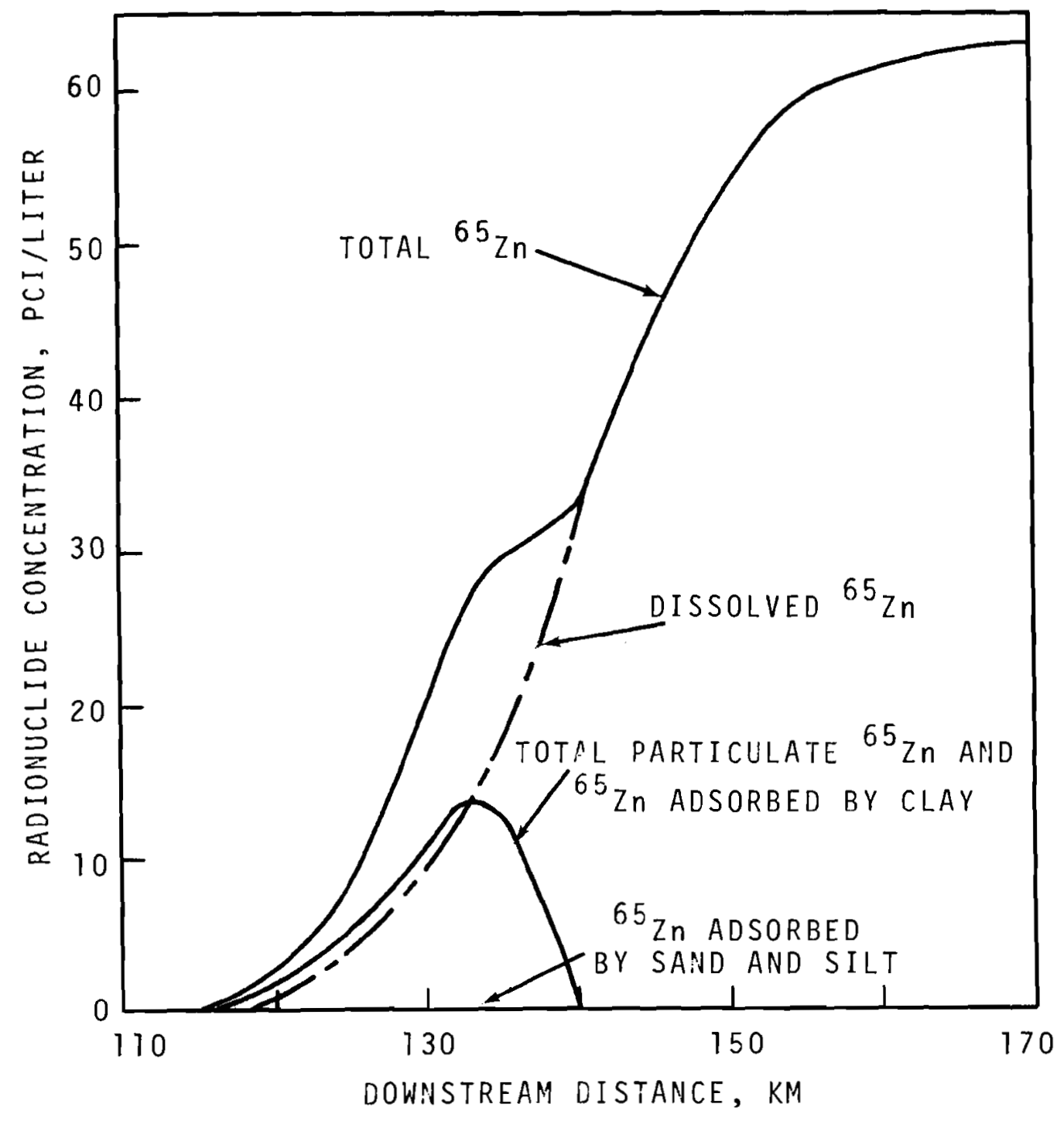

FIGURE 27. Longitudinal Distributions of Total, Dissolved and Particulate Zinc-65 Concentrations at 240 Hours, Case 4 


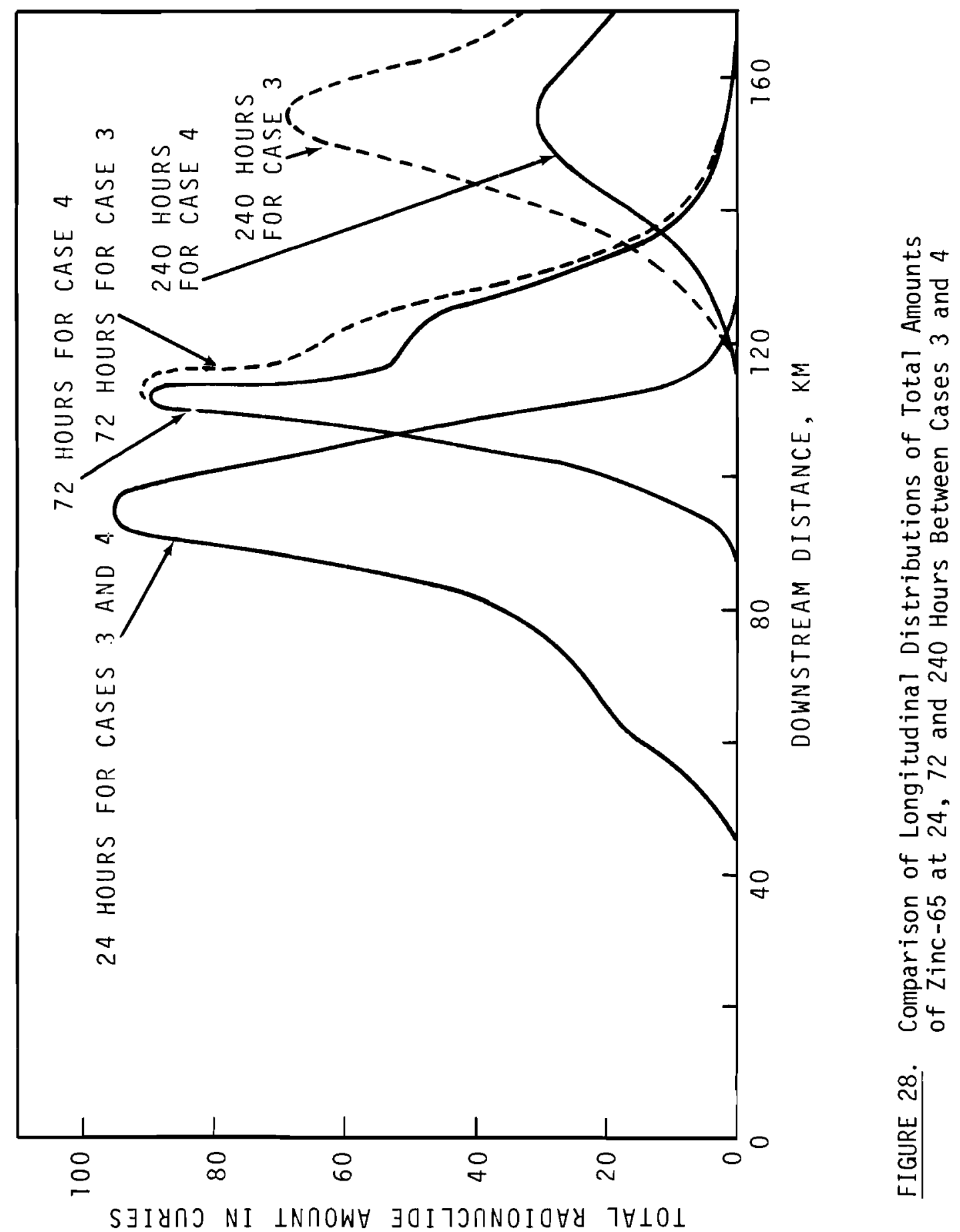




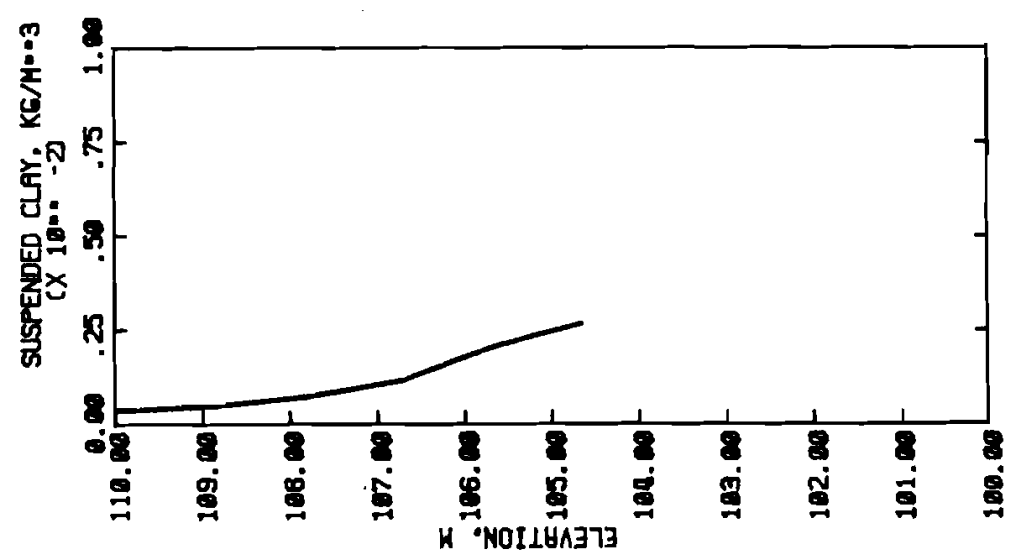

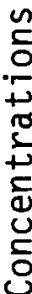

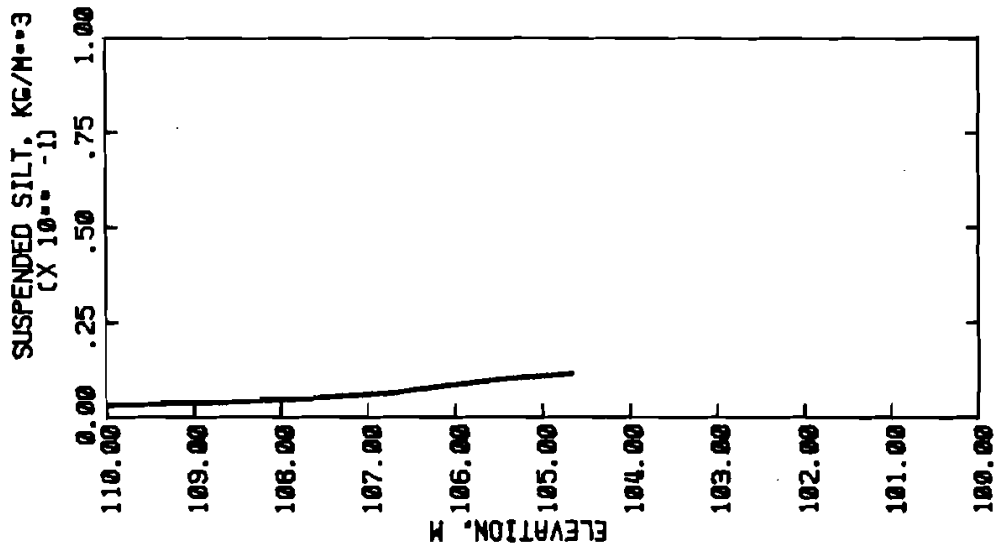

点

ช్

ธิ

尺

号 岕

范

동도

구

文4

ธะ

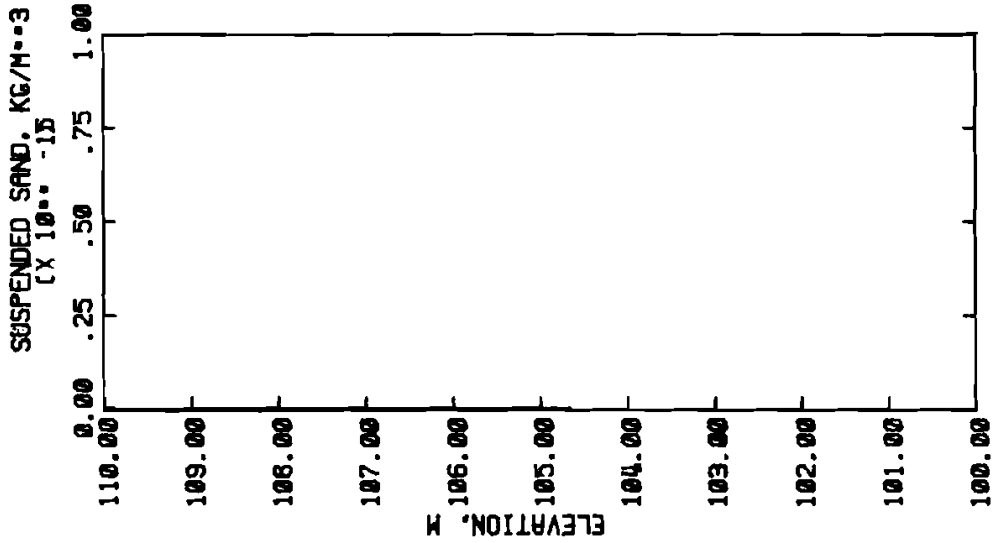

이노

0

$+\square$

$\stackrel{4}{>}$

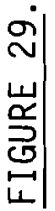




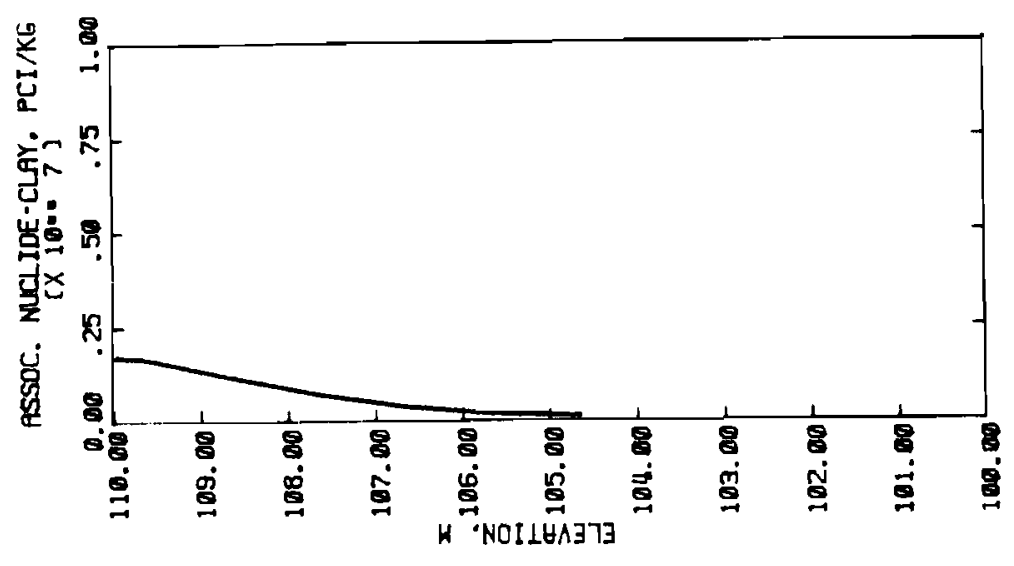

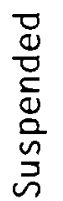

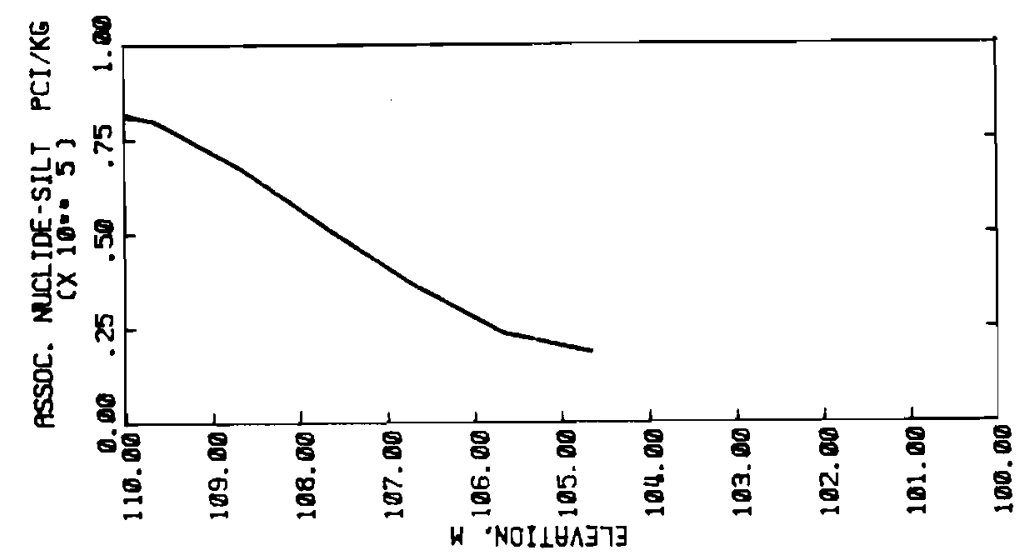

ते

망

웡

운

$5 \mathrm{~m}$

ع

U.

Nㅗㅇ

ᄂᄂ

ธิธ

든독

공

衣

$\sim+$

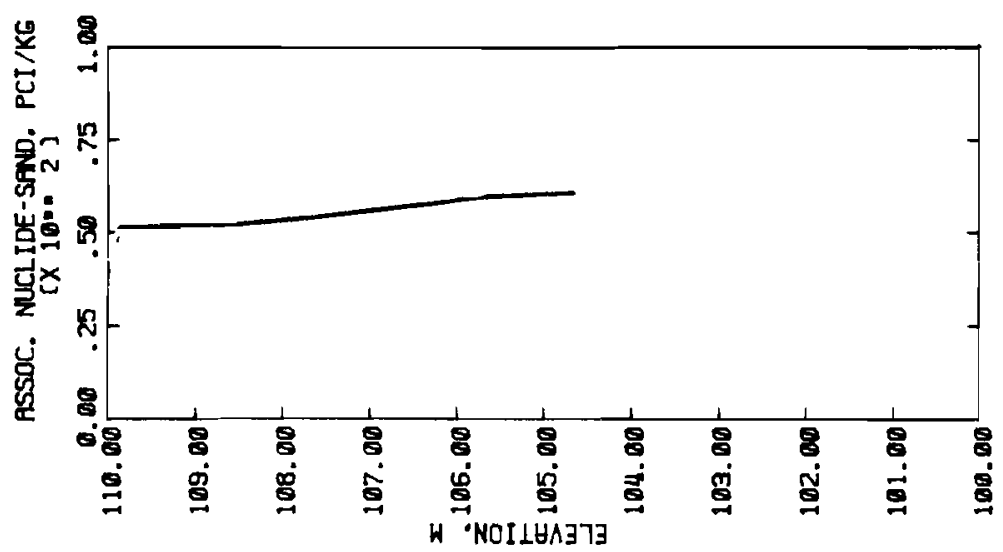

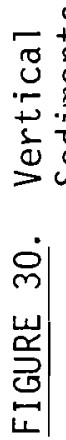




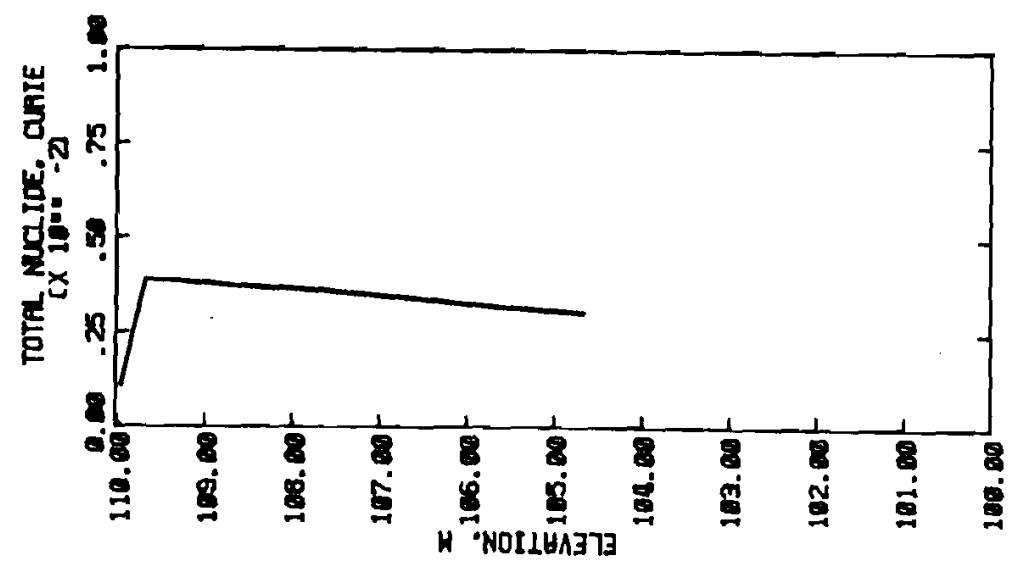

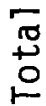

믕

ช

$\frac{\circ}{\circ}$

जि

๑ บ

$4 \simeq$

논

은

†告

市

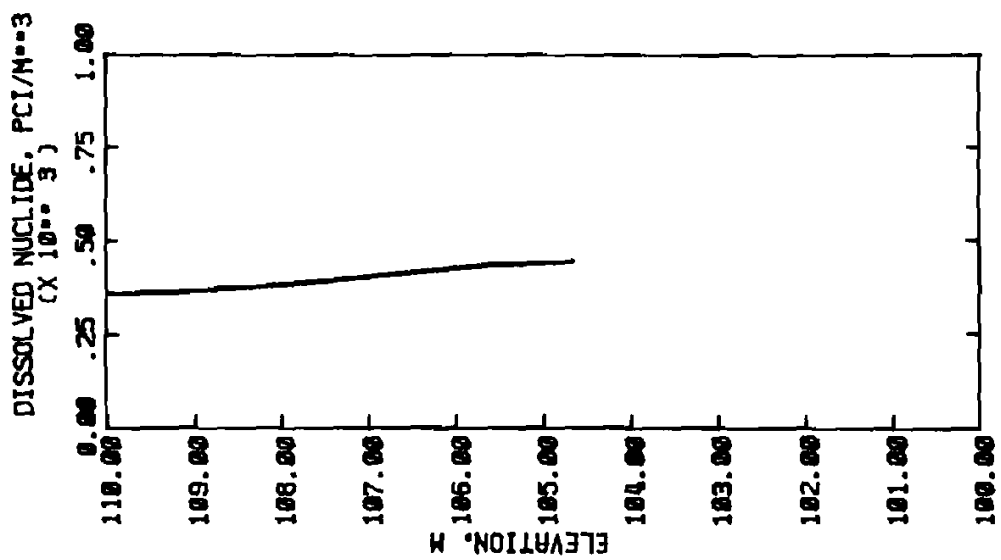

U

$0+0$

مـ

I 文

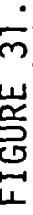



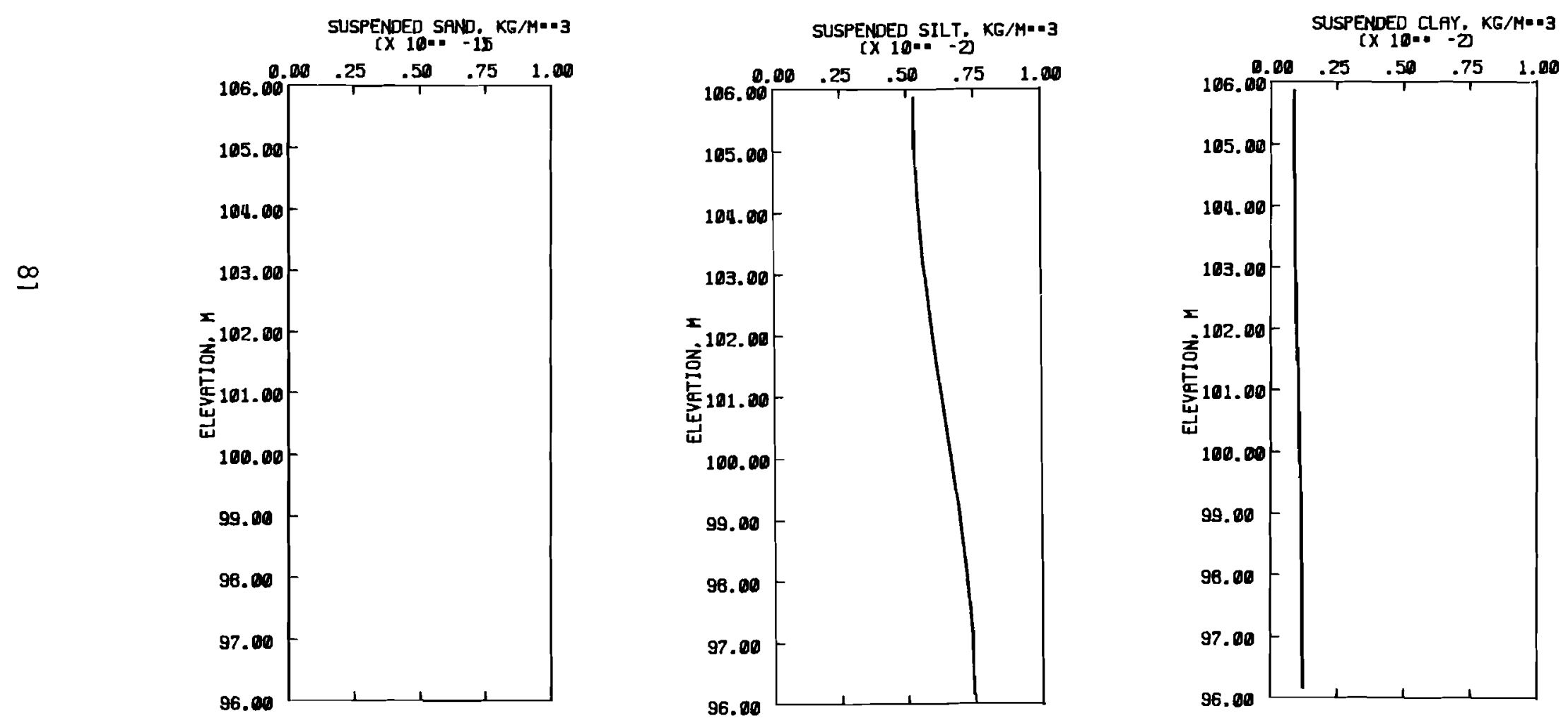

FIGURE 32. Vertical Distributions of Suspended Sediment Concentrations at 24 Hours for Reach 5 (River Miles 354.3 to 364.3 ), Case 4 


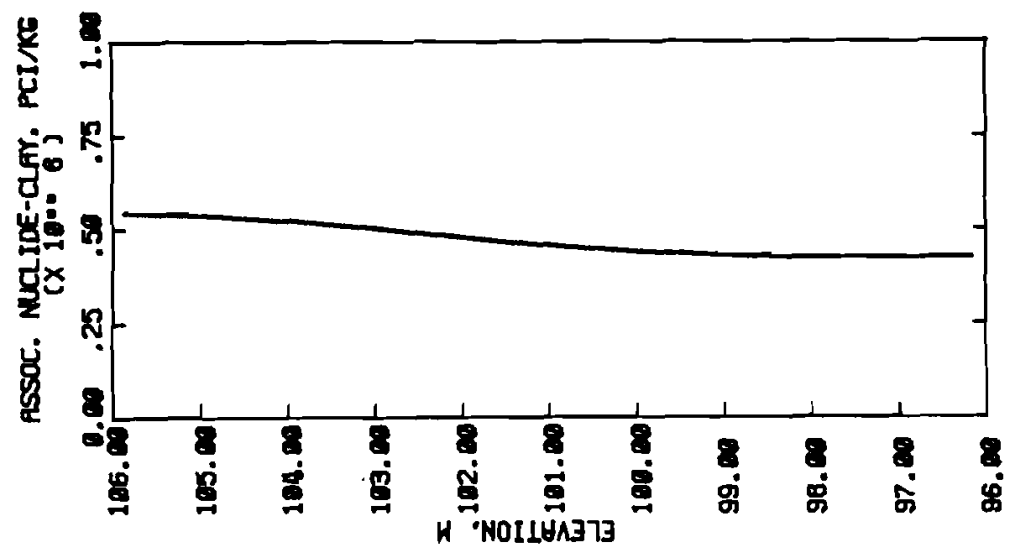

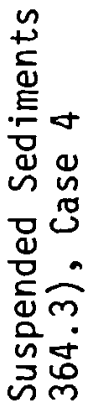

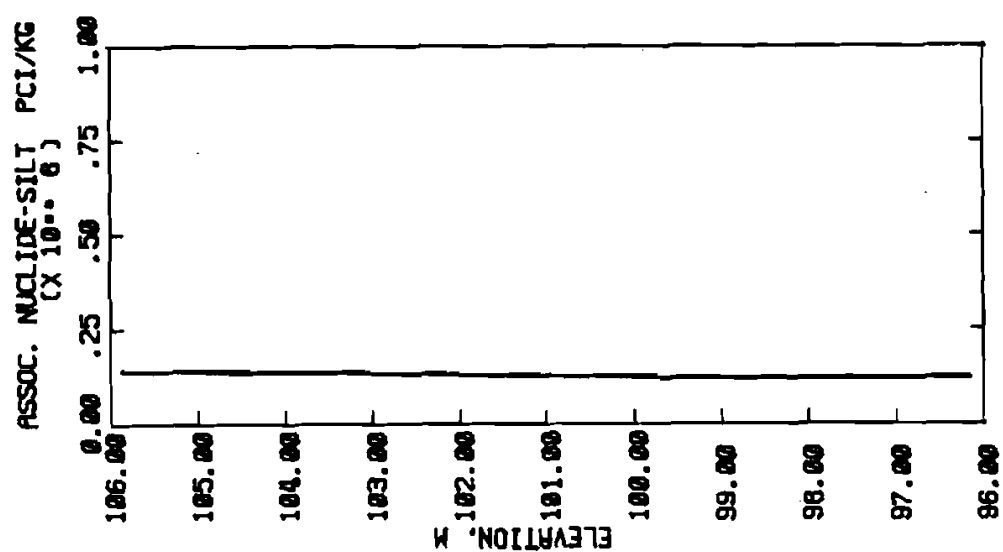

궁

एँ

造

政

운

ᄂ

1

.

N.

4

in

동녕

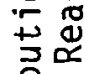

잉

政

哟

도오

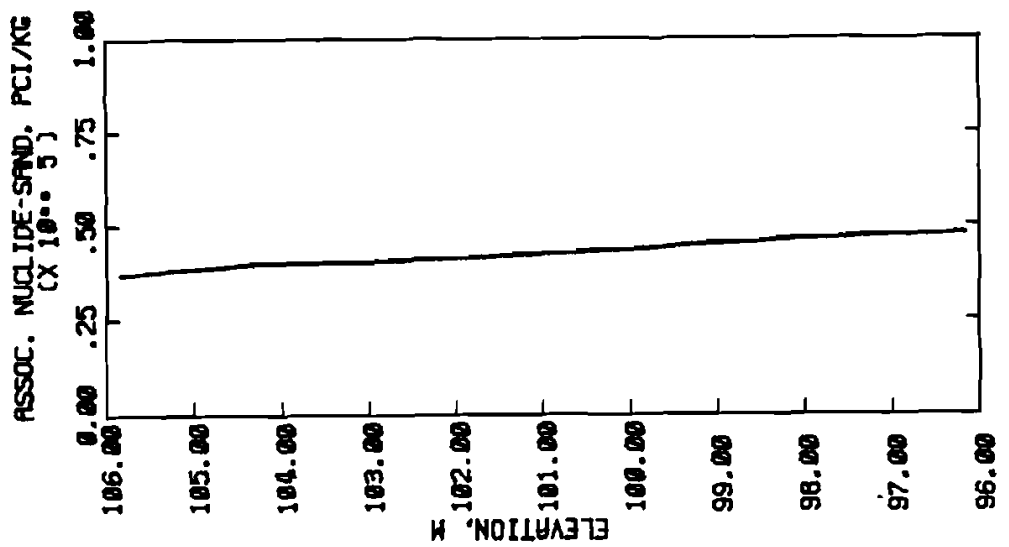

U

N

齐

离 


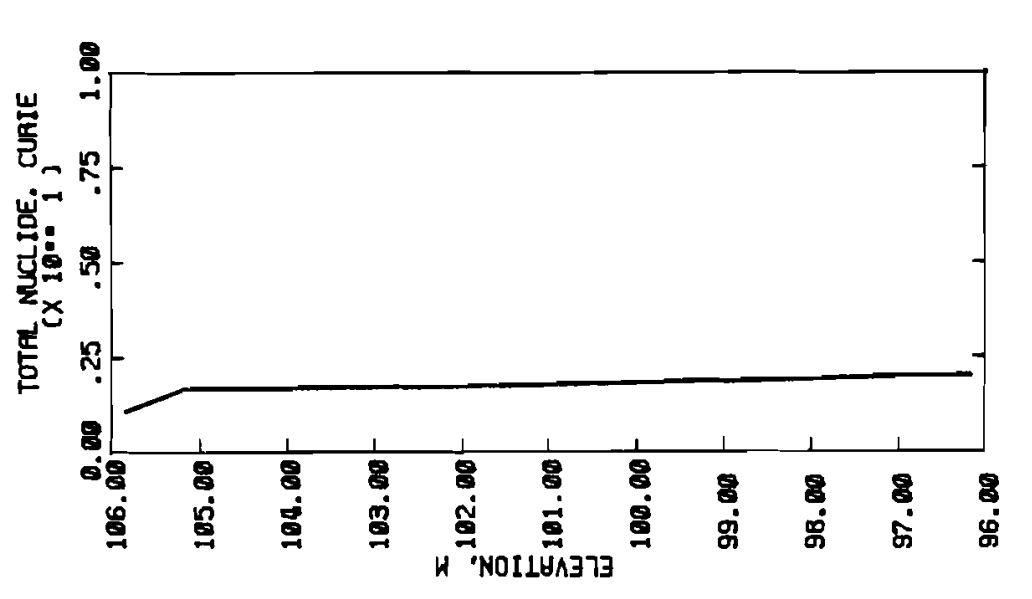

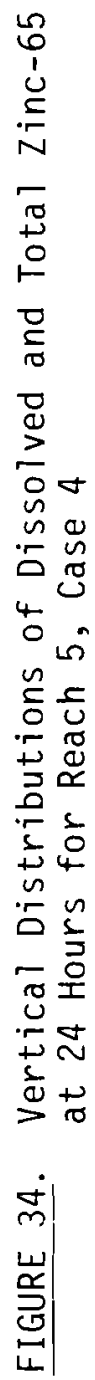




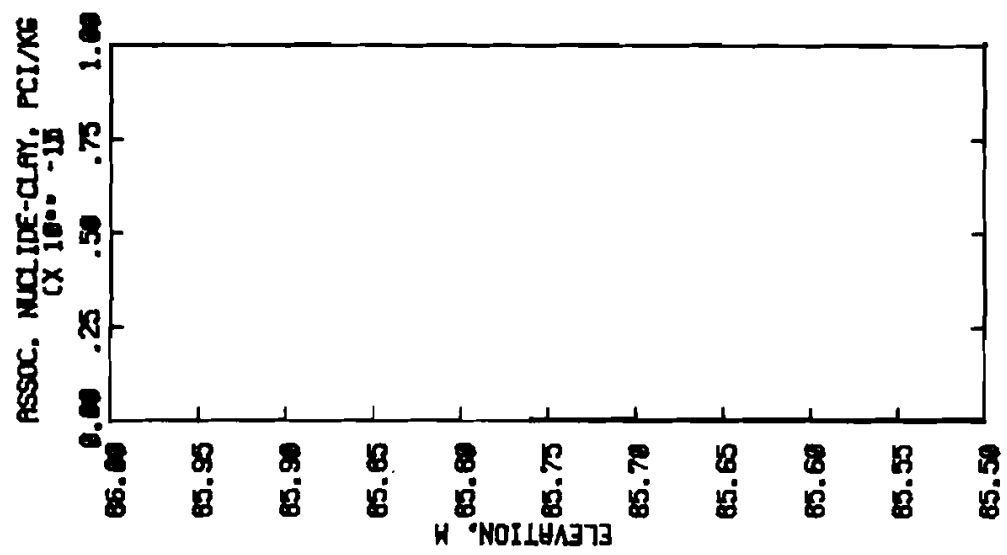

$\frac{\square}{\infty}$

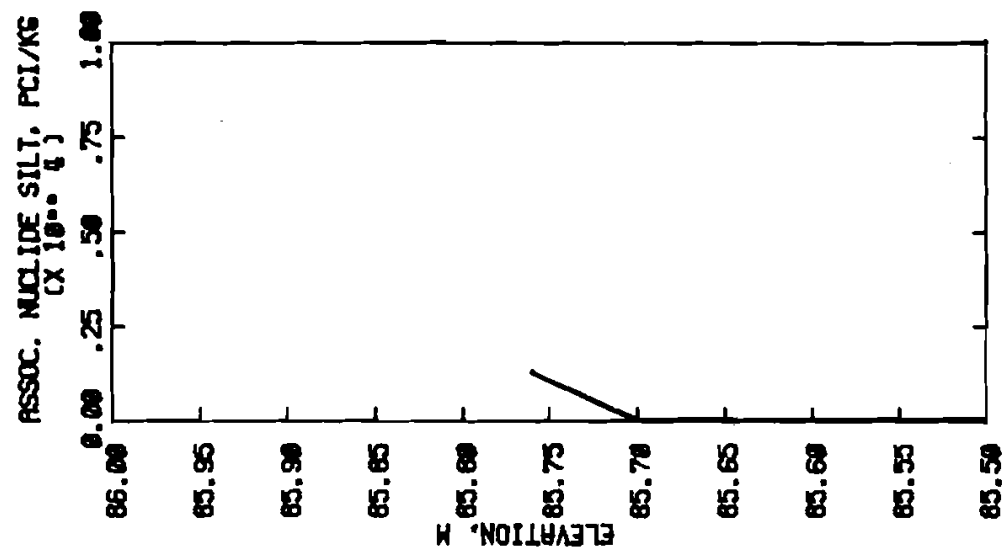

是

$\varepsilon$

ธิ

Uీ N

4.

is

은

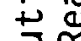

무

눈

号

종 오

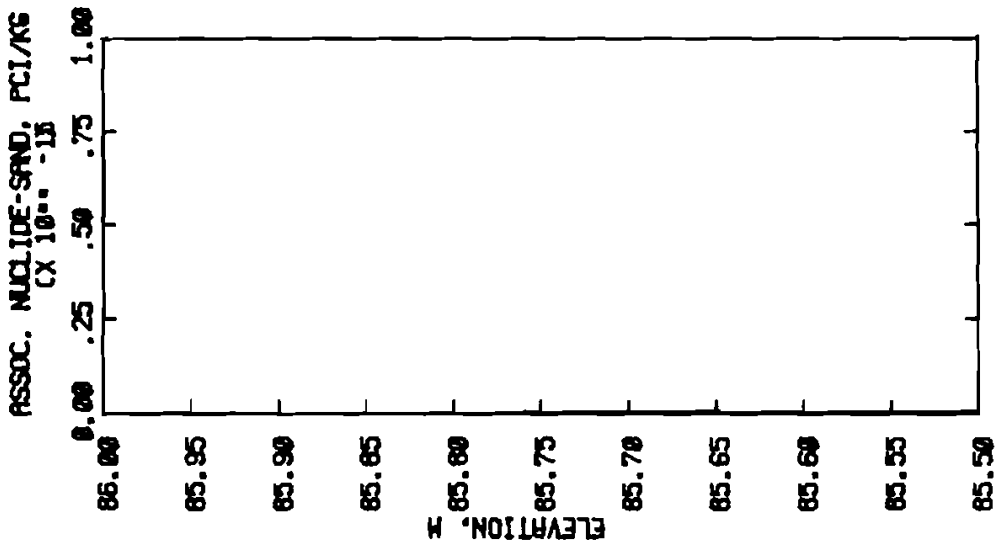

N

N

$\stackrel{1}{>}+$

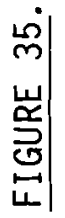




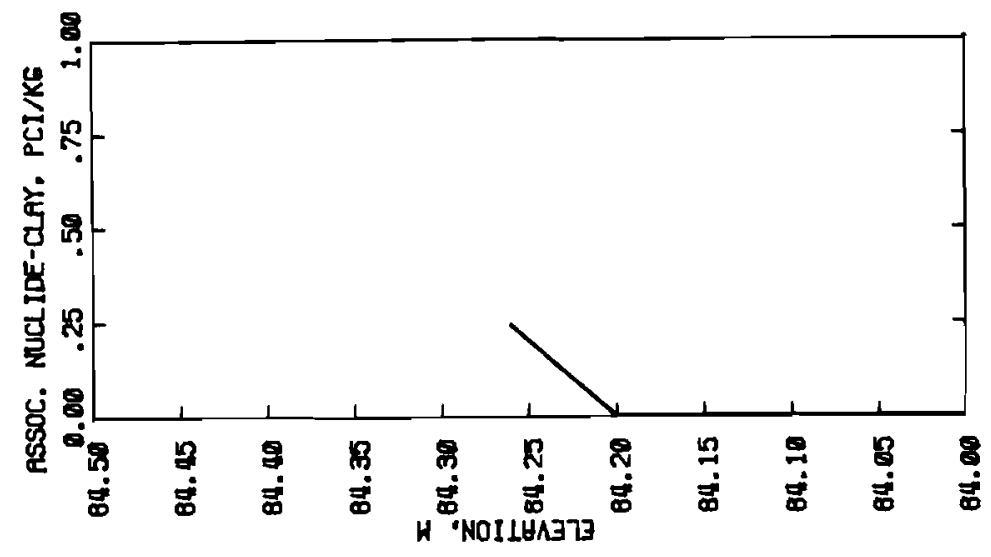

$\frac{0}{d}$

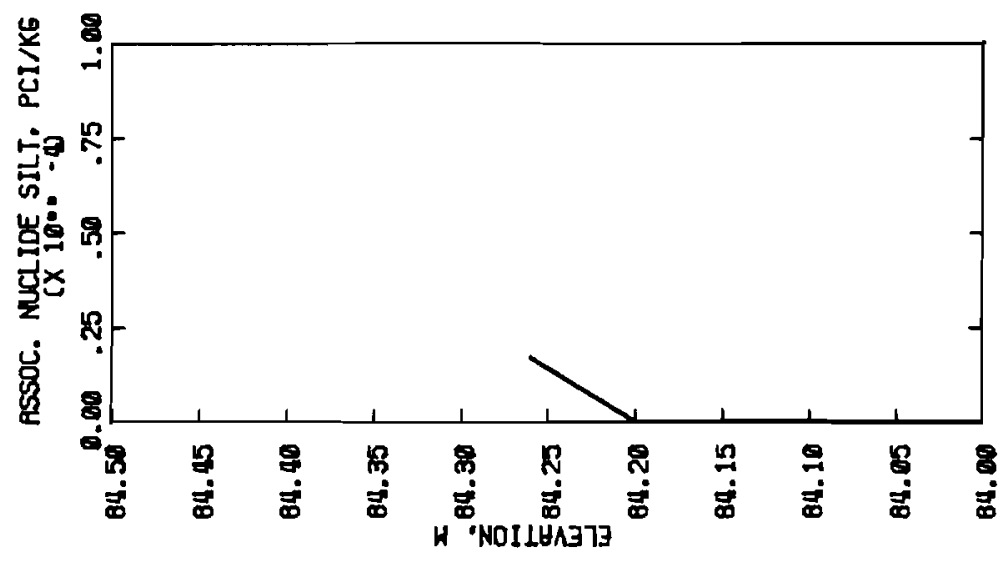

$\stackrel{Ð}{\ddagger}$

$\approx$

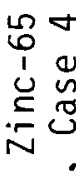

46

동

둉

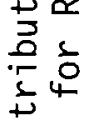

in $\frac{1}{5}$

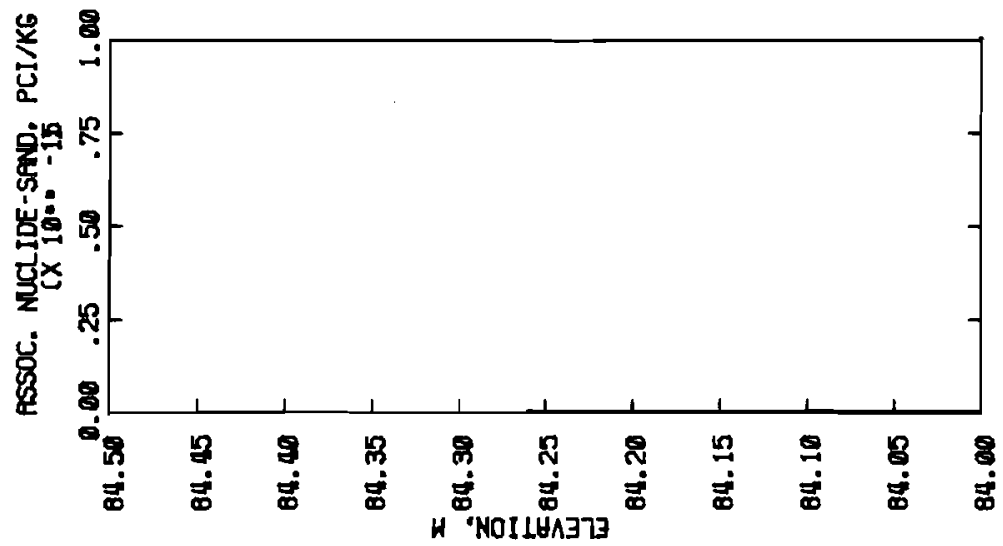

호

넝오

허

过范

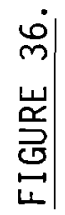




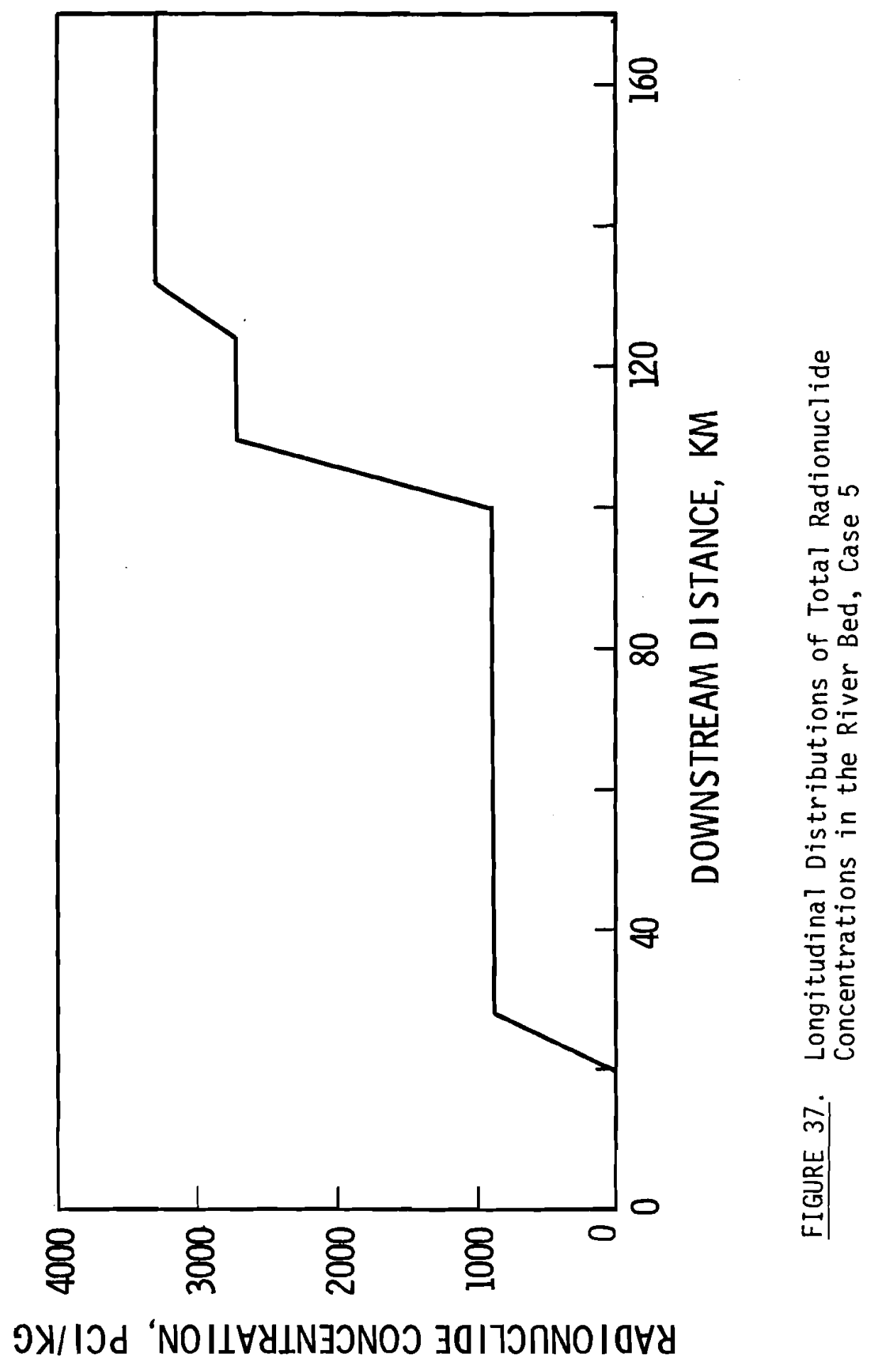




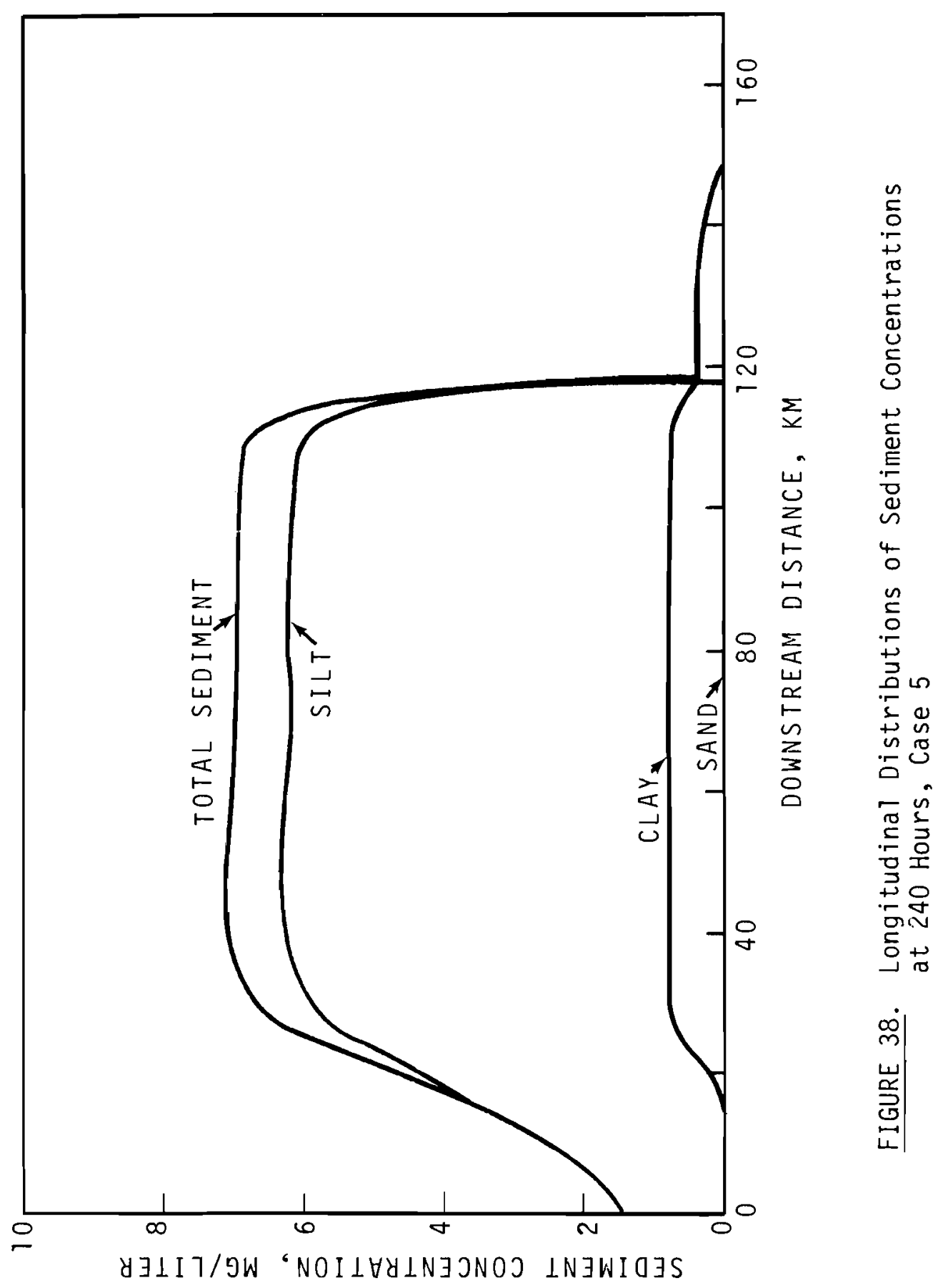




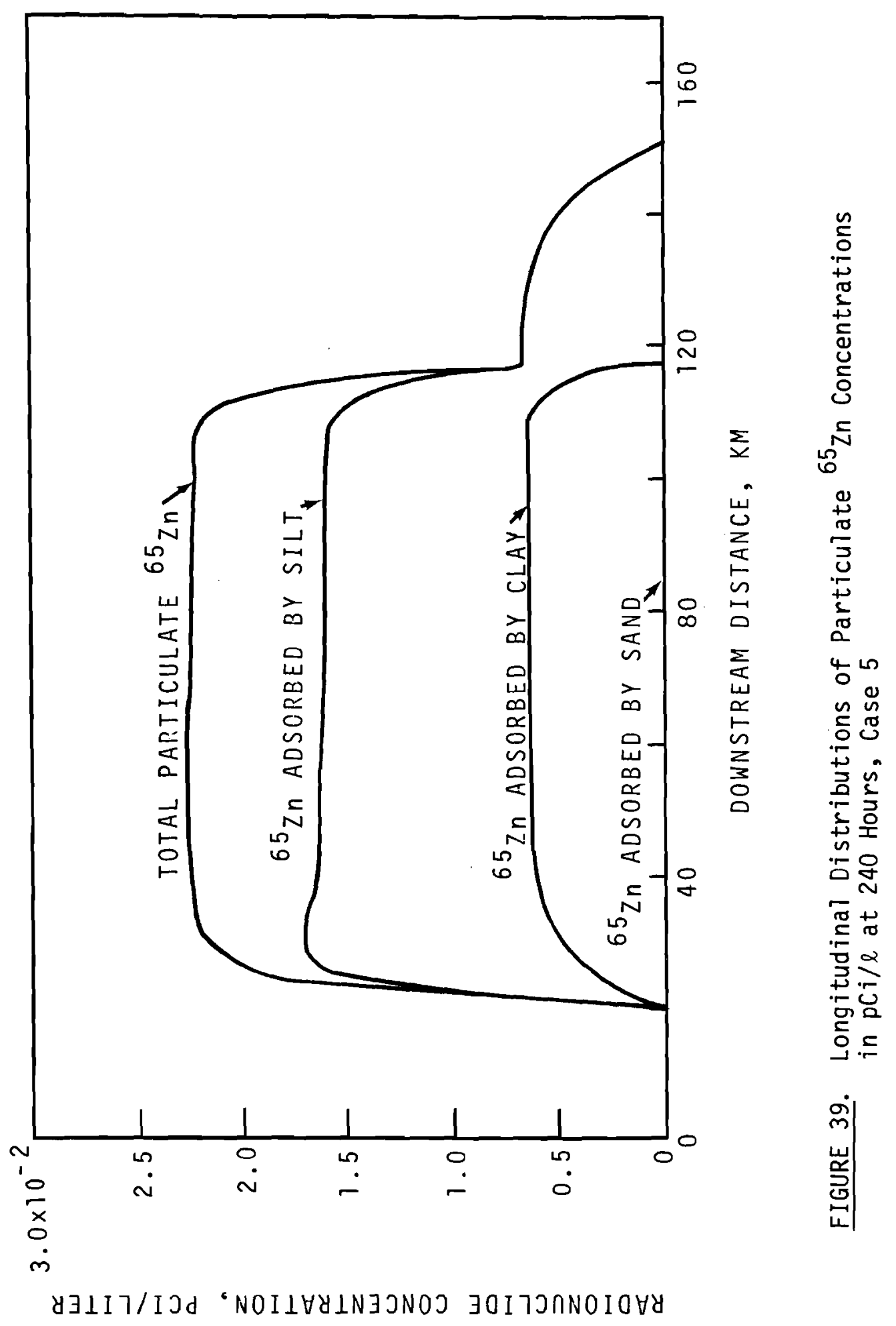




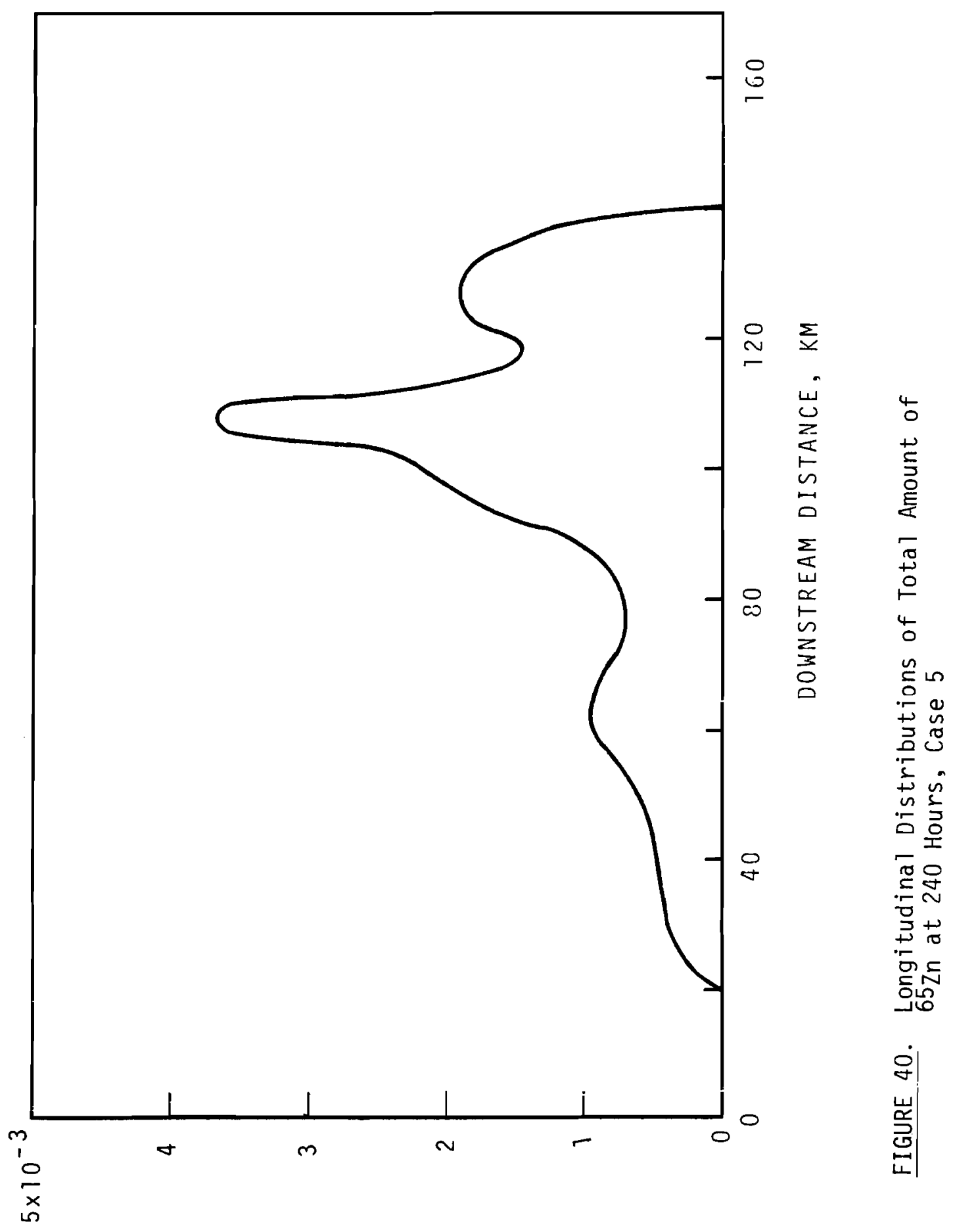

SヨIYกว ' $\exists$ ITJกNOIOHY $7 \forall \perp O \perp$ 

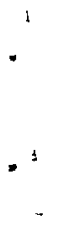


\section{REFERENCES}

1. W. L. Haushild, H. H. Stevens, Jr., J. L. Nelson, and G. R. Dempster, Jr. Radionuclides in Transport in the Columbia River from Pasco to Vancouver, Washington, Geological Survey Professional Paper 433-N, U.S. Geological Survey, 1973.

2. D. W. Hubbel1 and J. L. Glenn, Distribution of Radionuclides in Bottom Sediments of the Columbia River Estuary, Geological Survey Professional Paper 433-L, U.S. Geological Survey, 1973.

3. J. L. Nelson and W. L. Haushild, "Accumulation of Radionuclides in Bed Sediments of the Columbia River Between the Hanford Reactors and McNary Dam," Water Resources Research, 6(1):130-137, February 1970.

4. B. E. Vaughan, Pacific Northwest Laboratory Arınual Report for 1973 to the USAEC Division of Biomedical and Environmental Research, Part 2. Ecological Sciences, BNWL-1850, Batte11e, Pacific Northwest Laboratories, Richland, Washington, January 1974.

5. R. F. Foster and I. C. Nelson, Evaluation of Radiological Conditions in the Vicinity of Hanford for 1961, HW-71999, Hanford Atomic Production Operation, General Electric Co., Rich1and, WA, March 1, 1962.

6. R. F. Foster and R. H. Wilson, Evaluation of Radiological Conditions in the Vicinity of Hanford for 1962, HW-76526, Hanford Atomic Productions Operation, General Electric Co., Richland, WA, February 25, 1963.

7. A. T. Pruter and D. L. Alverson, The Columbia River Estuary and Adjacent Ocean Waters--Bioenvirormental Studies, University of Washington Press, Seattle, WA, 1972.

8. Nuclear Regulatory Commission, Regulatory Guide 1. EE, Methods for Estimating Aquatic Dispersion of Liquid Effluents from Routine Reactor Releases for the Purpose of Implementing, Appendix I, Washington, DC, 1976.

9. Y. Onishi, P. A. Johanson, R. G. Baca, and E. L. Hilty, Studies of Columbia River Water Quality--Development of Mathematical Models for Sediment and Radionuclide Transport Analysis, BNWL-B-452, Battelle, Pacific Northwest Laboratories, Richland, WA, January 1976.

10. Y. Onishi, Finite Element Models for Sediment and Contaminant Transport in Surface Waters--Transport of Sediment and Radionuclides in the Clinch River, BNWL-2227, Battelle, Pacific Northwest Laboratories, Richland, WA, July 1977. 
11. J. M. Nielson and R. W. Perkins, Removal of Radioisotopes from the Columbia River by Natural Processes, HW-SA-2411, 1962.

12. J. T. Whetten, J. C. Kelley and L. G. Hanson, "Characteristics of Columbia River Sediment and Sediment Transport," Journal of Sedimentary Petrology 39(3):1149-1166, 1969.

13. J. L. Nelson, R. W. Perkins and J. M. Nielsen, Progress in Studies of Radionuclides in Columbia River Sediments, A Summary of Hanford Achievements in this Program Under General Electric 1963-1964, AEC Research and Development Report HW-83614, General Electric, Richland, WA, 1964.

14. R. W. Perkins, J. L. Nelson and W. L. Haushild, "Behavior and Transport of Radionuclides in the Columbia River Between Hanford and Vancouver, Washington," Limnology \& Oceanography II:235-248, 1966.

15. J. L. Nelson and W. L. Haushild, "Accumulation of Radionuclides in Bed Sediments of the Columbia River Between Hanford Reactors and McNary Dam," BNWL-SA-2571, Battelle, Pacific Northwest Laboratories, Richland, WA, 1969.

16. D. E. Robertson, W. B. Silker, J. C. Langford, M. R. Petersen and R. W. Perkins, "Transport and Depletion of Radionuclides in the Columbia River," Reprint from Radioactive Contamination of the Marine Environment, International Atomic Energy Agency, Vienna, pp. 141-148, 1973.

17. C. E. Cushing, D. G. Watson, D. E. Robertson and W. B. Silker, "Factors Affecting Biogeochemical Cycling," Pacific Northwest Laboratory Annual Report for 1973 to the USAEC Division of Biomedical and Environmental Research, Part 2--Ecologic Sciences, BNWL-1850, Battel1e, Pacific Northwest Laboratories, Richland, WA, 1974.

18. Radioactivity in the Marine Environment, prepared by the Panel on Radioactivity in the Marine Environment of the Committee on Oceanography National Research Council, National Academy of Science, 1971.

19. E. Partheniades, A Study of Erosion and Deposition of Cohesive Soils in Salt Water, Ph.D. Thesis, University of California, 1962.

20. R. B. Krone, Flume Studies of the Transport of Sediment in Estuarial Shoaling Processes, University of California, Hydraulic Engineering Laboratory and Sanitary Engineering Research Laboratory, 1962. 
21. V. A. Vanoni, Editor, "Sedimentation Engineering," ASCE Task Committee for the Presentation of the Manual on Sedimentation of the Sedimentation Committee of the Hydraulics Division, ASCE, 1975.

22. E. F. Gloyna, S. K. Bhagat, Y. Yousef, and C. Shin, "Transport of Radionuclides in a Model River," Proceedings of a Symposium Disposal of Radioactive Wastes into Seas, Oceans and Surface Waters, International Atomic Energy Agency, Vienna, May 16-20, 1966, pp. 11-32.

23. C. S. Desai and J. F. Abel, Introduction to the Finite Element Method, A Numerical Method for Engineering Analysis, Van Nostrand Reinhold Company, New York, 1972.

24. W. R. Norton, I. P. King and G. T. Orlob, A Finite Element Model for Lower Granite Reservoir, Water Resources Engineers, Inc., Walnut Creek California, 1973.

25. R. Ariathurai, A Finite Element Model for Sediment Transport in Estuaries, Ph.D. Thesis, University of California at Davis, 1974.

26. A. Brandstetter, R. G. Baca, A. F. Gasperino, and A. S. Myhres, Water Quality Models for Municipal Water Supply Reservoirs--Part 1. Summary, Battelle, Pacific Northwest Laboratories, Richland, WA, Submitted to the City of Adelaide, South Australia, 1976.

27. R. S. Varga, Matrix Iterative Analysis, Prentice-Ha11 Inc., 1965.

28. J. M. Nielsen and R. W. Perkins, The Removal of Radioisotopes from the Columbia River by Natural Processes, HW-SA-24.11, Hanford Laboratories Operation, General Electric Co., Richland, WA, Apri1 10, 1962.

29. J. L. Nelson, R. W. Perkins, J. M. Nielsen and W. L. Haushild, "Reactions of Radionuclides from the Hanford Reactors with Columbia River Sediments," Proceedings of a Symposium on Disposal of Radioactive Wastes into Seas, 0ceans and Surface Waters, Vienna, Austria, pp. 139-161, May 16-20, 1966.

30. M. A. Churchi11, J. A. Cragwal1, Jr., R. W. Andres and S. L. Jones, Concentrations, Total Stream Loads and Mass Transport of Radionucl ides in the Clinch and Tennessee Rivers, ORNL-3721, Supp1. 1, Oak Ridge National Laboratory, Oak Ridge, TN, August 1965.

31. R. G. Baca, W. W. Waddel, C. R. Cole, A. Brandstetter, D. B. Cearlock, EXPLORE-I: A River Basin Water Qual ity Model, Battelle, Pacific Northwest Laboratories, Richland, WA, Submitted to U.S. Environmental Protection Agency, August 1973. 
32. W. L. Haushild, R. W. Perkins, H. H. Stevens, G. R. Dempster, Jr., and J. L. Glenn, Progress Report--Radionuclide Transport of the Columbia River, Pasco to Vancouver, Washington Reach, July 1962 to September 1963 , Open-file report, U.S. Geological Survey, Portland, OR, 1966.

33. W. H. Graf, Hydraulics of Sediment Transport, McGraw-Hi11, Inc., 1971. 
BNWL -2228

UC -11

\section{DISTRIBUTION}

No. of

Copies

OFFSITE

A. A. Churm

ERDA Chicago Patent Group

U.S. Energy Research and Development Administration

Argonne, IL 60439

\section{ERDA Technical Information} Center

\section{W. 0. Forster}

ERDA Division of Biomedical and Enviromental Research

Washington, DC 20545

R. Watters

ERDA Division of Biomedical and Environmental Research

Washington, DC 20545

Atomic Industrial Forum, Inc. 475 Park Avenue South

New York, NY 10016

J. 0. Duquid

Battelle Memorial Institute

505 King Avenue

Columbus, $\mathrm{OH} 43201$

F. A. Limpert

Bonneville Power Administration

P. 0. Box 3621

Portland, OR 97208

R. Savage

Corps of Engineers

U.S. Army Coastal Engineering Research Center

Ft. Belvoir, VA 22060
No. of

Copies

S. P. Cobb

Corps of Engineers

U.S. Army Engineering Waterways Experiment Station

Vicksburg, MS 39180

J. G. Collins

Corps of Engineers

U.S. Army Engineery Waterways Experiment Station

Vicksburg, MS 39180

W. McAnally

Corps of Engineers

U.S. Army Engineering Waterways Experiment Station

Vicksburg, MS 39180

M. P. Keown

Corps of Engineers

U.S. Army Engineering Waterways Experiment Station

Vicksburg, MS 39180

F. Herrmarın

Corps of Engineers

U.S. Army Engineering Waterways Experimental Station

Vickburg, MS 39180

D. Bastian

Corps of Engineers

Chesapeake Bay Model Project

Stevensville, MD 21666

B. Doyle

Corps of Engineers

North Pacific Division

Water Quality Section

210 Custom House

Portland, OR 97209 
No. of

Copies

R. Waits

Corps of Engineers

Portland District Office

Portland, OR 97209

N. McDonald

Corps of Engineers

Seattle District Office

4735 East Marginal Way South

Seattle, WA 98134

W. E. Sivley

Corps of Engineers

North Pacific Division

Walla Walla District Office

Bldg. 602, City-County Airport

Walla Walla, WA 99362

G. Gates

Corps of Engineers

Sacramento District

650 Capitol Mal1

Sacramento, CA 95814

W. A. Thomas

Corps of Engineers

U.S. Army Engineering Waterways Experiment Station

Vicksburg, MS 39180

H. E. Pape, Jr.

Corps of Engineers

San Francisco District

100 McAllister St.

San Francisco, CA 94102

D. W. Davis

Corps of Engineers

Hydrologic Engineering Center 609 Second St.

Davis, CA 95616

J. F. Sustar

Corps of Engineers

San Francisco District

100 McAllister St.

San Francisco, CA 94102
No. of

Copies

M. Gee

Corps of Engineering

Hydrologic Engineering Center

609 Second St.

Davis, CA 95616

J. H. Moellering

Corps of Engineers

Vicksburg District

Vicksburg, MS 39180

J. Henley

Corps of Engineers

Vicksburg District

Vicksburg, MS 39180

B. R. Winkley

Corps of Engineers

Vicksburg District

Vicksburg, MS 39180

R. Goldstein

Electric Power Research Institute

3412 Hillview Avenue

Palo Alto, CA 94304

J. Maulbetsch

Electric Power Research Institute

3412 Hillview Avenue

Palo Alto, CA 94304

S. A. Schurr

Electric Power Research Institute

3412 Hillview Avenue

Palo Alto, CA 94304

R. Bauer

Environmental Protection Agency

Region $X$

1200 Sixth Avenue

Seattle, WA 98101 
No. of

Copies

T. A. Murphy

Environmental Protection

Agency

Non-Point Source Control

Division

Washington, DC 20460

D. R. Wright

Environmental Protection Agency

Municipal Pollution Control

Division

Control and Treatment Integration Branch

Washington, DC 20460

M. Shirazi

Environmental Protection Agency

Pacific Northwest Water Laboratory

200 S.W. 35th St.

Corvallis, OR 97331

B. A. Tichener

Environmental Protection Agency

Pacific Northwest Water Laboratory

200 S.W. 35th St.

Corvallis, OR 97331

J. Falco

Environmental Protection Agency

Environmental Research Laboratory

Athens, GA 30603

L. Mulkey

Environmental Protection Agency

Environmental Research Laboratory

Athens, GA 30603
No. of

Copies

R. Swank

Environmental Protection

Agency

Environmental Research

Laboratory

Athens, GA 30603

S. Gilje

Federal Highway Administration HRS -42

Washington, DC 20590

J. Pferd

New York State Geological

Survey

Room 973, State Education Building

Albany, New York 12234

F. O. Hoffman

Oak Ridge National Laboratory

Oak Ridge, TN 37820

T. Tamura

Oak Ridge National Laboratory

Oak Ridge, TN 37820

R. F. Cayot

Pacific Gas \& Electric Co.

Department of Engineering

Research

Emeryville, CA 94608

T. Ashton

Pacific Power \& Light Co.

920 S.W. 6th Ave.

Portland, OR 97204

R. Lacey

San Diego Gas and Electric Co.

1001 Ash Street

San Diego, CA 92101

J. H. Mckinley

Southern California Edison Co. Los Angeles, CA 90053 
No. of

Copies

P. A. Krenkel

Tennessee Valley Authority

410 Edney B1dg.

Chattanooga, TN 37402

E. F. Gloyna

Department of Civil Engineering University of Texas

Center for Research in Water

Resources

Austin, TX 78705

G. R. Snyder

U.S. Bureau of Commercial

Fisheries

B1dg. 67

Sandpoint Naval Air Station

Seattle, WA 98115

T. A. Henrie

U.S. Bureau of Mines

Washington, DC 20241

R. Sarina

U.S. Bureau of Reclamation

Pacific Northwest Region

Boise, ID 83707

D. R. Carder

U.S. Department of Agriculture

Forest Service

C.4. Box 4106, N.A.U.

Flagstaff, $A Z 86001$

P. D. Duffy

U.S. Department of Agriculture

Forest Service

Box 947

Oxford, MS 38655
No. of

Copies

B. Medford

U.S. Department of Agriculture

Forest Service

Room 720

1720 Peachtree Street, N.W.

Atlanta, GA 30309

D. A. Farrel1

U.S. Department of Agriculture Agriculture Research Service

Room 234, B-005, BARC-W

Beltsville, MD 20704

R. U1mer

U.S. Department of Agriculture Soil Conservation Service

Box 61

Jackson, MS 39205

C. V. Alonso

U.S. Department of Agriculture Sedimentation Laboratory

Southern Region, Agricultural

Research Center

P.0. Box 1157

Oxford, MS 38655

D. G. DeCoursey

U.S. Department of Agriculture Sedimentation Laboratory

Southern Region, Agricultural

Research Center

P.0. Box 1157

0xford, MS 38655

D. L. Alverson

U.S. Department of Commerce National Oceanic and Atmospheric Administration

North Pacific Fisheries Research Center

National Marine Fisheries Service

Seattle, WA 98115 
No. of

Copies

A. T. Pruter

U.S. Department of Commerce National Oceanic and Atmospheric Administration

Exploratory Fishing and Gear Research Base

National Marine Fisheries Service

Seattle, WA 98115

W. D. Simons

U.S. Geodetic Survey

Water Resources Division

1305 Tacoma Ave.

South Tacoma, WA 98402

P.C. Benedict

U.S. Geological Survey

345 Middlefield Road

Menlo Park, CA 94025

W. L. Haushild

U.S. Geological Survey

Water Resources Division

1305 Tacoma Ave.

South Tacoma, WA 98402

D. W. Hubbe 11

U.S. Geological Survey

Mississippi Test Facility

Gulf Coast Hydroscience Center

Bay St. Louis, MS 39520

R. B. Code 11

U.S. Nuclear Regulatory Commission

Washington, DC 20555

L. G. Hulman

U.S. Nuclear Regulatory

Commission

Washington, DC 20555
No. of

Copies

D. L. Schreiber

U.S. Nuclear Regulatory Commission

Washington, DC 20555

J. Adam

U.S. Nuclear Regulatory Commission

Washington DC 20555

C. B. Bartlett

U.S. Nuclear Regulatory Commission

Washington, DC 20555

W. Bevins

U.S. Nuclear Regulatory Commission

Washington, DC 20555

F. Swanberg

U.S. Nuclear Regulatory Commission

Washington, DC 20555

W. P. Bishop

U.S. Nuclear Regulatory Commission

Washington, DC 20555

P. H. Lohaus

U.S. Nuclear Regulatory Commission

Washington, DC 20555

W. Hallaeur

Washington State Department of Ecology

Olympia, WA 98504 
No. of

Copies

FOREIGN

Director, Division of Health Safety and Waste Management

International Atomic Energy Agency

Vienna 1, Kaerntnerring 11, Austria

\section{ONSITE}

6 ERDA Richland Operations Office

H. E. Ramson

M. W. Tiernan (2)

D. R. Elle

P. F. X. Dunigan, Jr. (2)

Rockwell Hanford Operations RHO File

United Nuclear Industries, Inc. UNI File

18 Battelle-Pacific Northwest

Laboratories

S. M. Brown

N. E. Carter

D. B. Cearlock

D. W. Dragnich

R. M. Ecker

J. J. Fix

Y. Onishi (3)

J. M. Nielsen

B. E. Vaughan

C. M. Unruh

Technical Information (5)

Technical Publications (KKS) 